\title{
Circuit analysis tools for evaluating separation efficiency of dense medium separators
}

Hongyan Sun

West Virginia University

Follow this and additional works at: https://researchrepository.wvu.edu/etd

\section{Recommended Citation}

Sun, Hongyan, "Circuit analysis tools for evaluating separation efficiency of dense medium separators" (2005). Graduate Theses, Dissertations, and Problem Reports. 4197.

https://researchrepository.wvu.edu/etd/4197

This Thesis is protected by copyright and/or related rights. It has been brought to you by the The Research Repository @ WVU with permission from the rights-holder(s). You are free to use this Thesis in any way that is permitted by the copyright and related rights legislation that applies to your use. For other uses you must obtain permission from the rights-holder(s) directly, unless additional rights are indicated by a Creative Commons license in the record and/ or on the work itself. This Thesis has been accepted for inclusion in WVU Graduate Theses, Dissertations, and Problem Reports collection by an authorized administrator of The Research Repository @ WVU. For more information, please contact researchrepository@mail.wvu.edu. 


\title{
Circuit Analysis Tools for Evaluating Separation Efficiency of Dense Medium Separators
}

\author{
Hongyan Sun \\ Thesis submitted to \\ College of Engineering and Mineral Resources \\ at West Virginia University \\ in partial fulfillment of the requirements \\ for the degree of
}

Master of Science

in

Mining Engineering

Felicia F. Peng, Ph.D., Chair

Syd S. Peng, Ph.D.

Yi Luo, Ph.D.

Department of Mining Engineering

Morgantown, West Virginia

2005

Keywords: circuit analysis, dense medium cyclones, coal cleaning technology, gravity separation, two stage dynamic cyclone circuit. 


\section{ABSTRACT \\ Circuit Analysis Tools for Evaluating Separation Efficiency of Dense Medium Separators}

\section{Hongyan Sun}

In order to evaluate the relative separation efficiency among various circuits, a modified circuit analysis tools has been developed and applied to some circuits based upon dense medium separation. The results indicated that this circuit analysis method could predict separation efficiency of different circuit configuration without using washability data.

Based on the selective function for one stage separation, the selective functions for multi-stage circuit configurations were derived, and used to simulate the various circuit configurations. The simulation results demonstrated that some circuit configurations can improve the separation efficiency.

In-plant data for two-stage dense medium cylindrical and conical cyclone circuits without recirculation were studied. The results show that these circuits not only improve the separation efficiencies, but also the qualities of the product by reduction of misplaced materials. The relative separation efficiencies are closed to the calculated value of 1.17 by circuit analysis tool. 


\section{ACKNOWLEDGEMENTS}

The author would like to express her sincere appreciation to her academic advisor and thesis committee Chair, Dr. Felicia F. Peng for her persistent encouragement, support and guidance during the period of graduate study and thesis work. Wherever in the academic field, in the work, the author learned a lot from Dr. Peng the values of hard working, and great personality. The author acknowledges the pleasure to have her as a mentor.

Thanks are also expressed to the thesis committee members, Dr. Syd S. Peng, and Dr. Yi Luo, for their valuable and constructive suggestions, comments and advice.

The financial support from West Virginia Coal Research Bureau to the author for this study is greatly acknowledged.

The author wishes to thank her parents in China for their continued support and encouragement. The author would like to give her deepest appreciation to her husband, Qinghua Jin, and her son, Dun Jin, for their constant understanding, support, endurance and love. 


\section{TABLE OF CONTENTS}

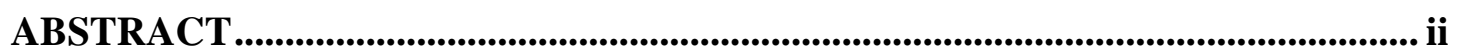

TABLE OF CONTENTS .............................................................................................................iv

LIST OF TABLES ........................................................................................................

LIST OF FIGURES .......................................................................................................... vii

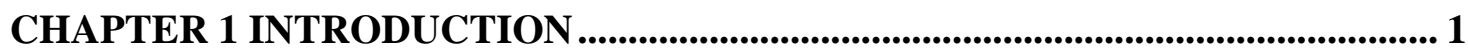

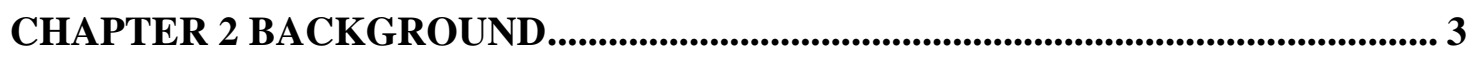

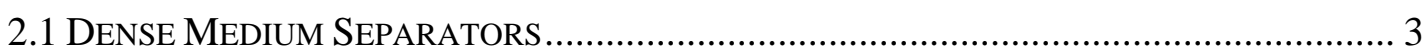

2.1.1 Dynamic Dense Medium Conical Cyclone ..................................................... 5

2.1.2 Large Diameter Dense Medium Conical Cyclone .......................................... 5

2.1.3 Large Coal Dense Medium Separator ............................................................ 6

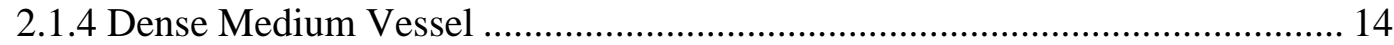

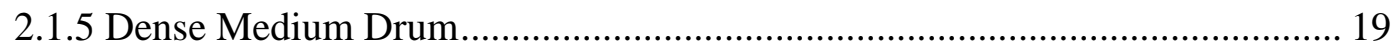

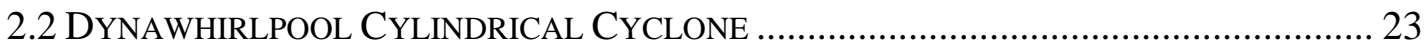

2.3 Two Stage Dynamic Dense Medium CyLINDRICAL CyClone............................ 24

2.4 Standard Float-Sink Test and Tracer Techniques for Performance

EVALUATION OF SPECIFIC GRAVITY BASED SEPARATOR............................................ 33

CHAPTER 3 CIRCUIT ANALYSIS TOOLS FOR SOLID-SOLID SEPARATION

3.1 CONCEPT OF GENERALIZED Distribution CURVE................................................ 35

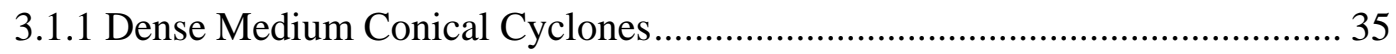

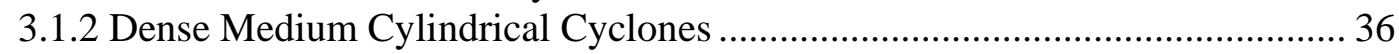

3.2 CirCuit ANALYSIS of CoAL AND Mineral ProcesSES ...................................... 41

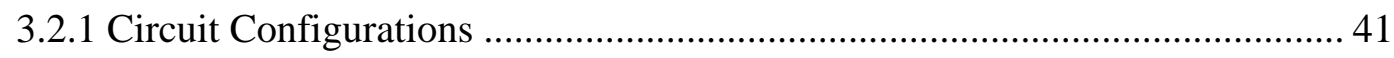

3.2.2 Circuit Analysis for Various Circuit Configurations ...................................... 45

3.2.3 Definition for Sharpness of Separation and Relative Separation Efficiency ... 46

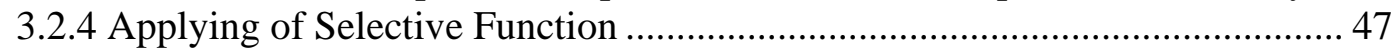

3.2.5 Dense Medium Conical Cyclone Separators ................................................ 57

CHAPTER 4 RESULTS AND DISCUSSION...........................................................62

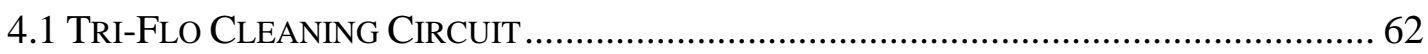

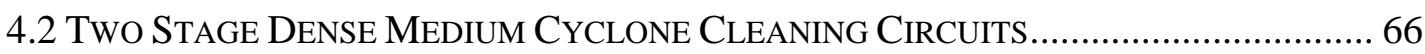


4.2.1 Two-stage Dense Medium Cyclone Circuit in Plant H ................................. 70

4.2.2 Two-stage Dense Medium Cyclone Circuit in Plant I.................................... 73

4.2.3 Two-stage Dense Medium Cyclone Circuit in Plant J.................................... 73

4.2.4 Two-stage Dense Medium Cyclone Circuit in Plant K .................................. 76

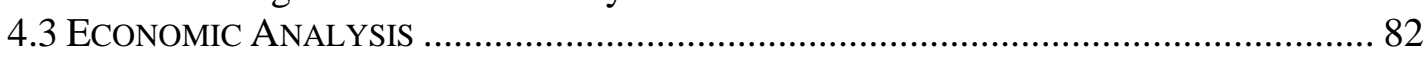

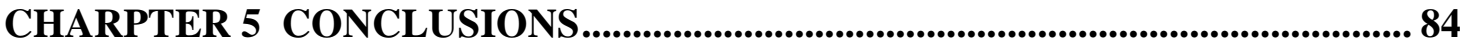

REFERENCE

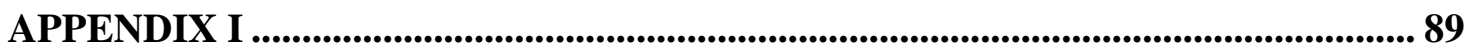

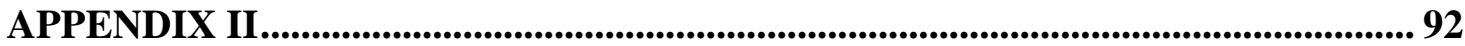

VITA 


\section{LIST OF TABLES}

Table 2-1 Average Dense Medium Conical Cyclone Performance Data, Australia ... 6

Table 2-2 Separation Distribution Curves Data for LARCODEM at Middelburg Mine (Duhva), South Africa .................................................................. 7

Table 2-3 Separation Distribution Curves Data for LARCODEM at Tavistotk Colliery Using Tracer Tests, South Africa ............................................. 10

Table 2-4 Separation Distribution Curves Data for LARCODEM at Tavistotk Colliery Using Tracer Tests, South Africa .............................................. 13

Table 2-5 Size Distribution of Feed for Dense Medium Vessel, Pittsburgh Seam

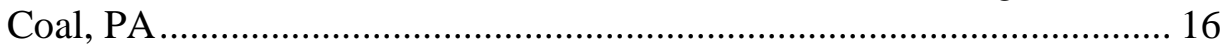

Table 2-6 In-plant Performance Data and Simulation Data for Pittsburgh Seam Coal,

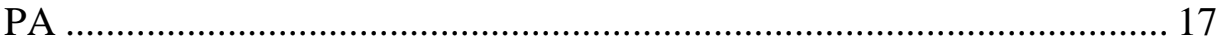

Table 2-7 Performance Parameters of A Dense Medium Drum for Three Tests...... 21

Table 2-8 Distribution Curve Data of a Dense Medium Drum for $-31.5 \mathrm{~mm}+16 \mathrm{~mm}$ Size Fraction.................................................. 21

Table 2-9 In-Plant Data for Conical Dense Medium Cyclone and Tri-Flo Separator Using Tracer Tests ..................................................... 28

Table 2-10 Distribution Curve Data of Conical Dense Medium Cyclone for Different Size Fractions Using Tracer Tests ..................................... 28

Table 2-11 Separation Distribution Curve Data for Tri-Flo Separator at Different Size Fractions Using Tracer Tests ................................................................. 29

Table 2-12 Distribution Curve Data for Tri-Flo Separator Using Tracer Tests .......... 32

Table 3-1 Concentration Circuit Configurations.................................................... 43

Table 3-2 Products for Various Concentration Circuit Configurations .................... 49

Table 3-3 Simulation Results of SG50 and Relative Separation Efficiencies for Various Concentration Circuit Configurations ...................................... 55

Table 3-4 Relative Separation Efficiencies of Dense Medium Separators Based Various Concentration Circuit Configurations ......................................... 60

Table 4-1 Separation Results of Coal Rejects by Rougher and Tri-Flo Separator.... 64

Table 4-2 Cyclone Dimensions and Particle Size Range Used for Various Two-stage Dense Medium Conical Cyclone Plants ............................................... 70

Table 4-3 Performance Data for Dense Medium Cyclones at Various Plants .......... 72

Table 4-4 Ash, Sulfur Contents and Yields of Clean Coal Producty for Rougher, Cleaner and Overall Circuit at Various Size Fractions. 80 
Table 4-5 Summary of Annual Economic Analysis for Dense Medium Circuit Product in Plant H................................................................................. 83

Table I-1 Separation Distribution Data for Dense Medium Conical Cyclones at Seven Coal Preparation Plants .................................................................... 90

Table I-2 Performance Characteristics of Dense Medium Conical Cyclones at Seven Coal Preparation Plants............................................................................. 91

Table II-1 Separation Distribution Data for Dynawhirlpool Separators at Four Coal

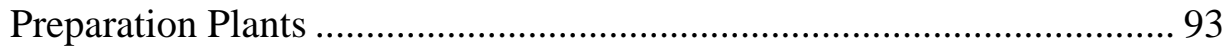

Table II-2 Performance Characteristics of Dynawhirlpool Separators at Four Coal Preparation Plants...............................................94 


\section{LIST OF FIGURES}

Figure 2-1 Dense Medium Cyclone Separators: a) DSM conical cyclone, b) Dynawhirlpool Separator, c) Tri-Flo two stage-in-one cylindrical cyclone, d) LARCODEM. 4

Figure 2-2 Separation Distribution Curves for LARCODEM at Middelburg Mine (Duhva), South Africa 8

Figure 2-3 Separation Distribution Curves for LARCODEM at Tavistotk Colliery, South Africa

Figure 2-4 Separation Distribution Curves of Various Size Fractions for LARCODEM at Tavistotk Colliery, South Africa

Figure 2-5 Schematic Diagram of Dense Medium Vessel ....................................... 15

Figure 2-6 Distribution Curves for a Pittsburgh Seam Coal, In-plant Data and Model Data............................................................... 18

Figure 2-7 Schematic Diagram of Dense Medium Drum Separator .......................... 20

Figure 2-8 Distribution Curve of Dense Medium Drum for $-31.5 \mathrm{~mm}+16 \mathrm{~mm}$ Size Fraction of Raw Coal ................................ 22

Figure 2-9 Distribution Curves for Conical Dense Medium Cyclone with Various Size Fractions ....................................................................... 26

Figure 2-10 Distribution Curves for Tri-Flo Cyclone for Various Size Fractions of Raw Coal ................................................. 27

Figure 2-11 Distribution Curves for Tri-Flo Separator Using Tracer Test .................. 31

Figure 3-1 Distribution Curves for Dense Medium Conical Cyclones Operated at Various SG50s

Figure 3-2 Generalized Distribution Curves for Dense Medium Conical Cyclones Operated at Various SG50s........................................................................ 38

Figure 3-3 Distribution Curves for Dynawhirlpool Separators Operated at Various SG50s

Figure 3-4 Generalized Distribution Curves for Dynawhirlpool Separators Operated at Various SG50s

Figure 3-5 Rougher-Cleaner without Recirculation Circuit .45

Figure 3-6 Overall Separation Distribution Curves for Nine Different Circuit Configurations.

Figure 3-7 Generalized Overall Distribution Curves for Nine Different Circuit Configurations. 
Figure 3-8 Separation Distribution Curves of Dense Medium Conical Cyclones for Rougher, Cleaner, and Rougher-Cleaner without Recirculation ............... 58

Figure 3-9 Generalized Distribution Curves of Dense Medium Conical Cyclones for Rougher, Cleaner and Rougher-Cleaner without Recirculation ............... 59

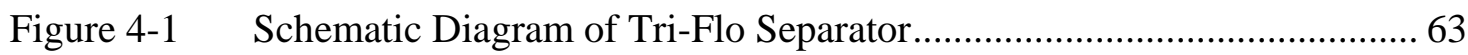

Figure 4-2 Separation Distribution Curves of Tri-Flo for Rougher and Overall Circuit (Combined Two Stage Separators) .......................................................... 65

Figure 4-3 Schematic Diagram of Dense Medium Conical Cyclone ......................... 67

Figure 4-4 A Two-Stage Dense Medium Cyclone Circuit ........................................... 69

Figure 4-5 Separation Distribution Curves of Dense Medium Conical Cyclones for Rougher, and Rougher-Cleaner without Recirculation in Plant H .......... 71

Figure 4-6 Separation Distribution Curves of Dense Medium Conical Cyclones for Rougher, Cleaner, and Rougher-Cleaner without Recirculation in Plant I

Figure 4-7 Separation Distribution Curves of Dense Medium Conical Cyclones for Rougher, Scavenger, and Rougher-Scavenger without Recirculation in Plant J

Figure 4-8 Separation Distribution Curves of Dense Medium Conical Cyclones for Rougher, Cleaner, and Rougher-Cleaner without Recirculation in Plant K (size fraction $-37.5 \mathrm{~mm}+12.5 \mathrm{~mm}$ )

Figure 4-9 Separation Distribution Curves of Dense Medium Conical Cyclones for Rougher, Cleaner, and Rougher-Cleaner without Recirculation in Plant K (size fraction $-12.5 \mathrm{~mm}+6.3 \mathrm{~mm}$ )

Figure 4-10 Separation Distribution Curves of Dense Medium Conical Cyclones for Rougher, Cleaner, and Rougher-Cleaner without Recirculation in Plant K (size fraction $-37.5 \mathrm{~mm}+6.3 \mathrm{~mm}$ )

Figure 4-11 Separation Distribution Curves of Various Size Fractions for the Overall Circuit of Two-Stage Dense Medium Conical Cyclones, Plant K. 81 


\section{CHAPTER 1 INTRODUCTION}

For coal cleaning, two main separating principles dominate: (1) Separation based on differences in specific gravity between coal and associated mineral matter; and (2) Separation based on differences in surface properties between coals and associated mineral matter. Coal cleaning methods are often categorized by coal size range to be processed, i.e. coarse coal, intermediate coal, fine coal, and ultrafine coal. For coal and mineral processing, there are two main processes: (1) dense medium separation, which simulate the effect of using a heavy liquid of the appropriate specific gravity to affect a float/sink separation of coal from the associated mineral matter, by using the mixture of magnetite and water; and (2) Water based process, which relies on i) the pulsation of water through the particle bed to stratify particles of different specific gravity; ii) flowing film table with shaking action and flowing film with spiral downward flow action; and iii) counter current fluidized-bed principle. Both processes have found wide application in coal and mineral processing throughout the world. Since the 1950s, dense medium separation processes have become increasingly popular because of their potential for high efficiency and accuracy of separation. Currently, there is approximately $52 \%$ coal were cleaned using dense medium separation methods (Technology Report, 2001) in USA. Separators used in the dense medium plants can be static or dynamic separators. Dynamic dense medium separators include dense medium conical and cylindrical shaped cyclones. The dynamic cylindrical cyclones can be Dynawhirlpools, LARCODEM, and Tri-Flo cylindrical cyclones. They are suitable for processing larger particle size at size range of $-100 \mathrm{~mm}+5 \mathrm{~mm}$. The dynamic conical cyclones usually have the diameters of 500 
$\mathrm{mm}$ to $600 \mathrm{~mm}$. They are suitable for processing coarser and intermediate particle size at the size range of $-50 \mathrm{~mm}+2 \mathrm{~mm}$.

Dynamic specific gravity based dense medium separators performance very sharp separation in the laboratory, pilot scales, and full scales. The full scale units often misplace some clean coal and refuse particles due to dynamic flow conditions in the separators. Thus, multi-stage circuits are employed to obtain the optimal efficiency of separation for coal quantity and quality to prepare low ash and low sulfur metallurgical coal. More than one stage separation is also required to clean raw coal which is very difficult to clean or very friable.

For this work, a circuit analysis method is developed and used to evaluate the overall performance and effectiveness of multistage dense medium separation circuits. The objectives of this work are: (1) to develop a circuit analysis tool for multi-stage specific gravity based separation circuits; (2) to provide the theoretical justification using multi-stage separation circuit configurations; (3) to validate the circuit analysis method using in-plant data obtained from coal preparation plants. 


\section{CHAPTER 2 BACKGROUND}

\subsection{Dense Medium Separators}

Run-of-Mine (ROM), whether extracted from underground or surface mines, is cleaned to some degree by coal preparation or cleaning technology. Coal cleaning technology covers a wide range of separation and dewatering processes. The objective of coal cleaning is to improve the quality of coal to meet market requirements, to reject incombustible materials to save transportation and ash disposal cost, and to remove hazardous elements for environment considerations.

For processing coarser fraction of coal, except floatation of fine coal, two coalcleaning processes predominate. They are dense medium separation and water based separation using pulsation, shaking or spiraling downward flowing action utilizing thin film, and fluidization. Both of them have been commonly used in mining and mineral industry. Dense medium separator can be static or dynamic types. The majority of static separators are bath or rotating drum shape, because of the principles of equipment design, and requirement of processing coarse size fraction of coal. The static separator is limited only processing the size range of plus $6 \mathrm{~mm}$. The most commonly used dynamic dense medium cyclone separator is the Dutch State Mine (DSM) cyclone separator that has conical shape. As for cylindrical cyclones, they include two-stage-in-one dynamic dense medium cylindrical cyclone, Tri-Flo; large coal dense medium separator (LARCODEM); Dynawhilpool (DWP) separator (Nicole, 2001). Fig. 2-1 shows the typical dense medium separators used in coal and mineral industry. 


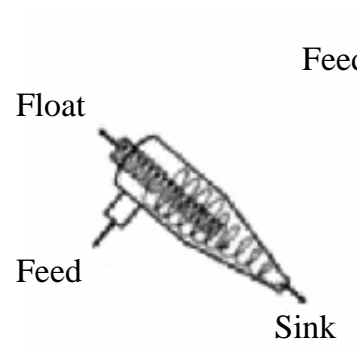

a)

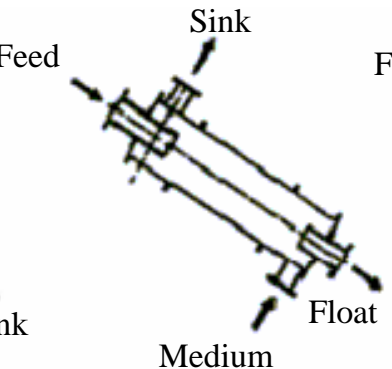

b)

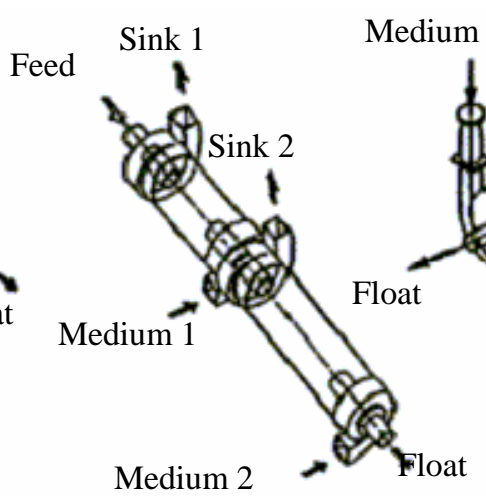

c)

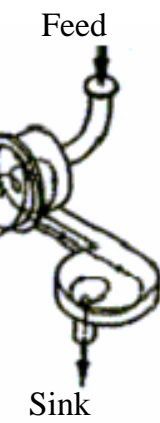

d)

Figure 2-1 Dense Medium Cyclone Separators: a) DSM conical cyclone, Dynawhirlpool Separator, c) Tri-Flo two stage-in-one cylindrical cyclone, d) LARCODEM. 


\subsubsection{Dynamic Dense Medium Conical Cyclone}

The conical dense medium cyclone separator was developed in the Netherlands and first described by Driessen in 1945. It gained acceptance in Europe very quickly. The first installation made in the United States was at the Jeddo Highland Coal Co, it is said to provide effective and sharp separation. The separator is particularly suitable for intermediate coal particle $(-6.35 \mathrm{~mm}+2 \mathrm{~mm})$ separation. Bureau of Mines investigated seven conical dense medium cyclones at various commercial plants in the United States, namely, plant A, B, C, D, E, F, and G, they located in north central West Virginia, eastern Kentucky, western Pennsylvania, southern Illinois, southern West Virginia, and southern West Virginia, respectively. The conical dense medium cyclone diameters are $500 \mathrm{~mm}$ or $600 \mathrm{~mm}$. According to their report, these seven dense medium cyclones can process feed of up to 44 percent of near-gravity material at the specific gravity of separating ranging from 1.42 to 1.55 , and the Ep value range from 0.026 to 0.034 , they all achieved very good separations results. Also, the coal particle size can be as small as $0.6 \mathrm{~mm}$. All the separation distribution data and other performance data are shown in Appendix I, Table I-1 and Table I-2. The seven separation distribution curves are shown in Fig. 3-1.

\subsubsection{Large Diameter Dense Medium Conical Cyclone}

The large diameter dense medium cyclone has become commonly used in Australian coal industry in recent year. The current largest dense medium cyclone being installed ranges from $1000 \mathrm{~mm}$ to $1300 \mathrm{~mm}$ in diameter (Weale, 2002). Table 2-1 summarizes in-plant 
performance data for seven plants in Australia. Their coal particle size is larger than $4 \mathrm{~mm}$ (Nicol, 2001). The specific gravity of separation or cut point, SG50s range from 1.33 to 1.75 , and Ep values range from 0.012 to 0.023 . The results show that all large diameter conical cyclones processed coarse coal has very efficient separation.

Table 2-1 Average Dense Medium Conical Cyclone Performance Data, Australia

\begin{tabular}{|l|c|c|c|c|}
\hline Diameter, mm & 1000 & 1000 & 1150 & 1300 \\
\hline $\begin{array}{l}\text { Specific Gravity of } \\
\text { Separation, SG50 }\end{array}$ & $1.33-1.40$ & $1.52-1.75$ & $1.65-1.66$ & 1.54 \\
\hline Probable Error, Ep & 0.012 & 0.019 & 0.023 & 0.021 \\
\hline
\end{tabular}

\subsubsection{Large Coal Dense Medium Separator}

LARCODEM was originally developed by coal preparation engineers at British Coal Technical Services and Research for separation of raw coal in $-100 \mathrm{~mm}+0.5 \mathrm{~mm}$ size range. Harrison, et al. (1998) reported applications of the LARCODEM technology on South African coals. The $1200 \mathrm{~mm}$ diameter LARCODEM vessel was installed at Middelburg Mine (Duhva). Twin module dense media separators process $350 \mathrm{tph}-100 \mathrm{~mm}+12 \mathrm{~mm}$ raw coal. The separation performances are given in Table 2-2, and the separation distribution curves are shown in the Fig. 2-2. For module 1 and module 2 LACODEM vessels, the SG50s are 1.81 and 1.88; and the Ep values are 0.005 and 0.011.

A $1000 \mathrm{~mm}$ diameter of LARCODEM vessel to process $-80 \mathrm{~mm}+10 \mathrm{~mm}$ raw coal was installed at Tavistock Colliery's No. 4 Seam Plant in South Africa (Harrison, et al. 1998). The in-plant performance test was conducted and the data are summarized in Table 2-3. The separation distribution curves are shown in Fig. 2-3. It shows that the LARCODEM vessel 
Table 2-2 Separation Distribution Curves Data for LARCODEM at Middelburg Mine (Duhva), South Africa

\begin{tabular}{|c|c|c|c|}
\hline \multicolumn{2}{|c|}{ Module 1 } & \multicolumn{2}{c|}{ Module 2 } \\
\hline $\begin{array}{c}\text { Specific Gravity } \\
\text { Interval }\end{array}$ & $\begin{array}{c}\text { Distribution } \\
\text { Factor, \% }\end{array}$ & $\begin{array}{c}\text { Specific Gravity } \\
\text { Interval }\end{array}$ & $\begin{array}{c}\text { Distribution } \\
\text { Factor, \% }\end{array}$ \\
\hline$<1.400$ & 100.0 & $<1.600$ & 100.0 \\
\hline $1.400-1.500$ & 100.0 & $1.600-1.700$ & 99.9 \\
\hline $1.500-1.600$ & 100.0 & $1.700-1.750$ & 99.7 \\
\hline $1.600-1.650$ & 99.9 & $1.750-1.800$ & 99.5 \\
\hline $1.650-1.700$ & 99.6 & $1.800-1.850$ & 93.4 \\
\hline $1.700-1.750$ & 99.0 & $1.850-1.900$ & 55.9 \\
\hline $1.750-1.800$ & 96.6 & $1.900-1.950$ & 4.3 \\
\hline $1.800-1.825$ & 53.7 & $1.950-2.000$ & 0.5 \\
\hline $1.825-1.850$ & 6.3 & $2.000-2.050$ & 0.6 \\
\hline $1.850-1.875$ & 3.0 & $2.050-2.100$ & 0.1 \\
\hline $1.875-1.900$ & 2.0 & $2.100-2.200$ & 0.0 \\
\hline $1.900-1.950$ & 1.3 & $>2.200$ & \\
\hline $1.950-2.000$ & 0.9 & & \\
\hline $2.000-2.100$ & 0.5 & & \\
\hline $2.100-2.200$ & 0.3 & & \\
\hline$>2.200$ & 0.0 & & \\
\hline
\end{tabular}




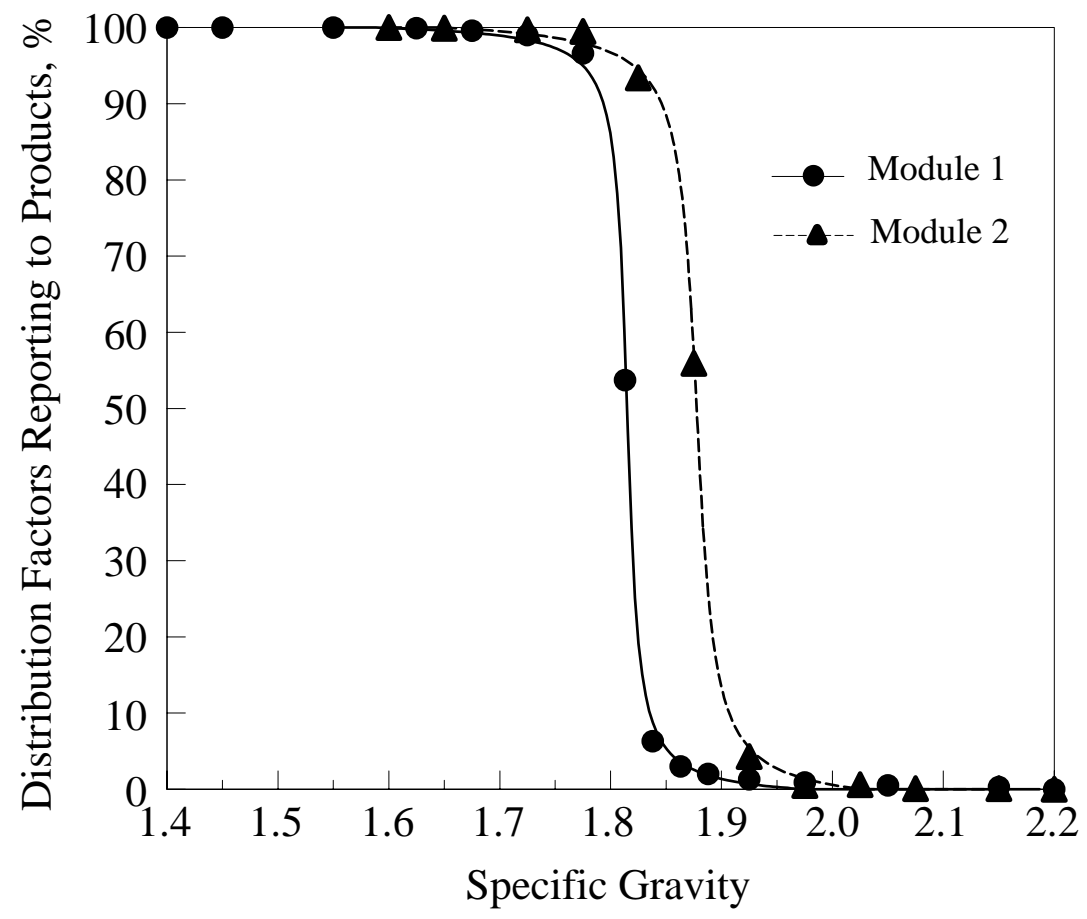

Figure 2-2 Separation Distribution Curves for LARCODEM at Middelburg Mine (Duhva), South Africa 
had a good separation performance.

Differences of LARCODEM vessel separation efficiency at various size fractions was investigated by Harrison, et al. (1998). Fig. 2-4 plots the separation distribution curves processed in different coarse coal particle sizes. Also, the data are shown in Table 2-4. From Fig. 2-4, the Probable error, Ep, of 0.0091 at SG50 of 1.484 is realized for $+40 \mathrm{~mm}$ size fraction. As the particle size ranges decreased, from $-40 \mathrm{~mm}+25 \mathrm{~mm}$ to $-25 \mathrm{~mm}+10 \mathrm{~mm}$, the Ep value decreased from 0.0105 to 0.0065 , at the SG50 of 1.464 to 1.473 , respectively. Based on the applications in South Africa, the LARCODEM vessels have shown the good performance efficiencies and often used for de-stoning and desliming purposes. Vessel serves as a coarse coal separator and has gained interest by coal operators in South Africa. One of the reasons is that the vessel is large and can process coals with a top size of up to $100 \mathrm{~mm}$ (Cammack, 1987). 
Table 2-3 Separation Distribution Curves Data for LARCODEM at Tavistotk Colliery Using Tracer Tests, South Africa

\begin{tabular}{|c|c|c|c|}
\hline \multicolumn{2}{|c|}{ SG50=1.60 } & \multicolumn{2}{c|}{ SG50=1.45 } \\
\hline $\begin{array}{c}\text { Specific } \\
\text { Gravity }\end{array}$ & $\begin{array}{c}\text { Distribution } \\
\text { Factor, } \%\end{array}$ & $\begin{array}{c}\text { Specific } \\
\text { Gravity }\end{array}$ & $\begin{array}{c}\text { Distribution } \\
\text { Factor, } \%\end{array}$ \\
\hline$<1.300$ & 98.9 & $<1.300$ & 96.6 \\
\hline 1.325 & 99.7 & 1.325 & 99.3 \\
\hline 1.375 & 99.8 & 1.375 & 99.3 \\
\hline 1.425 & 99.8 & 1.425 & 93.8 \\
\hline 1.475 & 99.8 & 1.475 & 24.0 \\
\hline 1.525 & 99.8 & 1.525 & 2.5 \\
\hline 1.575 & 98.4 & 1.575 & 1.0 \\
\hline 1.625 & 54.0 & 1.625 & 0.9 \\
\hline 1.675 & 16.9 & 1.675 & 0.6 \\
\hline 1.725 & 7.6 & 1.725 & 1.1 \\
\hline 1.775 & 1.0 & 1.775 & 0.2 \\
\hline 1.800 & 0.3 & 1.800 & 0.1 \\
\hline$>1.800$ & 0.0 & $>1.800$ & 0.0 \\
\hline
\end{tabular}




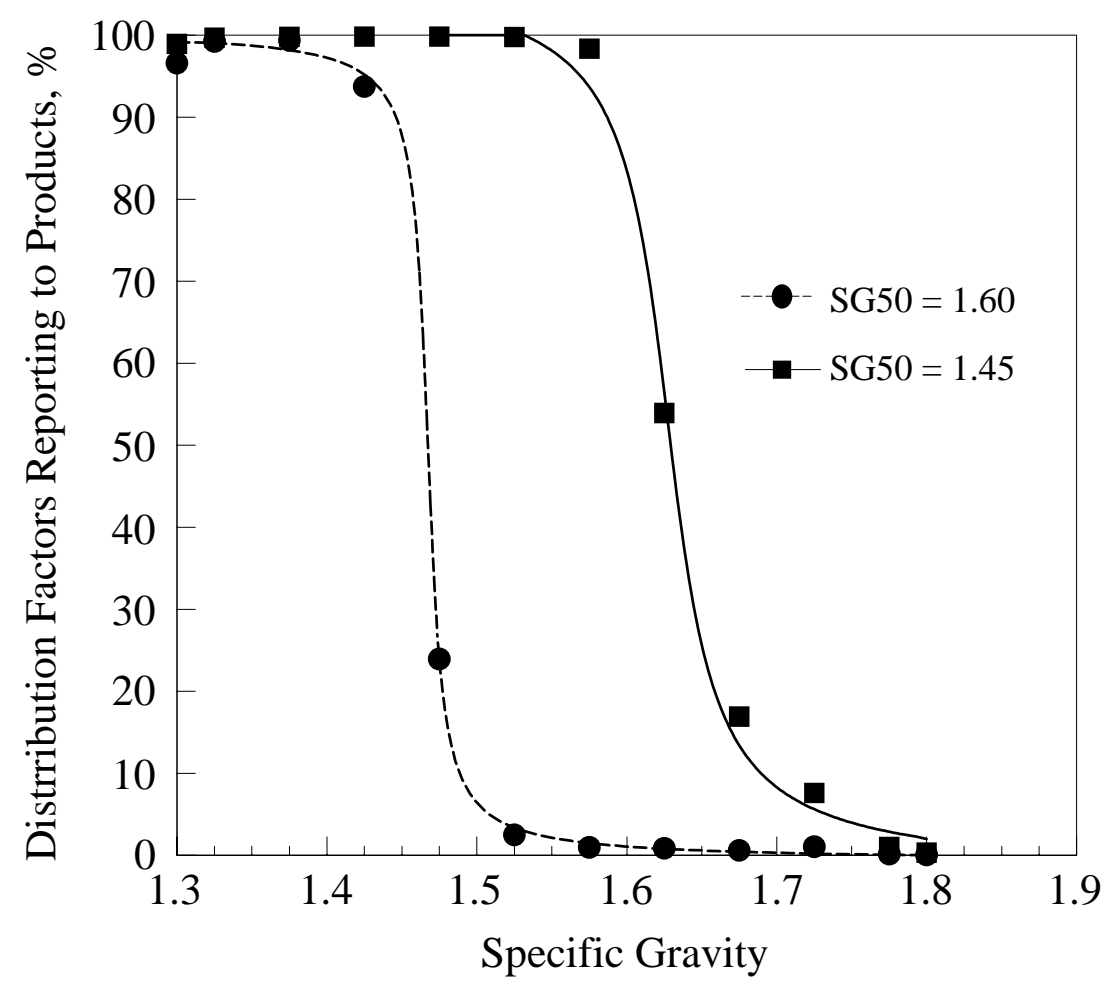

Figure 2-3 Separation Distribution Curves for LARCODEM at Tavistotk Colliery, South Africa 


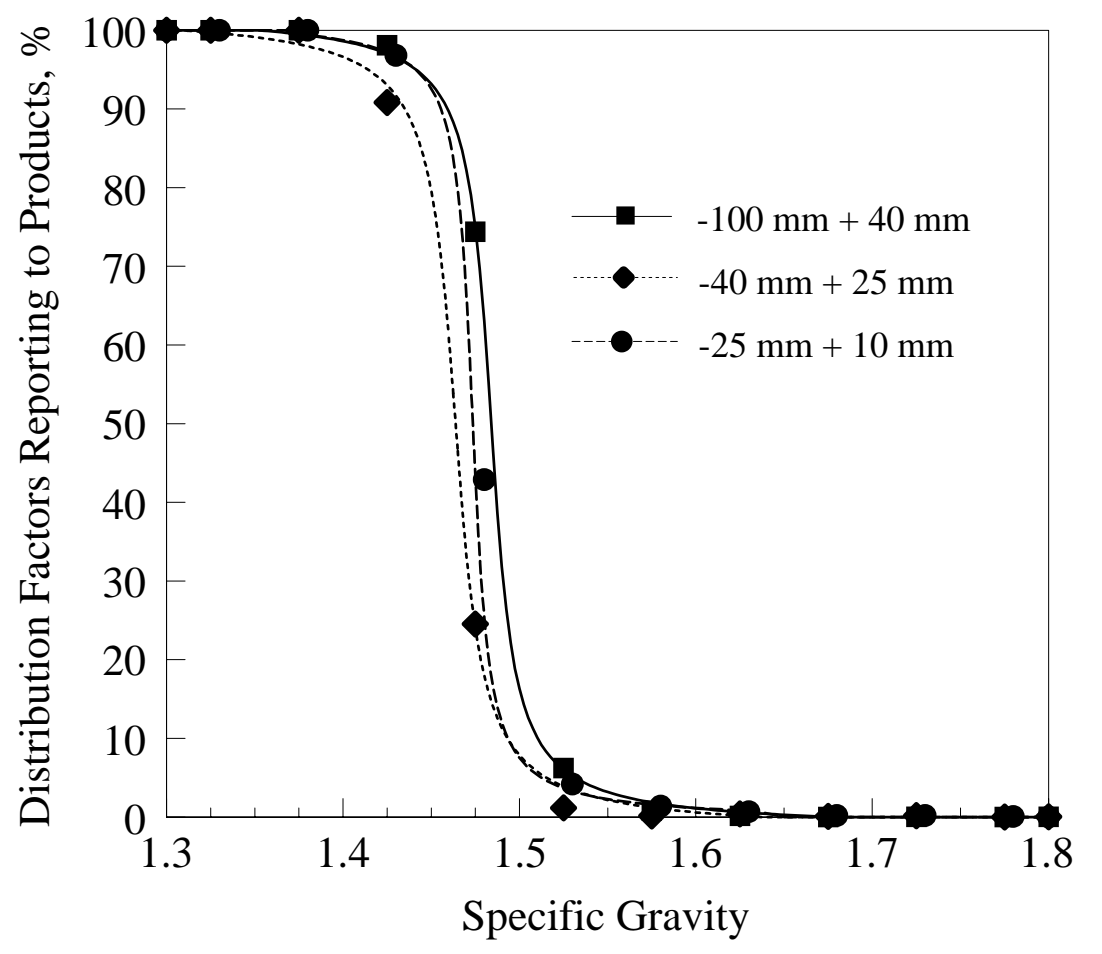

Figure 2-4 Separation Distribution Curves of Various Size Fractions for LARCODEM at Tavistotk Colliery, South Africa 
Table 2-4 Separation Distribution Curves Data for LARCODEM at Tavistotk Colliery Using Tracer Tests, South Africa

\begin{tabular}{|c|c|c|c|c|c|}
\hline \multicolumn{5}{|c|}{ Size Fractions $(\mathrm{mm})$} \\
\hline \multicolumn{2}{|c|}{$-100+40$} & \multicolumn{2}{c|}{$-40+25$} & \multicolumn{2}{c|}{$-25+10$} \\
\hline $\begin{array}{c}\text { Specific } \\
\text { Gravity }\end{array}$ & $\begin{array}{c}\text { Distribution } \\
\text { Factor, \% }\end{array}$ & $\begin{array}{c}\text { Specific } \\
\text { Gravity }\end{array}$ & $\begin{array}{c}\text { Distribution } \\
\text { Factor, \% }\end{array}$ & $\begin{array}{c}\text { Specific } \\
\text { Gravity }\end{array}$ & $\begin{array}{c}\text { Distribution } \\
\text { Factor, \% }\end{array}$ \\
\hline$<1.300$ & 100.00 & $<1.300$ & 100.00 & $<1.300$ & 100.00 \\
\hline 1.325 & 100.00 & 1.325 & 100.00 & 1.325 & 100.00 \\
\hline 1.375 & 100.00 & 1.375 & 100.00 & 1.375 & 100.00 \\
\hline 1.425 & 98.09 & 1.425 & 90.83 & 1.425 & 96.80 \\
\hline 1.475 & 74.39 & 1.475 & 24.54 & 1.475 & 42.90 \\
\hline 1.525 & 6.22 & 1.525 & 1.16 & 1.525 & 4.20 \\
\hline 1.575 & 0.80 & 1.575 & 0.13 & 1.575 & 1.40 \\
\hline 1.625 & 0.14 & 1.625 & 0.40 & 1.625 & 0.70 \\
\hline 1.675 & 0.00 & 1.675 & 0.08 & 1.675 & 0.20 \\
\hline 1.725 & 0.02 & 1.725 & 0.17 & 1.725 & 0.20 \\
\hline 1.775 & 0.00 & 1.775 & 0.01 & 1.775 & 0.10 \\
\hline 1.800 & 0.03 & 1.800 & 0.02 & 1.800 & 0.00 \\
\hline$>1.800$ & 0.00 & $>1.800$ & 0.00 & $>1.800$ & 0.0 \\
\hline
\end{tabular}




\subsubsection{Dense Medium Vessel}

Static Baths such as dense medium vessel (Jain, 2002) shown in Fig. 2-5 is commonly used to process coarse raw coal in coal preparation plants in the United States. The dip plate is used to deep feeding the raw coal into the vessel, which can be a straight or angled submerged plate. It has been used for effectively in separating $+6.35 \mathrm{~mm}$ size fraction. Dense medium vessel operates on the principle of hinder settling of particles in heavy liquid of given specific gravity. The particles lighter than the specific gravity of the dense medium made of the mixture of magnetite and water suspension, are the clean coal product, the particles heavier than the specific gravity of the medium are refuse. The unit operation has the ability to make relatively sharp separations; handle large amount of refuse and fluctuations in feed, and the adaptability for all types of coal.

Peng and Xia (2005) reported the results of a dense medium vessel separation performance for processing size range of $-50.8 \mathrm{~mm}+1 \mathrm{~mm}$. The raw coal was obtained from the coal preparation plant processing Pittsburgh Seam coal in southern part of Pennsylvania. The size distribution is exhibited in Table 2-5. In-plant test results for separation performance of the dense-medium vessel and the simulation values by a computational fluid dynamic (CFD) mathematical model are given in Table 2-6 and Fig. 2-6. 


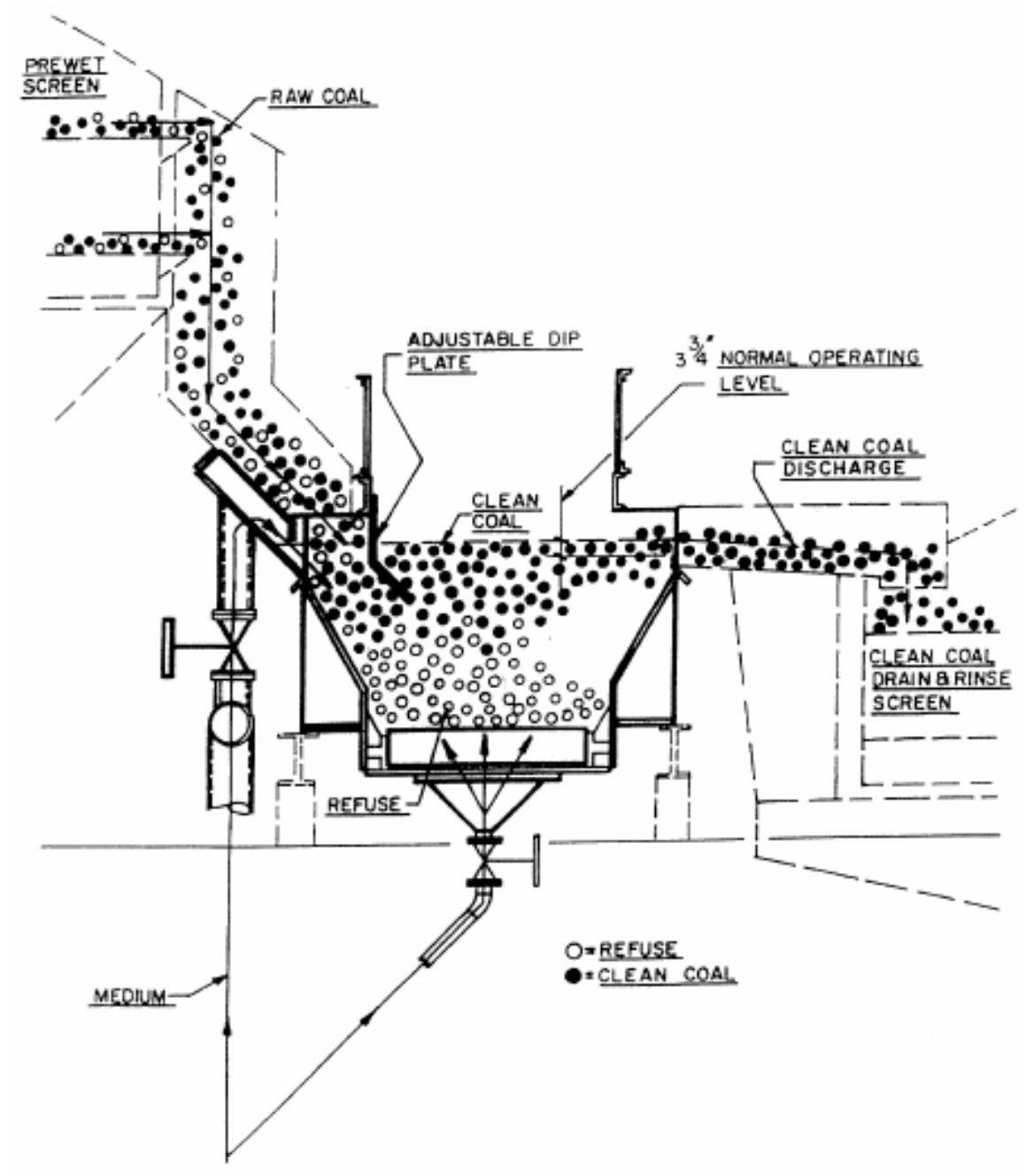

Figure 2-5 Schematic Diagram of Dense Medium Vessel 
Table 2-5 Size Distribution of Feed for Dense Medium Vessel, Pittsburgh Seam Coal, PA

\begin{tabular}{|c|c|}
\hline Size $(\mathrm{mm})$ & Weight Percentage $(\%)$ \\
\hline+50.8 & 17.51 \\
\hline$-50.8+25.4$ & 58.85 \\
\hline$-25.4+6.35$ & 22.19 \\
\hline$-6.35+1$ & 1.44 \\
\hline
\end{tabular}

The specific gravity of separation, or cut point, SG50 is 1.628 and the Ep value is 0.036 for plus $25.54 \mathrm{~mm}, 1.64$ and 0.048 for $-25.4 \mathrm{~mm}+6.35 \mathrm{~mm}$ and 1.67 and 0.14 for $6.35 \mathrm{~mm}+1 \mathrm{~mm}$ size fractions, respectively. For the overall separation performance of plus $1 \mathrm{~mm}$, the corresponding SG50 is 1.63 , and Ep value is 0.041 . The offset values define as SG50 subtract set point, are $+0.028,+0.04$, and +0.07 corresponding to the three size fractions mentioned above. The separation distribution curves show that highest sharpness of separation for plus $6.35 \mathrm{~mm}$, and much less sharpness of separation for $-6.35 \mathrm{~mm}+1 \mathrm{~mm}$ size fraction is obtained. From Table 2-5, the amount of $-6.35+1 \mathrm{~mm}$ size fraction only $1.44 \%$ of feed, which is misplaced materials from raw coal screen. Fig. 2-6 shows that the simulated distribution curves from CFD model for various size fractions are in good agreement with the in-plant results. The authors also reported the effects of pushing medium flow rate, solid flow rate and feed solid concentration on the separation performance. 
Table 2-6 In-plant Performance Data and Simulation Data for Pittsburgh Seam Coal, PA

\begin{tabular}{|c|c|c|c|c|c|c|c|c|}
\hline \multirow{2}{*}{$\begin{array}{c}\text { Specific } \\
\text { Gravity } \\
\text { Interval }\end{array}$} & \multicolumn{9}{|c|}{ Distribution Factor Reporting to Clean Coal Product, \% } \\
\cline { 2 - 9 } & \multicolumn{2}{|c|}{$+25.4 \mathrm{~mm}$} & \multicolumn{2}{|c|}{$-25.4+6.35 \mathrm{~mm}$} & \multicolumn{2}{c|}{$-6.35+1 \mathrm{~mm}$} & \multicolumn{2}{c|}{ Overall } \\
\cline { 2 - 10 } & Measured & Simulated & Measured & Simulated & Measured & Simulated & Measured & Simulated \\
\hline$<1.20$ & 100.00 & - & 100.00 & 100.00 & 100.00 & 100.00 & 100.00 & 100.00 \\
\hline $1.20-1.30$ & 99.99 & 100.00 & 100.00 & 99.65 & 95.00 & 99.98 & 100.00 & 95.83 \\
\hline $1.30-1.40$ & 99.95 & 99.98 & 96.00 & 99.36 & 92.00 & 99.87 & 98.00 & 92.66 \\
\hline $1.40-1.50$ & 99.30 & 99.56 & 98.21 & 99.12 & 80.00 & 98.68 & 97.00 & 85.01 \\
\hline $1.50-1.60$ & 90.14 & 91.50 & 91.00 & 92.02 & 70.54 & 88.29 & 91.00 & 71.82 \\
\hline $1.60-1.70$ & 37.19 & 33.87 & 39.00 & 35.80 & 55.83 & 43.22 & 33.00 & 53.39 \\
\hline $1.70-1.80$ & 3.69 & 2.38 & 13.00 & 8.09 & 39.75 & 7.13 & 7.00 & 33.98 \\
\hline $1.80-1.90$ & 0.25 & 0.12 & 2.93 & 1.71 & 11.42 & 0.77 & 3.00 & 18.79 \\
\hline $1.90-2.20$ & 0.00 & 0.00 & 0.14 & 0.08 & 0.97 & 0.00 & 0.04 & 3.04 \\
\hline$>2.20$ & 0.00 & 0.00 & - & 0.00 & - & 0.00 & - & 0.00 \\
\hline
\end{tabular}




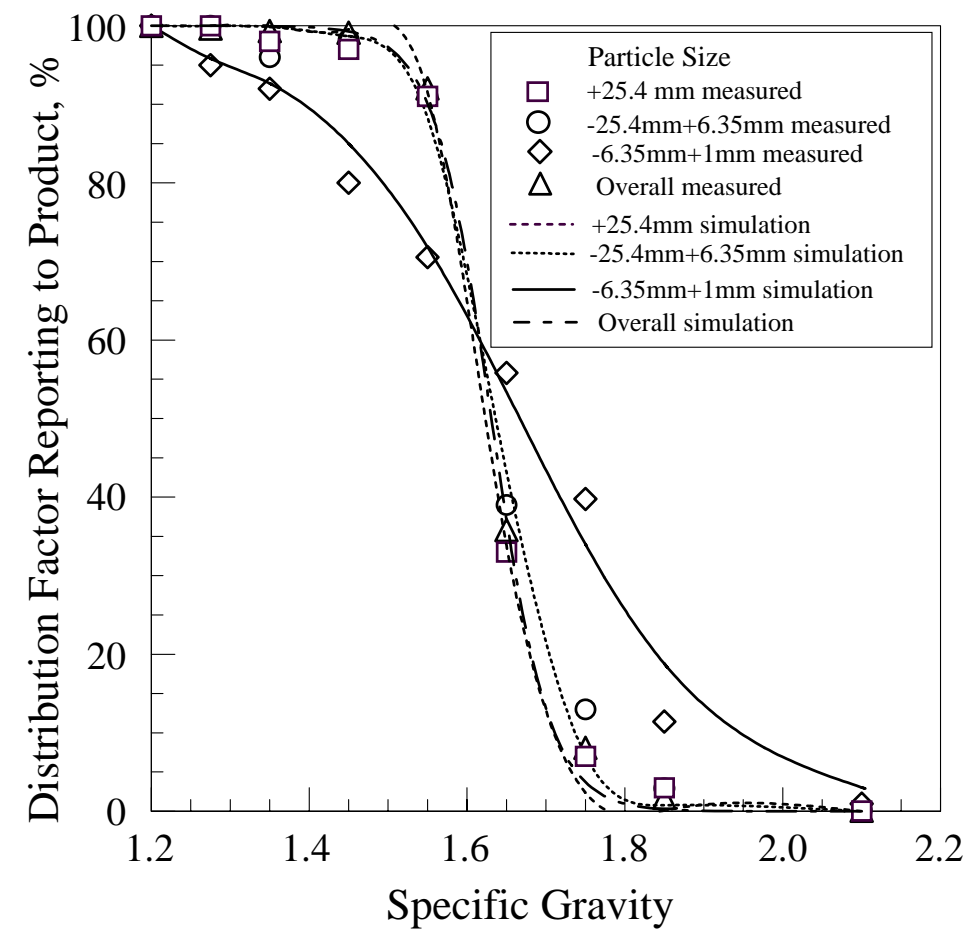

Figure 2-6 Distribution Curves for a Pittsburgh Seam Coal, In-plant Data and Model Data 


\subsubsection{Dense Medium Drum}

Dense medium drum is another type of static vessel for coal cleaning. The separator is particularly applicable for coarse particle separation. Fig. 2-7 shows the schematic diagram of dense medium drum separator. A study of rotating dense medium drum under three specified coal feed rates and dense medium slurry flow rates was conducted in a coal preparation plant (Peng, and Chang, 1996). The feed rate and medium flow rate to the dense medium drum for each test were: (A) 235 tph and $267 \mathrm{~m}^{3} / \mathrm{h}$ for test A, (B) 205 tph and 267 $\mathrm{m}^{3} / \mathrm{h}$ for test $\mathrm{B}$, (C) $163 \mathrm{tph}$ and $315 \mathrm{~m}^{3} / \mathrm{h}$ for test $\mathrm{C}$. The size distribution of coal samples was analyzed at sizes of $128,64,31.5,16,11.2,8,4,2$, and $1 \mathrm{~mm}$, the float-sink test analysis were conducted on the $-31.5+16,-16+11.2,-11.2+8$, and $-8+4 \mathrm{~mm}$ size fractions at specific gravities of $1.30,1.35,1.40,1.45,1.50,1.55,1.60,1.70,1.80,1.90$ and 2.0. The measured and the calculated data for the separation distribution curves at various size fractions processed by the dense medium drum are given in Table 2-7. The logistic functions (Klimam, and Luckie, 1986) were used to obtain the SG50 and Ep values.

In terms of the Ep value, the operating conditions in the Test B produced the best performance result, while the performance of the drum in the Test A was the least efficient. The specific gravity of separation, SG50, for all these three tests was close to the feed medium density 1.60 .

For the best performance Test $\mathrm{B}$, the off-set is ranged from +0.008 to +0.047 for particle size fractions of $31.3 \mathrm{~mm}$ to $4 \mathrm{~mm}$, but the off-set is only +0.009 for the overall size range tested. The distribution curve at the size range of $-31.5+16 \mathrm{~mm}$ is given in Fig. 2-8, it has very sharp shape. Similarly, the authors use the logistic function (Klimam, and Luckie, 
1986) to fit this curve, and the parameters SG50 and Ep of value are 1.608 and 0.033. For the separation distribution curve data is given in Table 2-8.

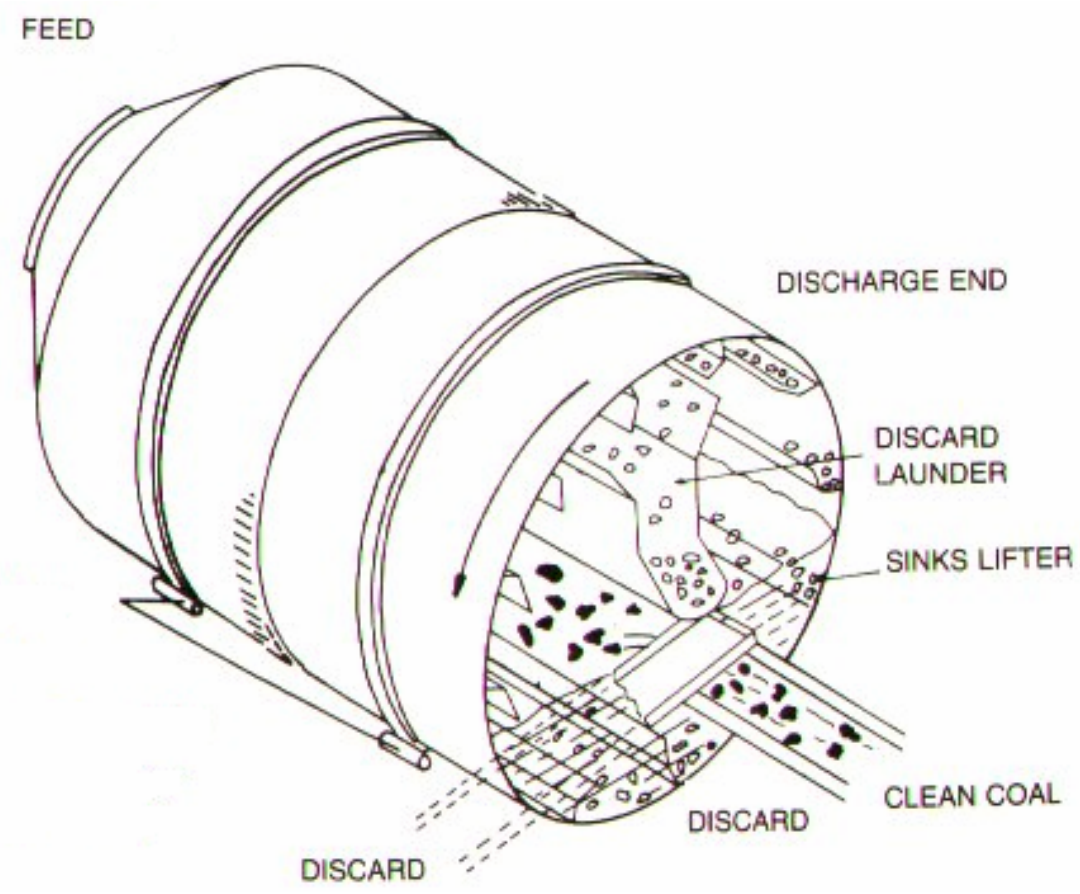

Figure 2-7 Schematic Diagram of Dense Medium Drum Separator 
Table 2-7 Performance Parameters of A Dense Medium Drum for Three Tests

\begin{tabular}{|c|c|c|c|c|c|c|c|}
\hline \multirow{2}{*}{ Size, mm } & \multicolumn{2}{|c|}{ Test A } & \multicolumn{2}{c|}{ Test B } & \multicolumn{2}{c|}{ Test C } & \multirow{2}{*}{ Off-set } \\
\cline { 2 - 7 } & SG50 & Ep & SG50 & Ep & SG50 & Ep & for Test B \\
\hline$-31.5+16.0$ & 1.587 & 0.044 & 1.608 & 0.033 & 1.606 & 0.036 & 0.008 \\
\hline$-16.0+11.2$ & 1.598 & 0.050 & 1.603 & 0.047 & 1.620 & 0.051 & 0.003 \\
\hline$-11.2+8.0$ & 1.625 & 0.077 & 1.620 & 0.061 & 1.637 & 0.055 & 0.020 \\
\hline$-8.0+4.0$ & 1.705 & 0.122 & 1.647 & 0.068 & 1.653 & 0.072 & 0.047 \\
\hline$-31.5+4.0$ & 1.595 & 0.049 & 1.609 & 0.039 & 1.613 & 0.042 & 0.009 \\
\hline-4.0 & - & - & - & - & - & - & - \\
\hline
\end{tabular}

Table 2-8 Distribution Curve Data of a Dense Medium Drum for $-31.5 \mathrm{~mm}+16 \mathrm{~mm}$ Size Fraction

\begin{tabular}{|c|c|}
\hline $\begin{array}{c}\text { Specific Gravity } \\
\text { Interval }\end{array}$ & $\begin{array}{c}\text { Distribution Factor Reporting to } \\
\text { Clean Coal Product, } \%\end{array}$ \\
\hline$<1.30$ & 99.60 \\
\hline $1.30-1.35$ & 99.60 \\
\hline $1.35-1.40$ & 99.40 \\
\hline $1.40-1.45$ & 99.30 \\
\hline $1.45-1.50$ & 97.30 \\
\hline $1.50-1.55$ & 95.30 \\
\hline $1.55-1.60$ & 74.90 \\
\hline $1.60-1.70$ & 19.50 \\
\hline $1.70-1.80$ & 1.90 \\
\hline $1.80-1.90$ & 0.00 \\
\hline $1.90-2.00$ & 0.00 \\
\hline$>2.00$ & 0.00 \\
\hline
\end{tabular}




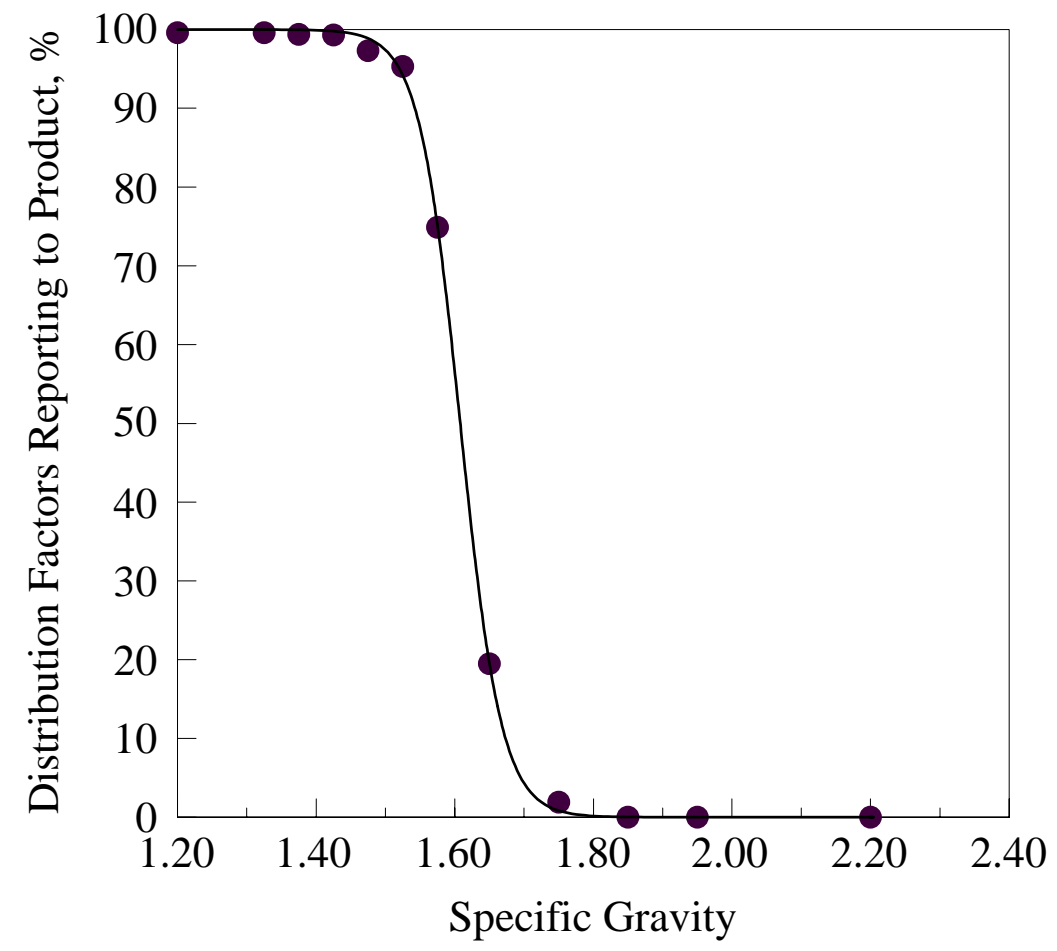

Figure 2-8 Distribution Curve of Dense Medium Drum for $-31.5 \mathrm{~mm}+16 \mathrm{~mm}$ Size Fraction of Raw Coal 


\subsection{Dynawhirlpool Cylindrical Cyclone}

Dynawhirlpool (DWP) separator was developed and patented by Rakowsky (1959). While the DWP separator was originally developed for the treatment of a wide range of mineral ores, it was first used in coal industry in 1977. There are some applications in France, Spain, Japan, and South Africa. The DWP consists of a cylinder with both an axial and a tangential port at each end as shown in Fig. $2-1$ b. It is operated at a $15^{\circ}$ to $25^{\circ}$ angle from the horizontal, the raw coal feed is added through the upper inlet with a small amount medium, under pressure, the centrifugal action of the medium creates an open vortex throughout the whole cylinder. The float ride down along the face of the vortex and discharge at the lower end of the cylinder, the sink are forced outward to the cylinder wall and out through the upper outlet.

The DWP separator has been used for the cleaning of coal in the $-9.375 \mathrm{~mm}$ or 6.25 $\mathrm{mm}+0.6 \mathrm{~mm}$ size range. However, raw coal feed size can reach as large as $37.5 \mathrm{~mm}$. Maronde et al. (1983) evaluated the performance characteristics from coal preparation plants utilized DWP separators. The separation distribution curves for these DWP separators are plotted in Fig. 3-3. The distribution curve data for DWP separators are shown in Appendix II, Table II-1. Based on the report for the composite plus $0.6 \mathrm{~mm}$ material, five DWP separators can process at specific gravity of separation range from 1.375 to 1.641, and the Ep values range from 0.05 to 0.066 . Good separation efficiencies were obtained. 


\subsection{Two Stage Dynamic Dense Medium Cylindrical Cyclone}

The Tri-Flo separator combines two stages of dense medium cylindrical cyclones separation in a single unit operation as shown in Fig. 2-1C and Fig. 4-1. The cylindrical body of the Tri-Flo consists of two consecutive cylindrical chambers with an axial orifice. Each cylindrical chamber is equipped with an involute media inlet and sink discharge. The feed is sluiced with a small amount of dense medium and add to the first chamber of the vessel at atmosphere pressure, produced float and sink 1 . The float from the first stage is the feed to the second chamber, at lower specific gravity, produced a sink 2 (middlings), and the final float product (clean coal) (Ruff, 1983). Operation of Tri-Flo cyclones in general can be fed by gravity flow using head tank. Thus, there is no need pumping of feed coal. It can reduce energy and wear on the pumps and any degradation of the product. Additionally, the low level feed entry makes a lower building and shorter feed conveyors, resulted in saving of space and cost.

Using dense medium cylindrical type cyclone separators in coal cleaning plant, the raw coal can enter the separator at a much larger inlet compared with a dense medium conical cyclone. Typical top size for Tri-Flo separator is $45 \mathrm{~mm}$ for a $500 \mathrm{ID}$ unit, and 70 $\mathrm{mm}$ for a $700 \mathrm{~mm}$ ID unit. In Tri-Flo separator, there are two sinks outlets available. The second cleaner stage ensures that any remaining heavy materials or near gravity materials are rejected in the second stage, so it has high sinks capacity. The advantages of implementation of two-stage-in-one dense medium cylindrical vessel, Tri-Flo, have been reported by Ferrara and Ruff (1982). Replacing a DWP (one cylindrical cyclone) by Tri-Flo resulted an improvement in yield comparing a two-stage and a single stage DWP in plant operation. 
It has been reported that a Zero Offset separation (defined as set point equals to SG50) can mean saving several million dollars a year for the Australian coal industry. A project to compare Tri-Flo cylindrical and a conical cyclone dense medium separator such as DWP separator, was conducted in Australia (Childs, 1996). A Tri-Flo separator was replaced a conical cyclone dense medium separator in a module of two separators in the Newdell Coal Preparation Plant. The Tri-Flo separator was $400 \mathrm{~mm}$ ID while the DWP separator was 500 mm. A tracer test, using cubical metal salt solid blocks at selected sizes and specific gravities, in the medium set-point at 1.58, was conducted (Davis, Wood, and Lyman, 1986). It proved that Ep was improved in the Tri-Flo separator especially for fine particles as shown in Table 2-9. Also, it shows that Tri-Flo separator was not a perfect Zero Offset separator but could obtain offsets that are very close to zero. The total difference in offset (offset $=$ SG50 medium set-point) was +0.044 for the Tri-Flo separator, and +0.175 for the conical dense medium separator, respectively. The SG50 of Tri-Flo separator increased with reducing size in much the same manner as the conical dense medium cyclone. Hence even if it were possible to tune Tri-Flo to zero offset for one size fraction or overall size, fine size can be still separated at a higher SG50. The distribution curves of dense medium conical cyclone are shown in Fig. 2-9, and those of Tri-Flo cylindrical cyclone are shown in Fig. 2-10. Distribution data are given in Table 2-10, and Table 2-11. From Table 2-9, Tri-Flo separator also shows sharper distribution curve, and has lower SG50 than conical dense medium cyclone for individual size fraction. 


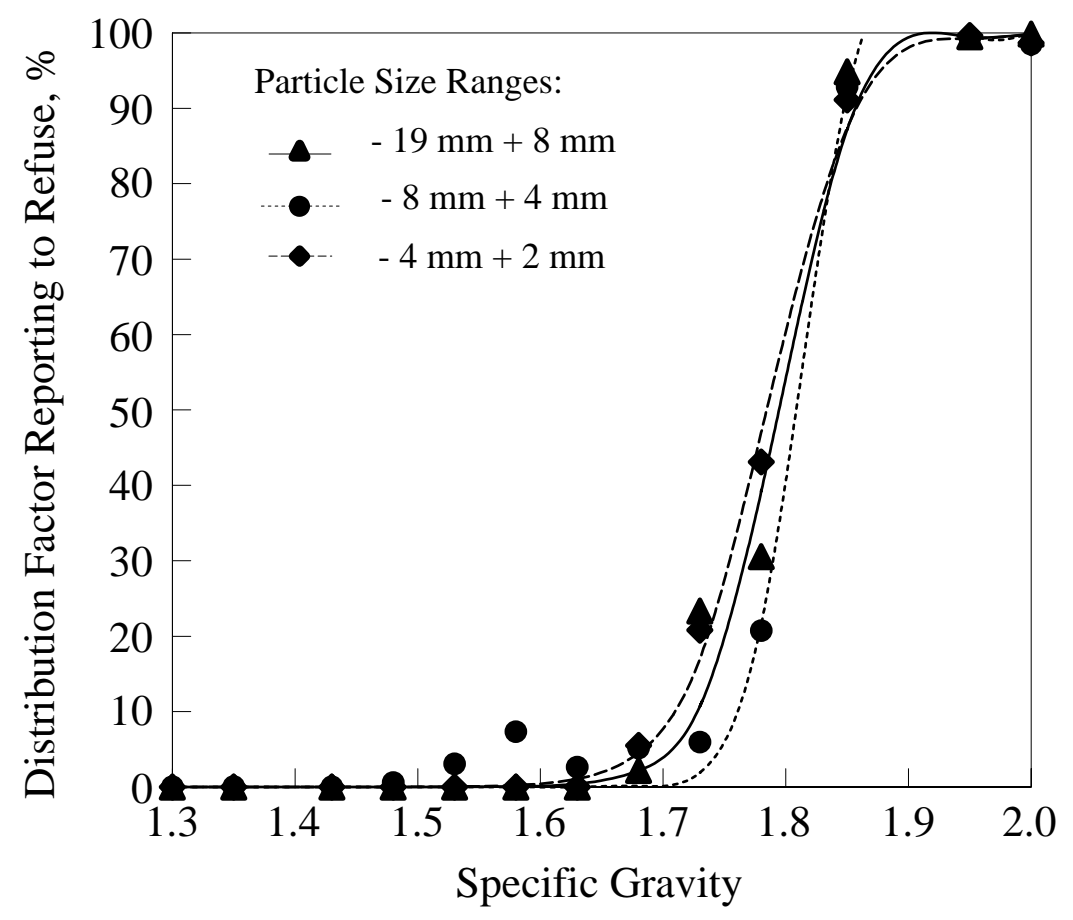

Figure 2-9 Distribution Curves for Conical Dense Medium Cyclone with Various Size Fractions 


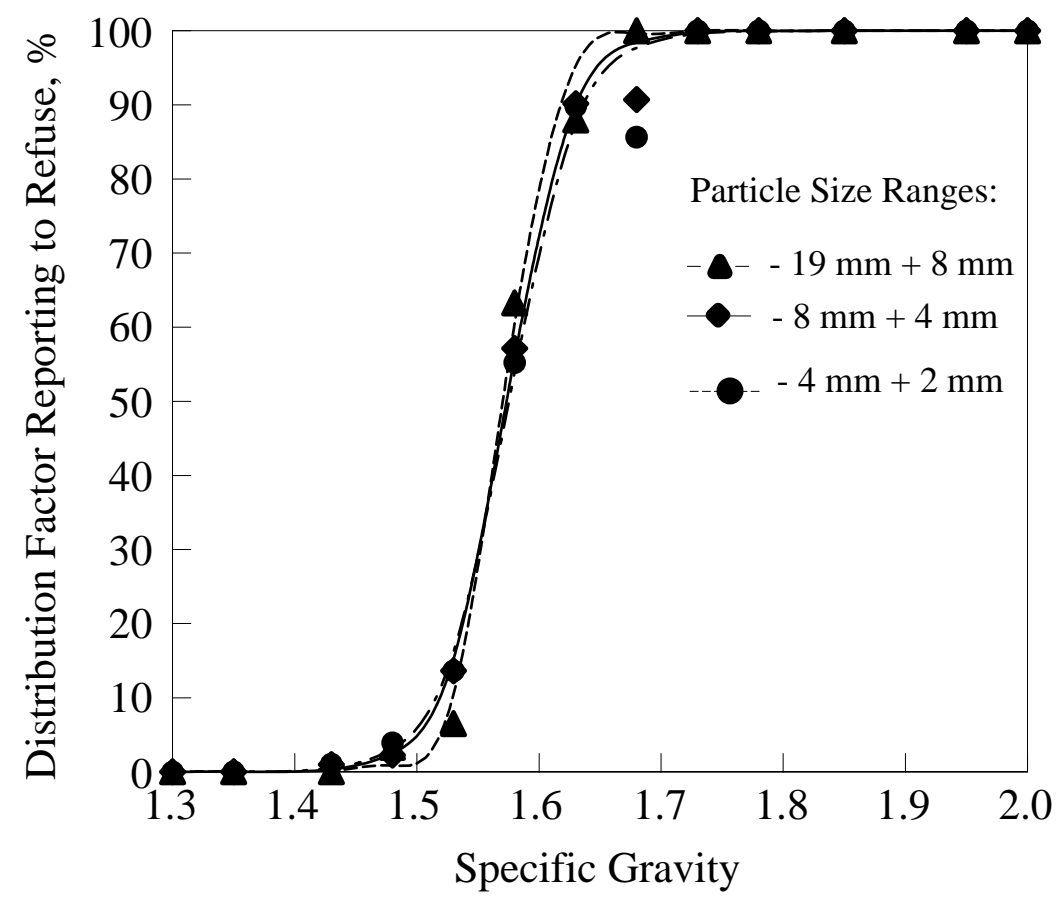

Figure 2-10 Distribution Curves for Tri-Flo Cyclone for Various Size Fractions of Raw Coal 
Table 2-9 In-Plant Data for Conical Dense Medium Cyclone and Tri-Flo Separator Using Tracer Tests

\begin{tabular}{|l|c|c|c|c|}
\hline & Size, $\mathrm{mm}$ & Ep & SG50 & Offset \\
\hline Conical Dense & \multirow{2}{*}{$\begin{array}{l}\text { Medium Cyclone } \\
\text { Tri-Flo }\end{array}$} & 0.029 & 1.802 & +0.202 \\
\cline { 1 - 3 } $\begin{array}{l}\text { Conical Dense } \\
\text { Medium Cyclone }\end{array}$ & $-8+4$ & 0.049 & 1.792 & +0.192 \\
\cline { 1 - 3 } Tri-Flo & \multirow{2}{*}{$\begin{array}{l}\text { Conical Dense } \\
\text { Medium Cyclone }\end{array}$} & 0.029 & 1.575 & -0.005 \\
\hline Tri-Flo & $-4+2$ & 0.027 & 1.577 & +0.212 \\
\cline { 1 - 3 } $\begin{array}{l}\text { Conical Dense } \\
\text { Medium Cyclone }\end{array}$ & $-2+1$ & 0.032 & 1.812 & -0.003 \\
\hline Tri-Flo & 0.101 & 1.967 & +0.367 \\
\cline { 3 - 5 } & & 0.050 & 1.616 & +0.036 \\
\hline
\end{tabular}

Table 2-10 Distribution Curve Data of Conical Dense Medium Cyclone for Different Size Fractions Using Tracer Tests

\begin{tabular}{|c|c|c|c|}
\hline \multirow{2}{*}{$\begin{array}{c}\text { Specific } \\
\text { Gravity }\end{array}$} & \multicolumn{3}{|c|}{ Distribution Factor Reporting to Refuse, \% } \\
\cline { 2 - 4 } Interval & $-19 \mathrm{~mm}+8 \mathrm{~mm}$ & $-8 \mathrm{~mm}+4 \mathrm{~mm}$ & $-4 \mathrm{~mm}+2 \mathrm{~mm}$ \\
\hline$<1.30$ & 0.00 & 0.00 & 0.02 \\
\hline $1.30-1.40$ & 0.00 & 0.00 & 0.06 \\
\hline $1.40-1.45$ & 0.00 & 0.00 & 0.03 \\
\hline $1.45-1.50$ & 0.00 & 0.00 & 0.59 \\
\hline $1.50-1.55$ & 0.00 & 0.00 & 3.08 \\
\hline $1.55-1.60$ & 0.00 & 0.00 & 7.35 \\
\hline $1.60-1.65$ & 0.00 & 0.00 & 2.65 \\
\hline $1.65-1.70$ & 2.20 & 5.51 & 5.16 \\
\hline $1.70-1.75$ & 23.33 & 20.79 & 5.97 \\
\hline $1.75-1.80$ & 30.54 & 43.12 & 20.75 \\
\hline $1.80-1.90$ & 94.84 & 91.12 & 92.83 \\
\hline $1.90-2.00$ & 99.48 & 99.63 & 99.33 \\
\hline$>2.00$ & 99.84 & 98.68 & 98.48 \\
\hline
\end{tabular}


Table 2-11 Separation Distribution Curve Data for Tri-Flo Separator at Different Size Fractions Using Tracer Tests

\begin{tabular}{|c|c|c|c|c|c|c|c|c|c|}
\hline \multirow{3}{*}{$\begin{array}{l}\text { Specific Gravity } \\
\text { Interval }\end{array}$} & \multicolumn{9}{|c|}{ Distribution Factor Reporting to Refuse, $\%$} \\
\hline & \multicolumn{3}{|c|}{$-19 \mathrm{~mm}+8 \mathrm{~mm}$} & \multicolumn{3}{|c|}{$-8 \mathrm{~mm}+4 \mathrm{~mm}$} & \multicolumn{3}{|c|}{$-4 m m+2 m m$} \\
\hline & Stage I & Stage II & Stage I + II & Stage I & Stage II & Stage I + II & Stage I & Stage II & Stage I + II \\
\hline$<1.30$ & 0.00 & 0.00 & 0.00 & 0.00 & 0.00 & 0.00 & 0.00 & 0.00 & 0.00 \\
\hline $1.30-1.40$ & 0.00 & 0.00 & 0.00 & 0.00 & 0.00 & 0.00 & 0.02 & 0.00 & 0.02 \\
\hline $1.40-1.45$ & 0.00 & 0.00 & 0.00 & 0.00 & 0.97 & 0.97 & 0.12 & 0.97 & 1.08 \\
\hline $1.45-1.50$ & 1.83 & 1.49 & 3.29 & 1.04 & 1.24 & 2.27 & 0.42 & 3.50 & 3.91 \\
\hline $1.50-1.55$ & 2.17 & 4.44 & 6.52 & 2.77 & 11.16 & 13.62 & 2.64 & 11.27 & 13.62 \\
\hline $1.55-1.60$ & 27.75 & 19.17 & 63.28 & 15.11 & 49.49 & 57.12 & 6.85 & 51.93 & 55.22 \\
\hline $1.60-1.65$ & 35.51 & 81.32 & 87.95 & 27.68 & 87.15 & 90.17 & 22.45 & 86.86 & 89.81 \\
\hline $1.65-1.70$ & 46.78 & 100.00 & 100.00 & 33.95 & 85.93 & 90.70 & 26.35 & 80.51 & 85.64 \\
\hline $1.70-1.75$ & 48.69 & 100.00 & 100.00 & 39.08 & 100.00 & 100.00 & 35.09 & 100.00 & 100.00 \\
\hline $1.75-1.80$ & 54.74 & 100.00 & 100.00 & 40.83 & 100.00 & 100.00 & 52.47 & 100.00 & 100.00 \\
\hline $1.80-1.90$ & 49.63 & 100.00 & 100.00 & 42.84 & 100.00 & 100.00 & 44.59 & 100.00 & 100.00 \\
\hline $1.90-2.00$ & 57.08 & 100.00 & 100.00 & 48.97 & 100.00 & 100.00 & 43.83 & 100.00 & 100.00 \\
\hline$>2.00$ & 63.17 & 100.00 & 100.00 & 51.66 & 100.00 & 100.00 & 59.07 & 100.00 & 100.00 \\
\hline
\end{tabular}


Childs also reported that an inefficiency of separation existed for the first chamber of Tri-Flo separator as shown in Fig. 2-11. For stage II and overall separation, the logistic function as shown in Eq 2-1 was used to fit the distribution curves and to derive SG50 and Ep values (Klima and Luckie, 1986). The corresponding distribution factors using tracer test are listed in Table 2-12.

$$
\mathrm{R}_{\mathrm{ji}}(\mathrm{x}, \mathrm{SG})=100-\frac{100}{1+\exp \left[\frac{1.098}{\mathrm{Ep}_{\mathrm{i}}}\left(\mathrm{SG}_{\mathrm{j}}-\mathrm{SG}_{\mathrm{j}} \mathrm{j}\right)\right]}
$$

where $R_{j i}$ is the percent of feed material in specific gravity interval of $S_{\mathrm{j}}$ and of $\mathrm{SG}_{\mathrm{j}+1}$ for size interval of $x_{i}$ and $x_{i+1}$ reporting to refuse; SG50; SG is any given mean specific gravity; and Ep is the probable error for the size $x_{i}$ to $x_{i}+d x_{i}$

Fig. 2-11 shows that the first stage of Tri-Flo (stage I) separator was not working properly. But the second stage of Tri-Flo (stage II) corrected the separation, and finally produced a shaper overall separation. The main reason to cause is due to an impropriate feeding system problem in stage I. A feeding system for dynamic cylindrical cyclone separators have been recently improved by using Dynafeed System, to avoid this type of poor feed distribution problem (Peng and Bozzato, 2002). The new feeding system is particularly critical for dynamic dense medium separator. Dynafeed system was also applied to single stage separators such as Dynawhilpool Separator to improve their separation as well. Because of the Tri-Flo separator has the features of low level feed entry, high sinks capacity, fine media, larger feed top size, and capable of treaty water degradable waste materials. Especially it has higher sharpness of separation using new feeding system, it becomes applicable in treating coal that difficult to clean. 


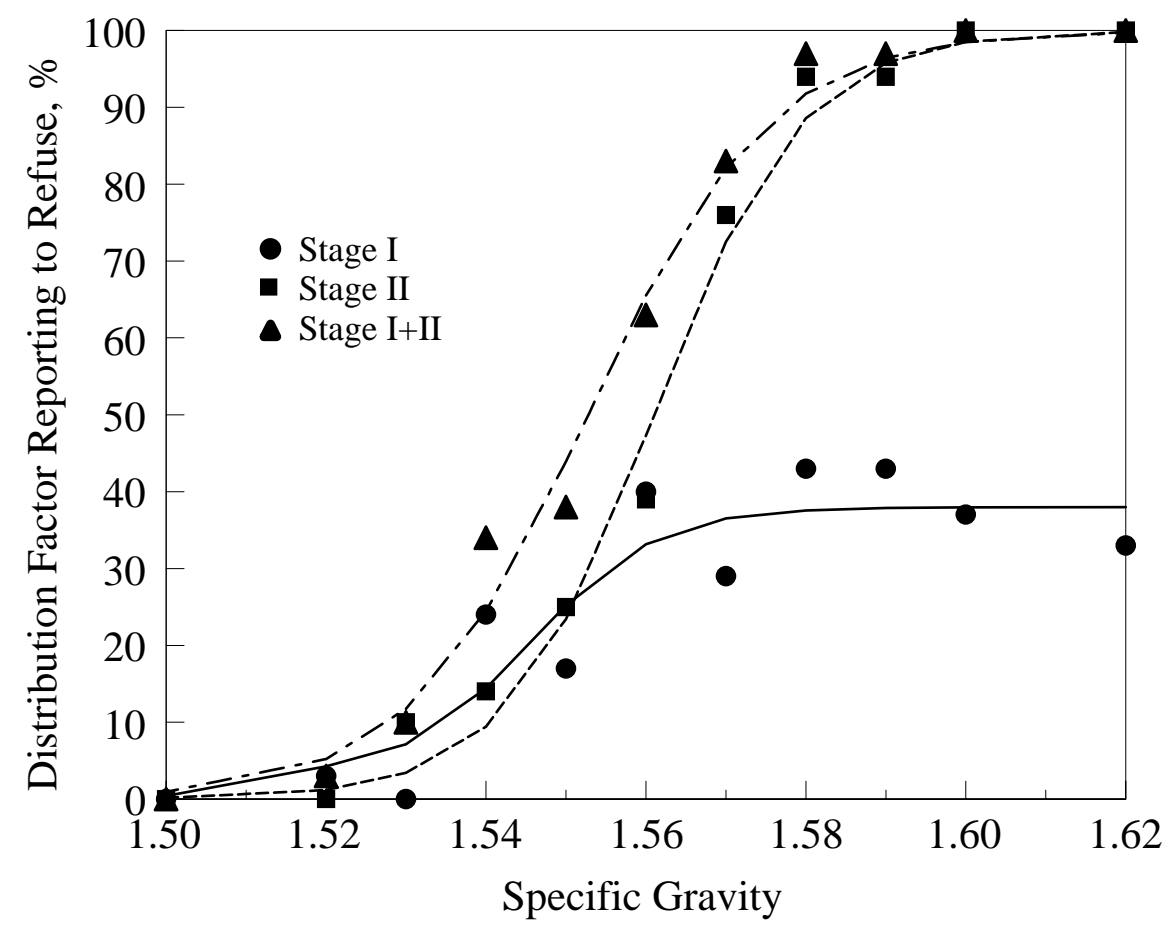

Figure 2-11 Distribution Curves for Tri-Flo Separator Using Tracer Test 
Table 2-12 Distribution Curve Data for Tri-Flo Separator Using Tracer Tests

\begin{tabular}{|c|c|c|c|}
\hline \multirow{2}{*}{$\begin{array}{c}\text { Specific } \\
\text { Gravity }\end{array}$} & \multicolumn{3}{|c|}{ Distribution Factors Reporting to Refuse, \% } \\
\cline { 2 - 4 } & Stage I & Stage II & Stage I + II \\
\hline 1.50 & 0.00 & 0.00 & 0.00 \\
\hline 1.52 & 3.00 & 0.00 & 3.00 \\
\hline 1.53 & 0.00 & 10.00 & 10.00 \\
\hline 1.54 & 24.00 & 14.00 & 34.00 \\
\hline 1.55 & 17.00 & 25.00 & 38.00 \\
\hline 1.56 & 40.00 & 39.00 & 63.00 \\
\hline 1.57 & 29.00 & 76.00 & 83.00 \\
\hline 1.58 & 43.00 & 94.00 & 97.00 \\
\hline 1.59 & 43.00 & 94.00 & 97.00 \\
\hline 1.60 & 37.00 & 100.00 & 100.00 \\
\hline 1.62 & 33.00 & 100.00 & 100.00 \\
\hline
\end{tabular}




\subsection{Standard Float-Sink Test and Tracer Techniques for Performance Evaluation of Specific Gravity Based Separator}

In order to evaluate the performance of the separation circuit, there are two methods can be used for sampling from each process stream, specific gravity distribution determinations and ash analysis.

(1) Conventional standard composite sampling technique:

The product sample from each stream or dewatering screen is obtained at predetermined time intervals. The composite sample size obtained from different time intervals depends on the capacity of separator. Subsequently, float-sink tests, dewatering, sizing, weighting, ashing, etc. are performed. The distribution curve of the separator is derived from the mass balanced the measured weight and ash distributions as function of mean specific gravity reporting to clean coal product and refuse (ASTM, 2002).

(2) Tracer technique:

The most common used tracers are metal salt density tracers. Tracers are made of metal salt, the specific gravity range from 1.24 to 3.50 , they can be various shapes and colors. The tracers with predetermined size are added to the feed. The tracers are then retrieved at the clean coal product dewatering screens and refuse screens, separately. Based on the amount of tracers reporting to clean coal product dewatering screens and refuse dewatering screens, the separation distribution curve reporting to clan coal product can be obtained (Davis, Wood, and Lyman, 1986). The advantage of using tracer technique is the elimination of float-sink tests to handling organic heavy liquids, dewatering, drying, and sizing of coal samples. Certainly, there are some disadvantages of using density tracer technique, such as excessive labors are needed for retrieving the 
tracers, difficulty in retrieving smaller tracers, loss of tracers in high tonnage separator, and the need of the statistical analysis of recovered tracers to assure the minimum errors in separation distribution curve. Additionally, using tracer method, in-plant ash contents of the products can not be measured. 


\section{CHAPTER 3 CIRCUIT ANALYSIS TOOLS FOR SOLID- SOLID SEPARATION}

\subsection{Concept of Generalized Distribution Curve}

\subsubsection{Dense Medium Conical Cyclones}

Most coal cleaning unit operations based on physical processes employed the principles of specific gravity difference between coal and mineral particles. Based on the specific gravity differences, raw coal feed are separated into clean coal product and refuse. The performance of each coal cleaning unit operation is characterized by a separation distribution curve, which express as the percentage of feed reporting to clean coal product or refuse as a function of mean specific gravity. For a given coal cleaning unit operation, a different separation distribution curves can be obtained at various operation conditions. These distribution curves can also plotted as the percentage of feed reporting to clean coal product or refuse as the ordinate, against the normalized mean specific gravity, $\mathrm{X}$ as the abscissa. The result is a single unified curve named as generalized distribution curve (Gottfried and Jacobsen, 1977). Apparently, these separation distribution curves operated at various SG50s are a group of family curves. The normalized mean specific gravity, $\mathrm{X}$, is defined as the ratio of the mean specific gravity, SG to the specific gravity of separation, SG50.

$$
\mathrm{X}=\frac{\mathrm{SG}}{\mathrm{SG} 50}
$$


Deurbrouck and Hudy (1972) investigated seven different coal preparation plants which utilized dense medium conical cyclones for coal cleaning. The separation distribution curves for the seven dense medium conical cyclones are shown in Fig. 3-1. For specific gravity based separators, a generalized distribution curve can be formed for the family distribution curves due to specific gravity of separation differences, as shown in Fig. 3-2. However, this can not be applied to the case of size differences. The dense medium cyclones separation distribution curve data and other performance data are shown in Appendix I, Table I-1 and Table I-2, respectively.

\subsubsection{Dense Medium Cylindrical Cyclones}

DWP separator is a single stage dense medium cylindrical cyclone. Maronde et al. (1983) evaluated the performance characteristics from coal preparation plants utilized DWP separators. The separation distribution curves for these DWP separators are plotted in Fig. 3-3. Similarly, for these DWP separators operated at different specific gravity of separation, a generalized distribution curve is obtained as shown in Fig. 3-4. The distribution curve data for DWP separators are shown in Appendix II, Table II-1. A summary of the performance data for the composite plus $0.6 \mathrm{~mm}$ material is also given in Appendix II, Table II-2. The generalized distribution curve is formed by normalizing mean specific gravity with respect to specific gravity of separation, thus it is independent of the specific gravity of separation. To obtain the performance data of a specific coal cleaning unit operated at different specific gravity of separation from a generalized separation distribution curve, it requires transforming the generalized distribution curve 


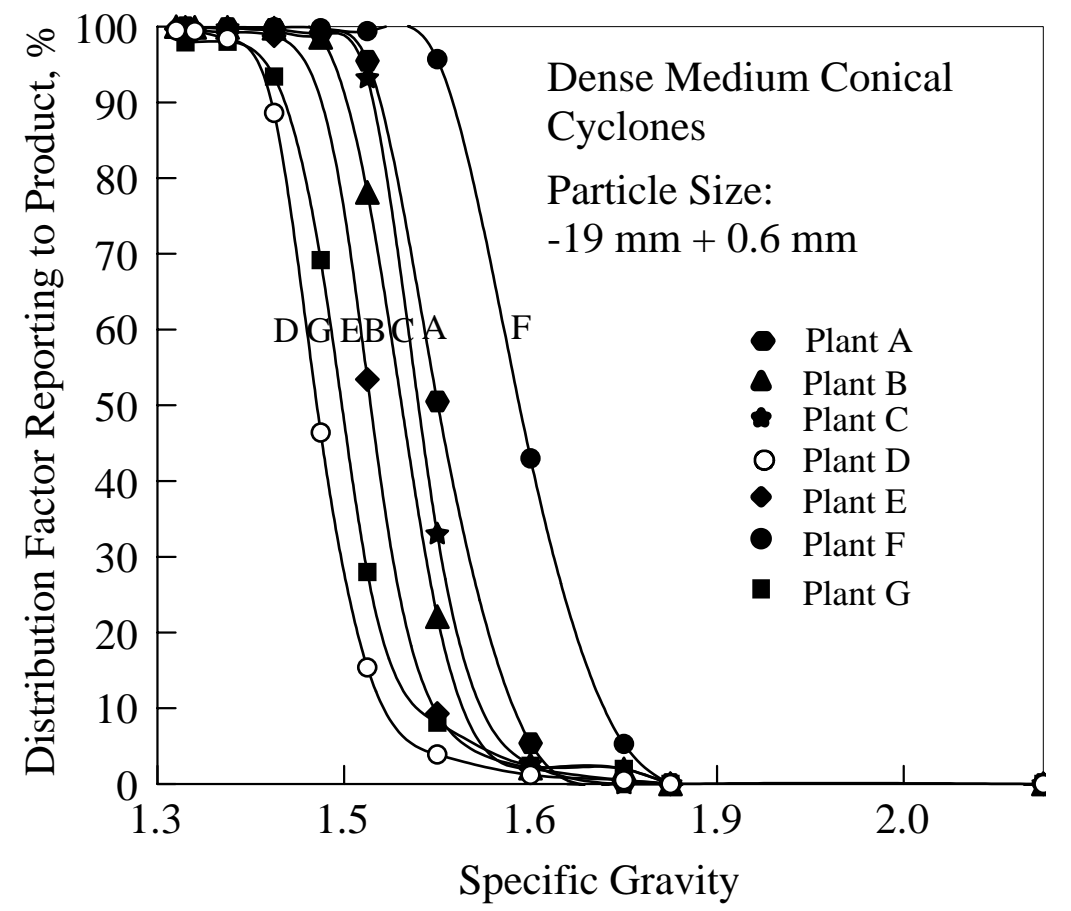

Figure 3-1 Distribution Curves for Dense Medium Conical Cyclones Operated at Various SG50s 


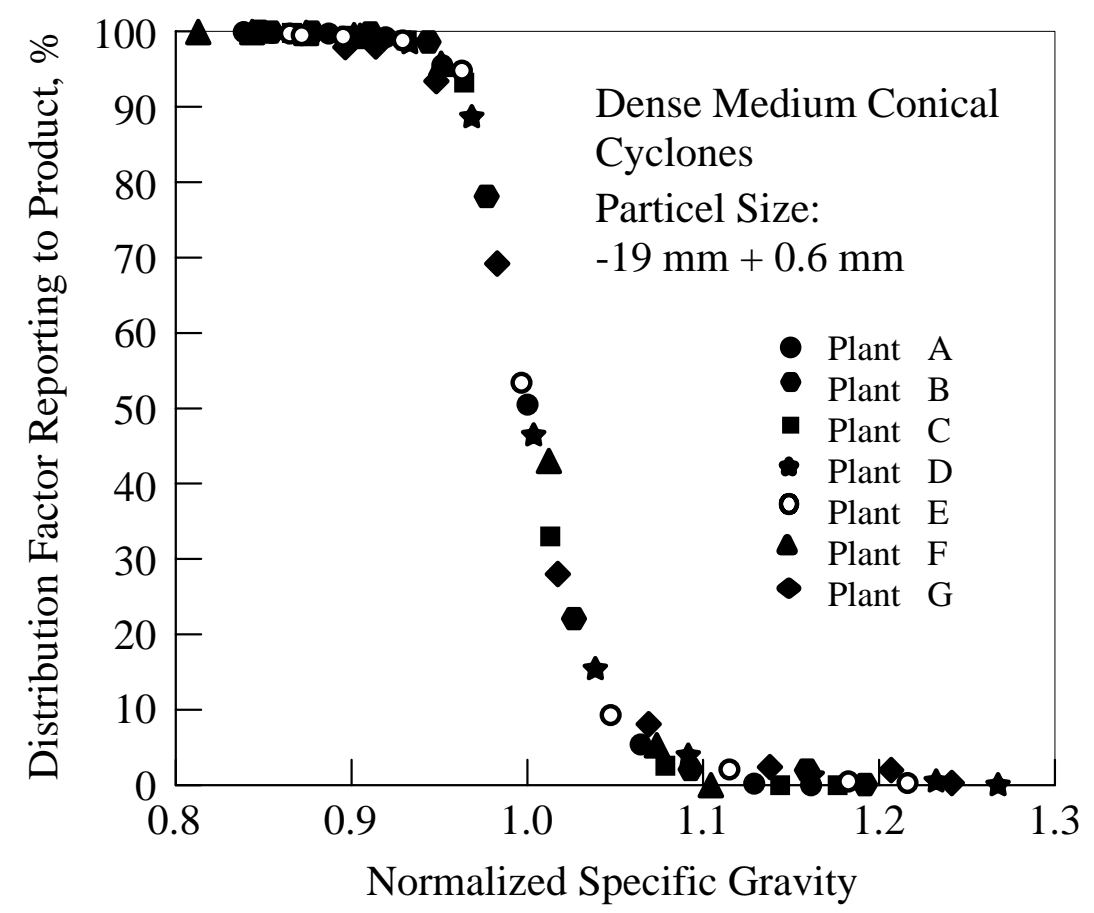

Figure 3-2 Generalized Distribution Curves for Dense Medium Conical Cyclones Operated at Various SG50s 


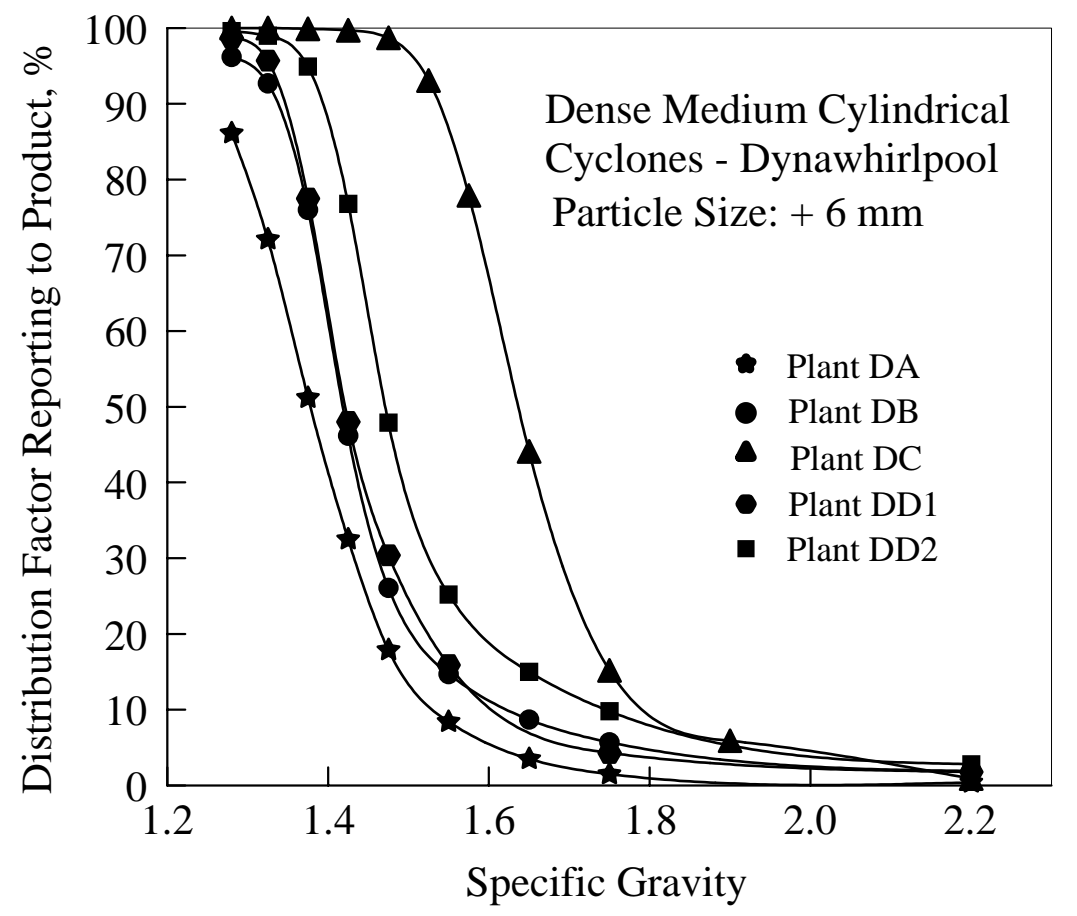

Figure 3-3 Distribution Curves for Dynawhirlpool Separators Operated at Various SG50s 


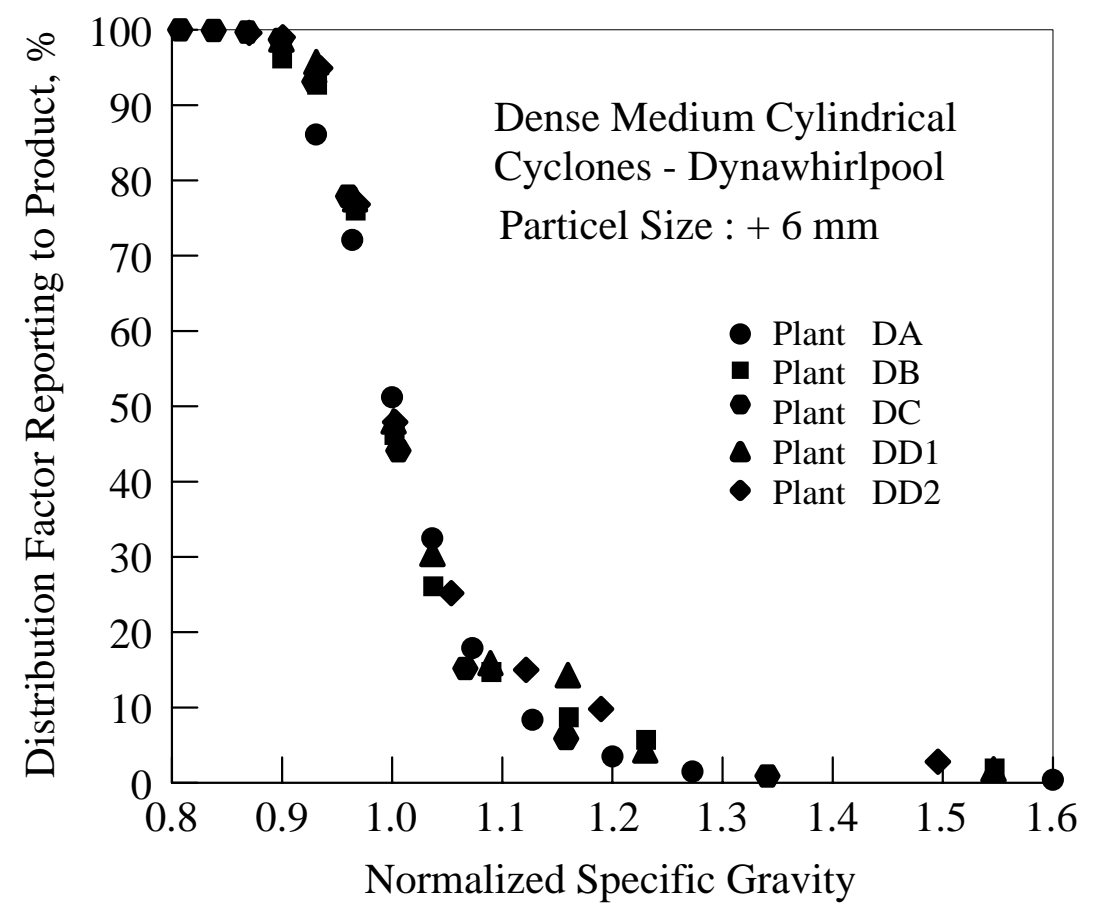

Figure 3-4 Generalized Distribution Curves for Dynawhirlpool Separators Operated at Various SG50s 
to the original separation distribution curve.

The probable error, Ep of a separation distribution curve can be defined as onehalf the specific gravity difference between $25 \%$ and $75 \%$ of feed reporting to clean coal product.

$$
\mathrm{Ep}=\frac{\mathrm{SG} 25-\mathrm{SG} 75}{2}
$$

The generalized probable error, GEp can then be derived as one-half normalized specific gravity difference between $25 \%$ and $75 \%$ of feed reporting to clean coal product.

$$
\mathrm{GEp}=\frac{\mathrm{X} 25-\mathrm{X} 75}{2}=\frac{\mathrm{SG} 25-\mathrm{SG} 75}{2 \cdot \mathrm{SG} 50}=\frac{\mathrm{Ep}}{\mathrm{SG} 50}
$$

where X25 and X75 are the normalized specific gravities corresponding to 25 and 75 percentages of feed reporting to clean coal product.

Therefore, the probable error can be obtained simply by multiplying the generalized probable error by the specific gravity of separation.

$$
\mathrm{Ep}=\mathrm{GEp} \cdot \mathrm{SG} 50
$$

GEp is independent of the specific gravity of separation for a given coal-cleaning unit, the probable error is dependent on the specific gravity of separation.

\subsection{Circuit Analysis of Coal and Mineral Processes}

\subsubsection{Circuit Configurations}

In order to prepare the products to meet market requirements, there are various separation circuit configurations of unit operations using in coal and mineral processing 
plants. Various circuit configurations can be developed for specific characteristics of coal or mineral to be processed as shown in Table 3-1. 
Table 3-1 Concentration Circuit Configurations

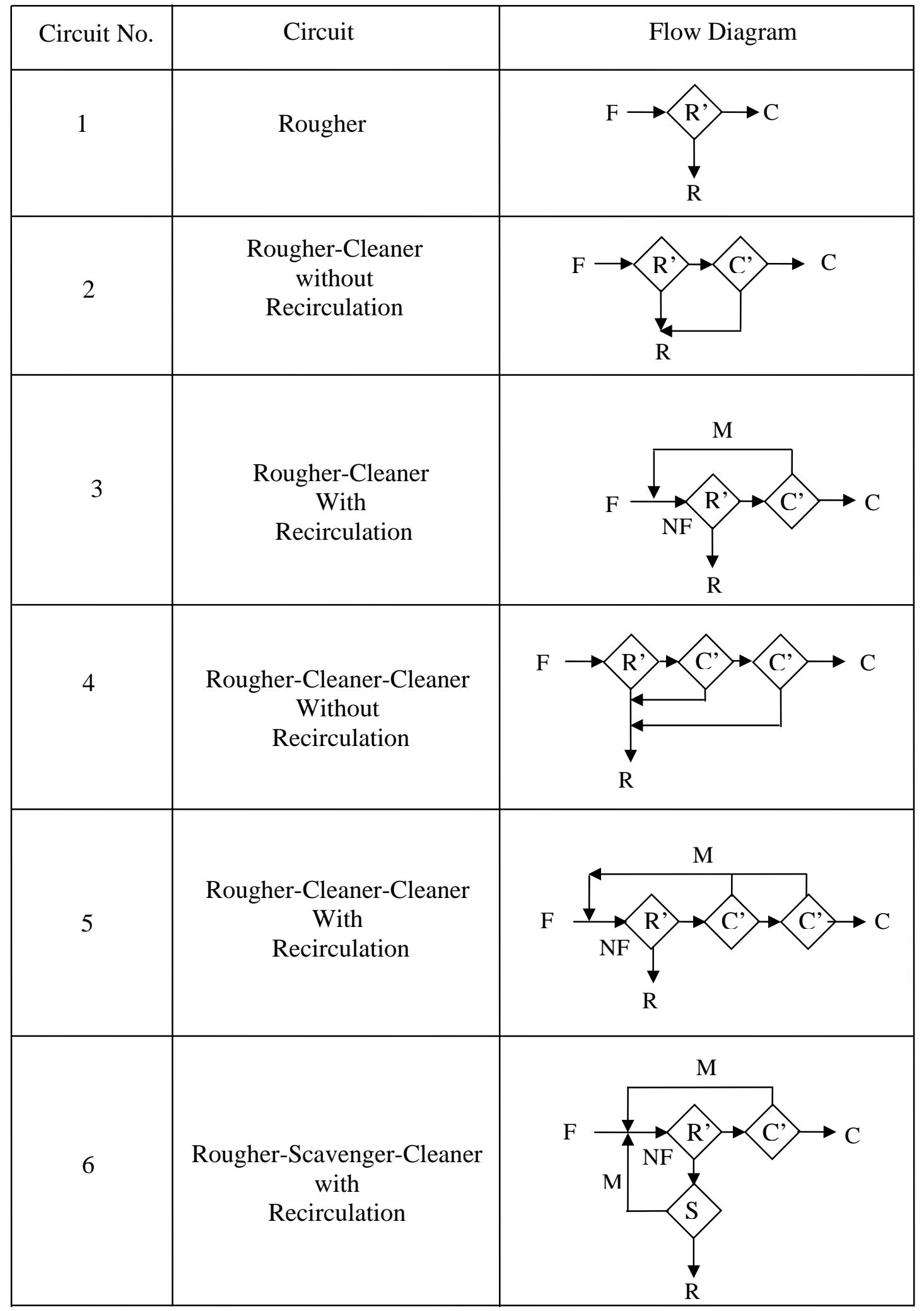


Table 3-1 Concentration Circuit Configurations (continued)

\begin{tabular}{|c|c|c|}
\hline Circuit No. & Circuit & $\begin{array}{c}\text { Rougher-Scavenger } \\
\text { with } \\
\text { Recirculation }\end{array}$ \\
\hline 8 & $\begin{array}{c}\text { Rougher-Scavenger-Cleaner } \\
\text { without } \\
\text { Recirculation }\end{array}$ & \\
\hline 9 & $\begin{array}{c}\text { Rougher-Scavenger } \\
\text { without } \\
\text { Recirculation }\end{array}$
\end{tabular}

Notes: $\mathrm{R}^{\prime}=$ rougher; $\mathrm{C}^{\prime}=$ cleaner; $\mathrm{S}^{\prime}=$ scavenger; $\mathrm{F}=$ feed $; \mathrm{R}=$ refuse; $\mathrm{C}=$ clean coal products; $\mathrm{M}=$ middling; and $\mathrm{NF}=$ new feed which combined feed and recirculated material. 


\subsubsection{Circuit Analysis for Various Circuit Configurations}

Circuit analysis can be applied to determine the improvement of separation efficiency over a single stage separation as shown in Figure 3-1 and Fig. 3-3. Separation distribution factor reporting to clean coal product, can be expressed as $\mathrm{P}=\mathrm{C} / \mathrm{F}$. For a single stage operation, the clean coal product, $\mathrm{C}$ and refuse, $\mathrm{R}$ can be calculated by

$$
\mathrm{C}=(\mathrm{P}) \cdot \mathrm{F}
$$

and

$$
\mathrm{R}=(1-\mathrm{P}) \cdot \mathrm{F}
$$

where $\mathrm{C}$ is clean coal product; $\mathrm{R}$ is refuse; and $\mathrm{F}$ is feed.

Consider a two stage separation by using rougher-cleaner without recirculation as shown in Fig. 3-5 (Circuit No. 2 in Table 3-1).

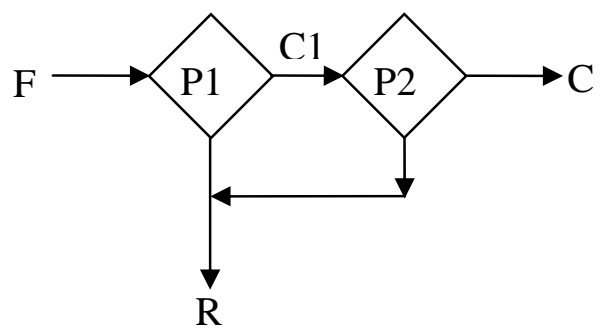

$\mathrm{C}=(\mathrm{P} 1)(\mathrm{P} 2) \mathrm{F}$

$\mathrm{R}=[1-(\mathrm{P} 1)(\mathrm{P} 2)] \mathrm{F}$

Figure 3-5 Rougher-Cleaner without Recirculation Circuit

where $\mathrm{C} 1$ is clean coal product for rougher; $\mathrm{P} 1=\mathrm{C} 1 / \mathrm{F}$ is the probability of feed reporting to clean coal product from rougher; $\mathrm{C} 2$ is the product from the cleaner; and $\mathrm{P} 2=\mathrm{C} / \mathrm{C} 1$ is the probability of rougher clean coal product reporting to overall clean coal product.

Thus clean coal product for rougher is calculated by 


$$
\mathrm{C} 1=(\mathrm{P} 1) \cdot \mathrm{F}
$$

The overall clean coal product for overall circuit, $\mathrm{C}$ is calculated by

$$
\mathrm{C}=(\mathrm{P} 2) \cdot \mathrm{C} 1
$$

By substituting Eq 3-6 to Eq 3-7, the product and refuse of the overall circuit are then expressed as

$$
\mathrm{C}=(\mathrm{P} 1) \cdot(\mathrm{P} 2) \cdot \mathrm{F}
$$

and

$$
\mathrm{R}=[1-(\mathrm{P} 1) \cdot(\mathrm{P} 2)] \cdot \mathrm{F}
$$

Therefore, the probability of separation distribution factor reporting to clean coal product for this circuit can be expressed by two distribution curves P1 and P2 as

$$
\mathrm{P}=\frac{\mathrm{C}}{\mathrm{F}}=(\mathrm{P} 1) \cdot(\mathrm{P} 2)
$$

\subsubsection{Definition for Sharpness of Separation and Relative Separation Efficiency}

The slope of the selective function of separation evaluated at SG=SG50 can be used to represent the separation efficiency of separation. For dense medium separation, which displays the linear slope between $25 \%$ and $75 \%$ of feed reporting to product can be derived mathematically by taking the partial derivative of selective function respect to specific gravity at $\mathrm{SG}=\mathrm{SG} 50$.

$$
\mathrm{SE}=\left.\frac{\partial\left(\frac{\mathrm{C}}{\mathrm{F}}\right)}{\partial(\mathrm{SG})}\right|_{\mathrm{SG} 50}=\left.\frac{\partial(\mathrm{P})}{\partial(\mathrm{SG})}\right|_{\mathrm{SG} 50}
$$


The linear sharpness of separation is then defined as the slope between $25 \%$ and $75 \%$ feed reporting to product at $\mathrm{SG}=\mathrm{SG} 50$

$$
\frac{\partial\left(\frac{\mathrm{C}}{\mathrm{F}}\right)}{\partial(\mathrm{SG})}=\frac{\partial \mathrm{P}}{\partial(\mathrm{SG})} \approx \frac{\Delta \mathrm{P}}{\Delta \mathrm{SG}}=\frac{0.25-0.75}{2 \cdot \mathrm{Ep}}=-\frac{1}{4 \cdot \mathrm{Ep}}
$$

For a given circuit configuration the relative separation efficiency, RSE, can be defined as

$$
\mathrm{RSE}=\frac{\text { sharpness of separation for a given circuit configuration at SG50 }}{\text { sharpness of separation for rougher at SG50 }}
$$

Therefore,

$$
\mathrm{RSE} \approx \frac{-\frac{1}{4 \cdot(\mathrm{Ep})_{\text {circuit }}}}{-\frac{1}{4 \cdot(\mathrm{Ep})_{\text {rougher }}}}=\frac{(\mathrm{Ep})_{\text {rougher }}}{(\mathrm{Ep})_{\text {circuit }}}
$$

\subsubsection{Applying of Selective Function}

The separation distribution curves such as P1, P2 and P can be described by selective or probability functions for dense medium separators. The selective function which is often being used to describe the separation distribution curve for reporting to product is logistic function, which has the form of Eq 3-15 (Klima and Luckie, 1986).

$$
\text { 1. Rougher: } \quad \mathrm{P}_{\text {rougher }}=\frac{1}{1+\exp \left[\frac{1.098}{\mathrm{Ep}}(\mathrm{SG}-\mathrm{SG50)}]\right.}
$$

where SG is the specific gravity; Ep is probable error; and $\mathrm{P}$ is the probability reporting to clean coal product. 
Using similar approach, the products for various concentration circuit configurations can be derived as follows, and summarized in Table 3-2.

2. R-C without recirculation: $\quad \mathrm{P}=\mathrm{P}^{2}$ rougher

3. R-C with recirculation $\quad: \quad \mathrm{P}=\frac{\mathrm{P}^{2}{ }_{\text {rougher }}}{1-\mathrm{P}_{\text {rougher }}+\mathrm{P}^{2}{ }_{\text {rougher }}^{2}}$

4. $\mathrm{R}-\mathrm{C}-\mathrm{C}$ without recirculation: $\quad \mathrm{P}=\mathrm{P}^{3}$ rougher

5. R-C-C with recirculation:

$$
\mathrm{P}=\frac{\mathrm{P}_{\text {rougher }}^{3}}{1-\mathrm{P}_{\text {rougher }}+\mathrm{P}^{3}{ }_{\text {rougher }}}
$$

6. R-C-S with recirculation:

$$
\mathrm{P}=\frac{\mathrm{P}_{\text {rougher }}^{2}}{1-2 \cdot \mathrm{P}_{\text {rougher }} \cdot\left(1-\mathrm{P}_{\text {rougher }}\right)}
$$

7. R-S with recirculation:

$$
\mathrm{P}=\frac{\mathrm{P}_{\text {rougher }}}{1-\mathrm{P}_{\text {rougher }}+\mathrm{P}^{2} \text { rougher }}
$$

8. R-S-C without recirculation: $\quad \mathrm{P}=\mathrm{P}_{\text {rougher }}$

9. R-S without recirculation: $\quad \mathrm{P}=2 \cdot \mathrm{P}_{\text {rougher }}-\mathrm{P}^{2}$ rougher 
Table 3-2 Products for Various Concentration Circuit Configurations

\begin{tabular}{|c|c|c|c|}
\hline $\begin{array}{l}\text { Circuit } \\
\text { No. }\end{array}$ & Circuit & Products & Flow Diagram \\
\hline 1 & Rougher & $\begin{array}{l}\mathrm{C}=(\mathrm{P} 1) \mathrm{F} \\
\mathrm{R}=[1-(\mathrm{P} 1)] \mathrm{F}\end{array}$ & $\begin{array}{l}\downarrow \\
\mathrm{R}\end{array}$ \\
\hline 2 & $\begin{array}{c}\text { Rougher-Cleaner } \\
\text { without } \\
\text { Recirculation }\end{array}$ & $\begin{array}{l}\mathrm{C}=(\mathrm{P} 1)(\mathrm{P} 2) \mathrm{F} \\
\mathrm{R}=[1-(\mathrm{P} 1)(\mathrm{P} 2)] \mathrm{F}\end{array}$ & $\mathrm{R}$ \\
\hline 3 & $\begin{array}{c}\text { Rougher-Cleaner } \\
\text { with } \\
\text { Recirculation }\end{array}$ & $\begin{array}{l}\mathrm{NF}=\mathrm{F}+\mathrm{M} \\
\mathrm{M}=[1-(\mathrm{P} 2)](\mathrm{P} 1)(\mathrm{NF}) \\
\mathrm{C}=(\mathrm{P} 1)(\mathrm{P} 2)(\mathrm{NF}) \\
\mathrm{R}=[1-(\mathrm{P} 1)](\mathrm{NF})\end{array}$ & M \\
\hline 4 & $\begin{array}{l}\text { Rougher-Cleaner } \\
\text {-Cleaner } \\
\text { without } \\
\text { Recirculation }\end{array}$ & $\begin{array}{l}\mathrm{C}=(\mathrm{P} 1)(\mathrm{P} 2)(\mathrm{P} 3) \mathrm{F} \\
\mathrm{R}=[1-(\mathrm{P} 1)(\mathrm{P} 2)(\mathrm{P} 3)] \mathrm{F}\end{array}$ & R \\
\hline 5 & $\begin{array}{l}\text { Rougher-Cleaner } \\
\text {-Cleaner } \\
\text { with } \\
\text { Recirculation }\end{array}$ & $\begin{array}{l}\mathrm{NF}=\mathrm{F}+\mathrm{M} \\
\mathrm{M}=(\mathrm{P} 1)[1-(\mathrm{P} 2)(\mathrm{P} 3)](\mathrm{NF}) \\
\mathrm{C}=(\mathrm{P} 1)(\mathrm{P} 2)(\mathrm{P} 3)(\mathrm{NF}) \\
\mathrm{R}=[1-(\mathrm{P} 1)](\mathrm{NF})\end{array}$ & $\begin{array}{l}\mathrm{R} \\
\mathrm{R}\end{array}$ \\
\hline 6 & $\begin{array}{c}\text { Rougher-Scavenger } \\
\text {-Cleaner } \\
\text { with } \\
\text { Recirculation }\end{array}$ & $\begin{aligned} & \mathrm{NF}=\mathrm{F}+\mathrm{M} \\
& \mathrm{M}= {[(\mathrm{P} 1)-(\mathrm{P} 1)(\mathrm{P} 2)+(\mathrm{P} 3)} \\
&-(\mathrm{P} 1)(\mathrm{P} 3)](\mathrm{NF}) \\
& \mathrm{C}=(\mathrm{P} 1)(\mathrm{P} 2)(\mathrm{NF}) \\
& \mathrm{R}= {[1-(\mathrm{P} 1)][1-(\mathrm{P} 3)](\mathrm{NF}) }\end{aligned}$ & $\begin{array}{l}\downarrow \\
\mathrm{R}\end{array}$ \\
\hline
\end{tabular}


Table 3-2 Products for Various Concentration Circuit Configurations (Continued)

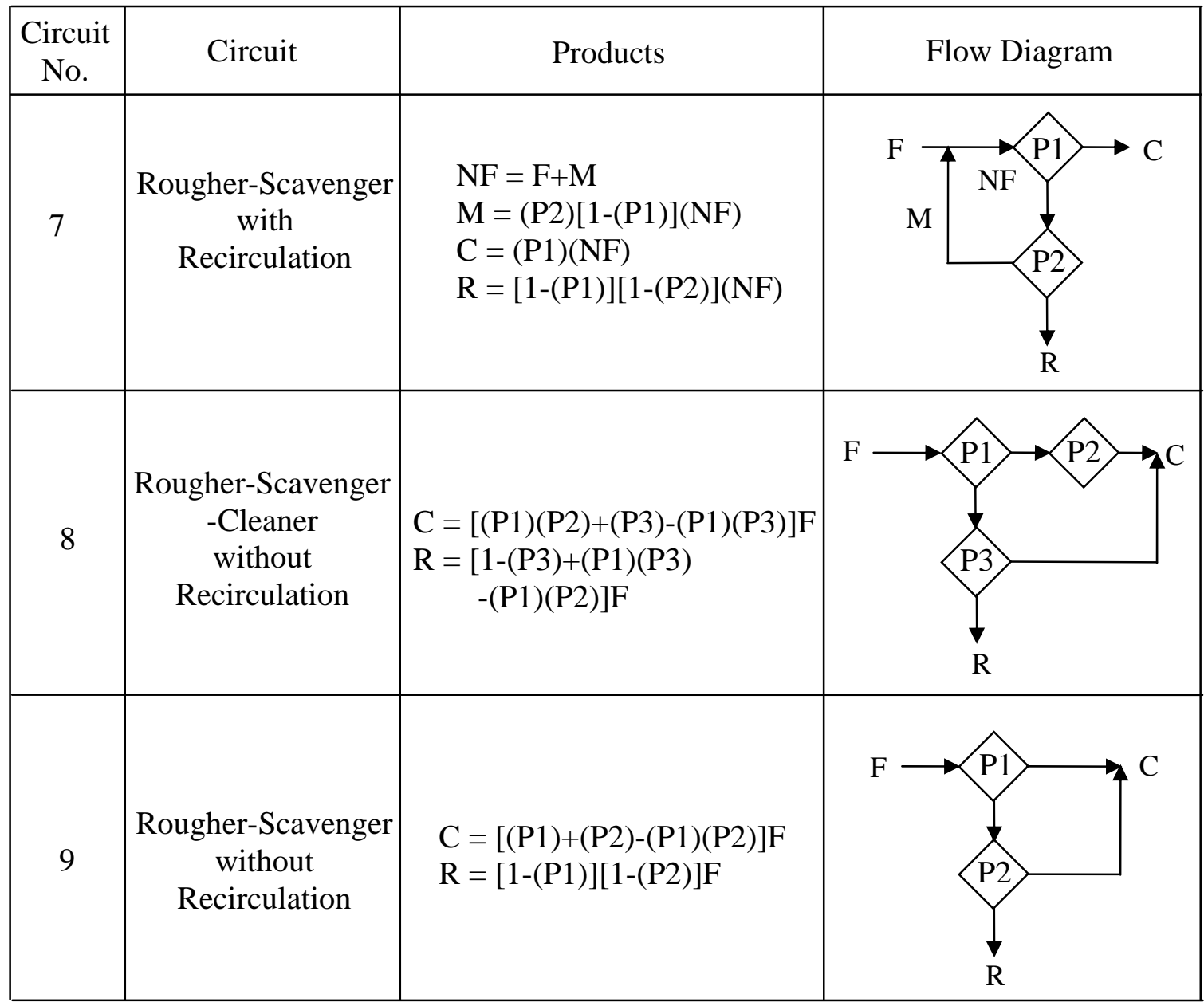

Notes: $\mathrm{R}=$ refuse $; \mathrm{C}=$ clean coal product $\mathrm{F}=$ feed $; \mathrm{M}=$ middling $; \mathrm{NF}=$ new feed which combined feed and recirculated material; and $\mathrm{P}=$ probability of feed reporting to clean coal product. 
Substitute Eq 3-15 to Eq 3-11, yield

$$
\mathrm{SE}=\left.\frac{\partial(\mathrm{P})}{\partial(\mathrm{SG})}\right|_{\mathrm{SG} 50}=\left.\frac{\partial\left(\frac{\mathrm{C}}{\mathrm{F}}\right)}{\partial(\mathrm{SG})}\right|_{\mathrm{SG} 50}=\frac{-1.0986}{4 \cdot \mathrm{Ep}}
$$

Probable error, Ep is often used to measure the separation efficiency of dense medium separators for coal cleaning as defined in Eq 3-2, the RSE for a given circuit configuration can be calculated as

$$
\mathrm{RSE} \approx \frac{-\frac{1.09861}{4 \cdot(\mathrm{Ep})_{\text {circuit }}}}{-\frac{1.0986}{4 \cdot(\mathrm{Ep})_{\text {rougher }}}}=\frac{(\mathrm{Ep})_{\text {rougher }}}{(\mathrm{Ep})_{\text {circuit }}}
$$

Computer simulations have been performed using the selective function, Eq 3-15 for rougher. In circuit analysis simulation, the specific gravity of separation, SG50 is set at 1.60 and Ep value of 0.03 for rougher, cleaner, and scavenger. By utilizing Eq 3-15 to Eq 3-23, the distribution curve for each circuit configuration can be derived. The simulation results are exhibited Fig. 3-6 for overall separation distribution curves of various circuit configurations. The corresponding generalized distribution curves for given circuit configurations are shown in Fig. 3-7. As can be seen, these generalized distribution curves of each circuit are not overlap to each other. They are not to form a unified curve with that rougher and cleaner. Each circuit configuration has its own distribution curve which is not belongs to the same family curves. The relative separation efficiencies for various concentration circuit configurations are calculated and summarized in Table 3-3. Although the operation conditions of rougher, cleaner and scavenger are the same, different circuit configurations have different specific gravities of 
separation and probability errors for overall circuit distribution curve. The following effects are also observed from the results of circuit analysis simulations: 1) addition of cleaner in the circuits will decrease overall SG50 of the circuit; 2) re-cleaning middlings will increase overall SG50 of the circuit; and 3) addition of scavenger in the circuit will increase overall SG50 of the circuit. 


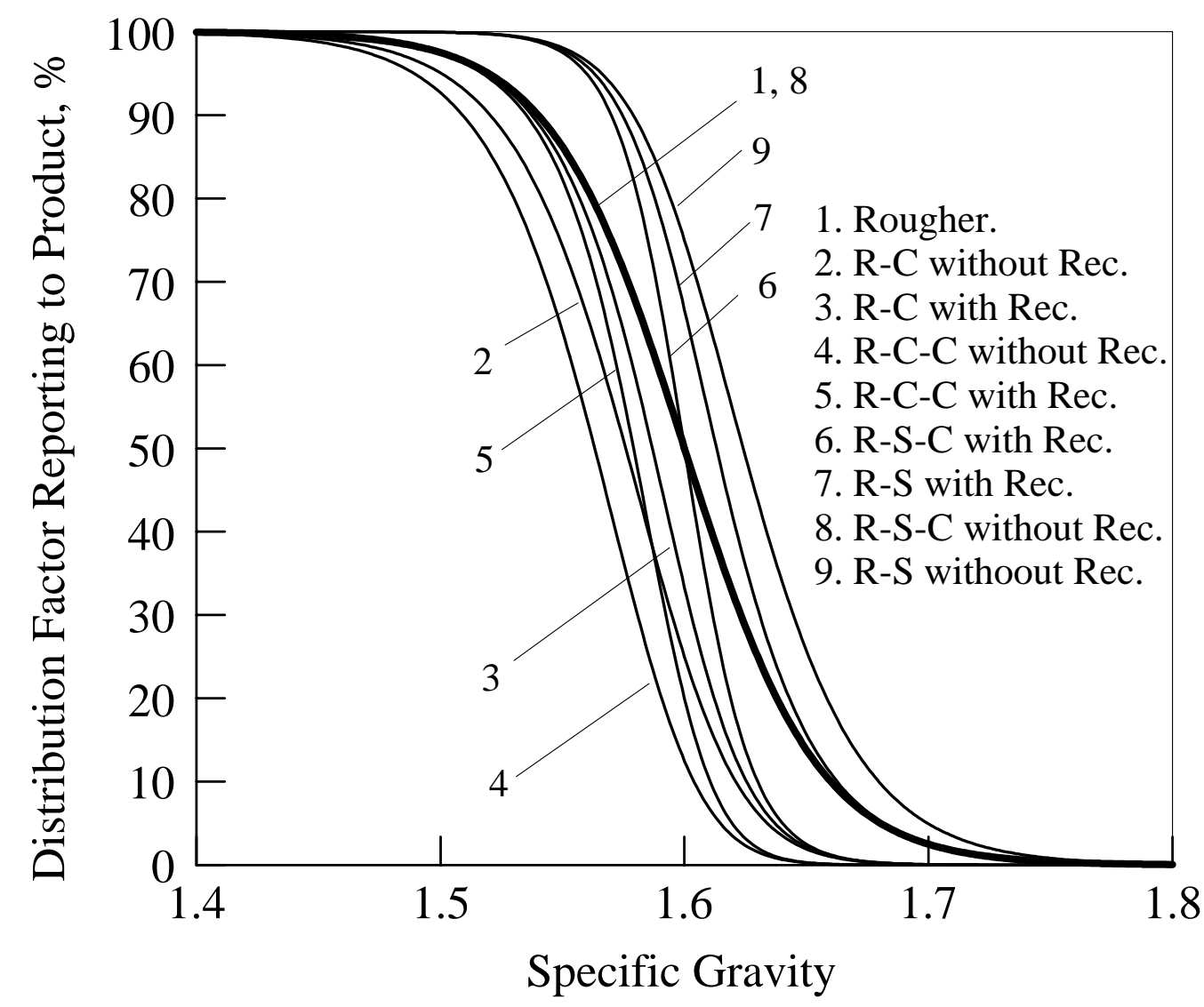

Figure 3-6 Overall Separation Distribution Curves for Nine Different Circuit Configurations 


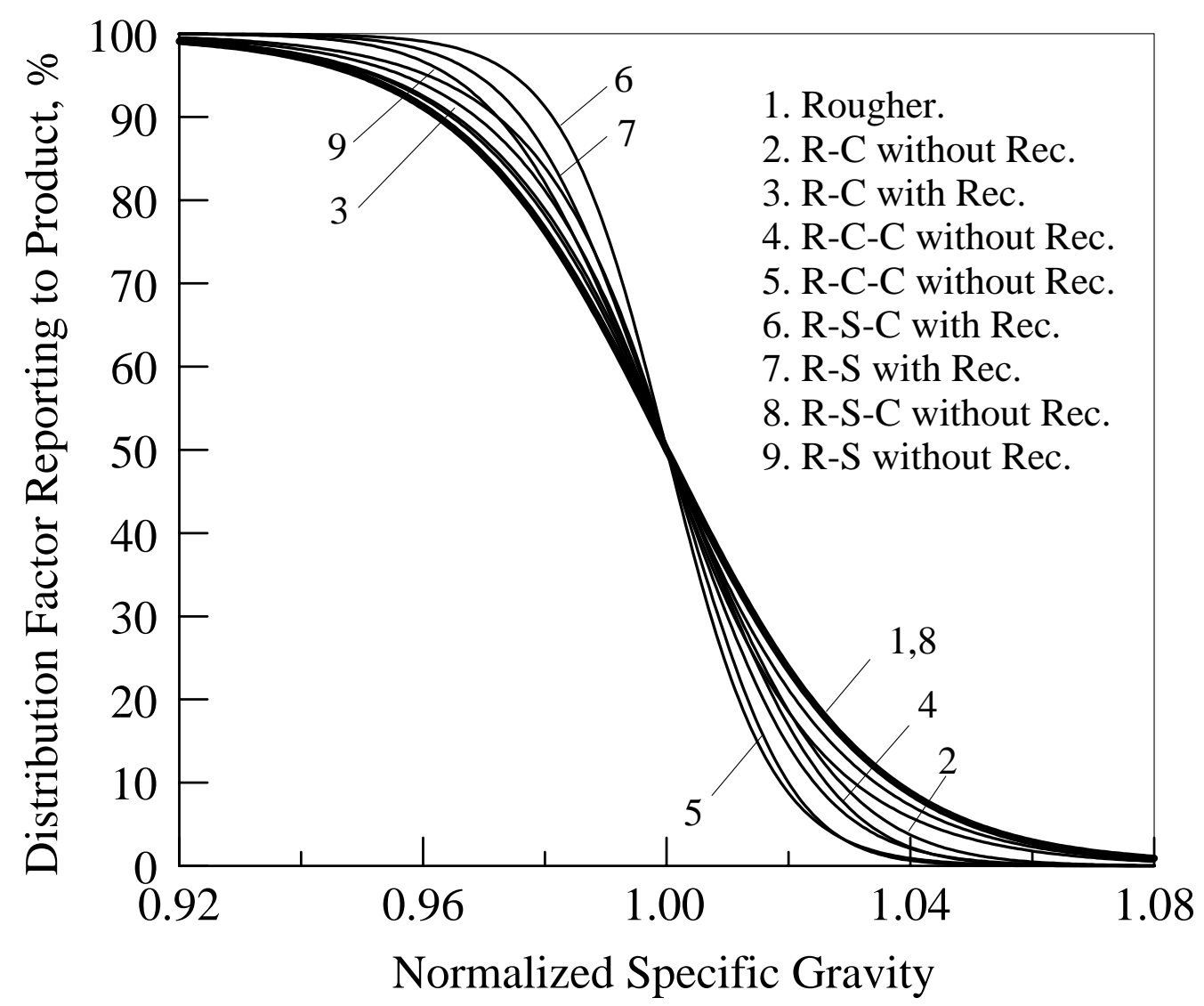

Figure 3-7 Generalized Overall Distribution Curves for Nine Different Circuit Configurations 
Table 3-3 Simulation Results of SG50 and Relative Separation Efficiencies for Various Concentration Circuit Configurations

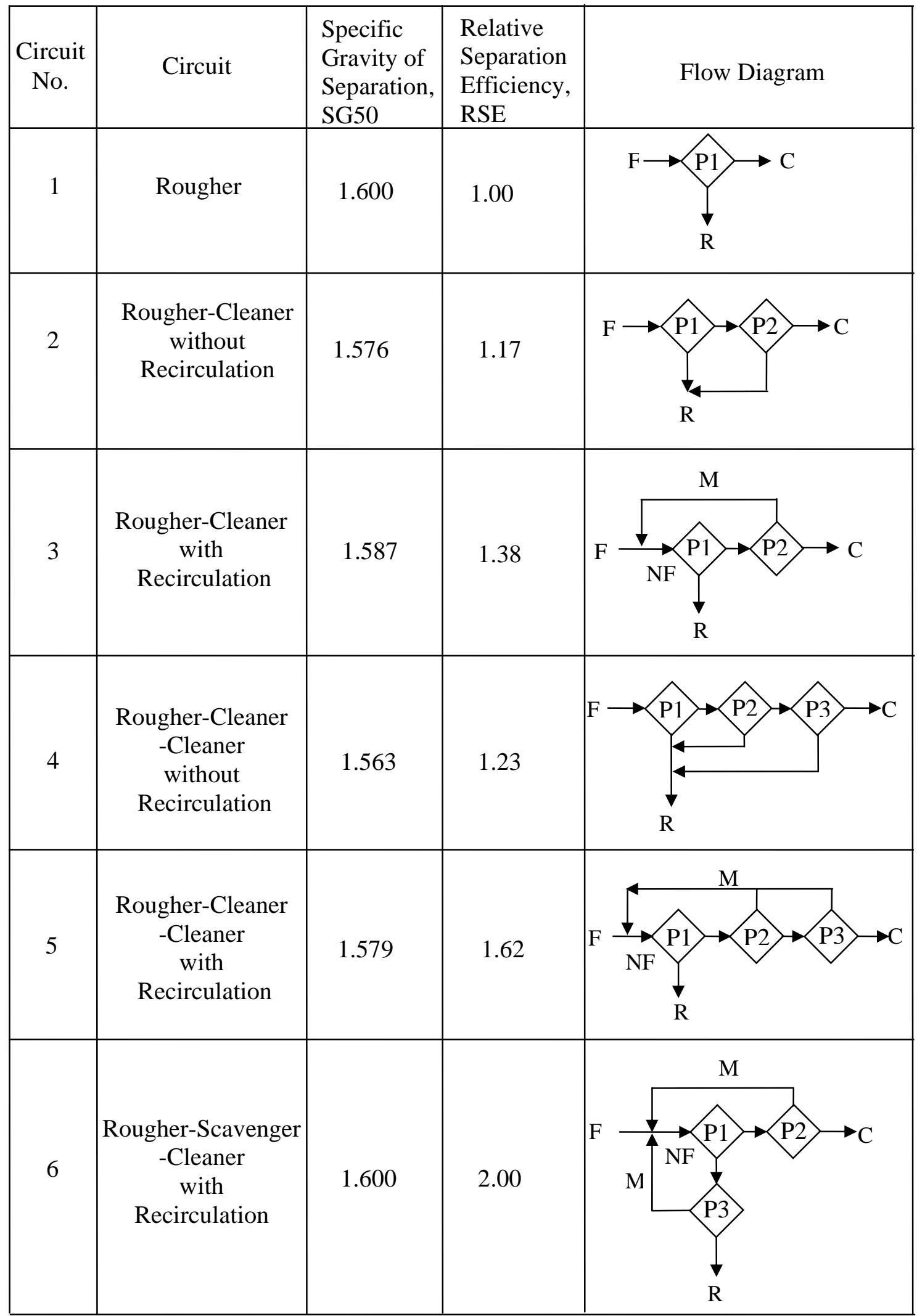


Table 3-3 Simulation Results of SG50 and Relative Separation Efficiencies for Various Concentration Circuit Configurations (Continued)

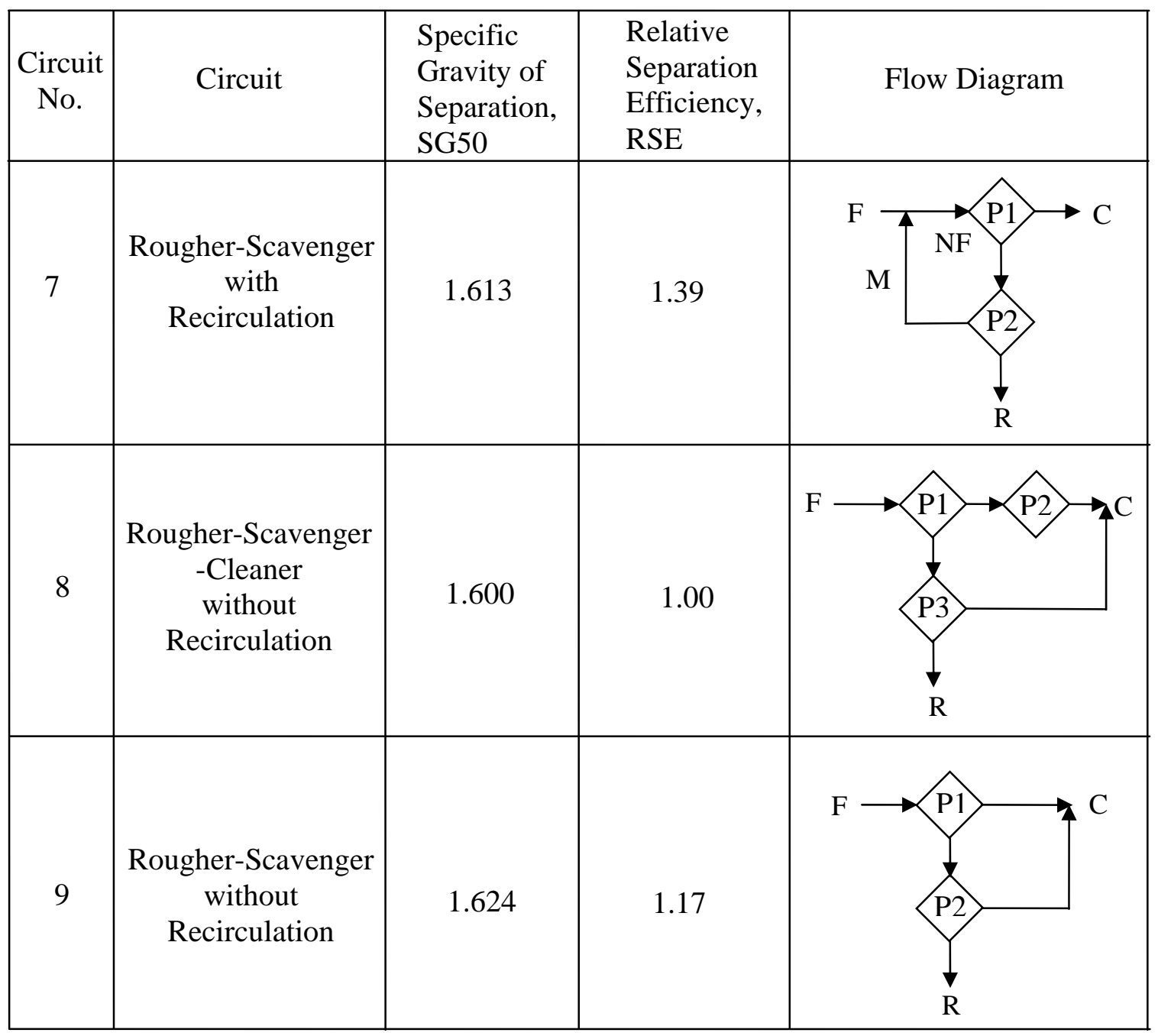

Notes: $\mathrm{R}=$ refuse $\mathrm{C}=$ clean coal product $\mathrm{F}=$ feed $\mathrm{M}=$ middling; $\mathrm{NF}=$ new feed which combined feed and recirculated material; and $\mathrm{P}=$ probability of feed reporting to clean coal product. 


\subsubsection{Dense Medium Conical Cyclone Separators}

The published data of dense medium conical cyclone from plant $\mathrm{B}$ shown in Appendix I Table I-1 (Deurbrouck and Hudy, 1972) are used to represent Rougher and Cleaner separation distribution curves for this case study. The separation distribution curves for Rougher and Rougher-Cleaner without recirculation circuit are plotted in Fig. 3-8, and their corresponding generalized distribution curves are shown in Fig. 3-9. Table 3-4 summarized the RSEs of dense medium conical cyclone based separation circuit configurations. The published literatures (Luttrell et al., 1998) defined the sharpness of separation for each circuit as the slope of generalized distribution curve at SG50. They reported, in case of Rougher-Cleaner without recirculation circuit configuration, has the RSE value of 1 at normalized specific gravity value of 1 . This result means the Rougher-Cleaner without recirculation circuit configuration, is not better efficient than the single rougher unit operation. However, it is clearly shown in Fig. 3-9, Rougher and Rougher-Cleaner circuits distribution curves are not coincide to form a generalized curve. Particularly, the lower part of distribution curve, the tail of the distribution curve of Rougher-Cleaner circuit, has large deviation (off) from the generalized curve of rougher or cleaner. The error area for RougherCleaner circuit is smaller than that of Rougher, which has smaller value of Ep than that of Rougher or Cleaner alone. It is also well known that the error areas represent the misplaced material or inefficiency of separation. This means Rougher-Cleaner without recirculation circuit configuration has higher separation efficiency. The whole distribution curve should be used to characterize performance of each separation circuit. Also, from Table 3-4, a RSE value of 1.17 calculated by circuit analysis tool developed by this work for Rougher-Cleaner without 


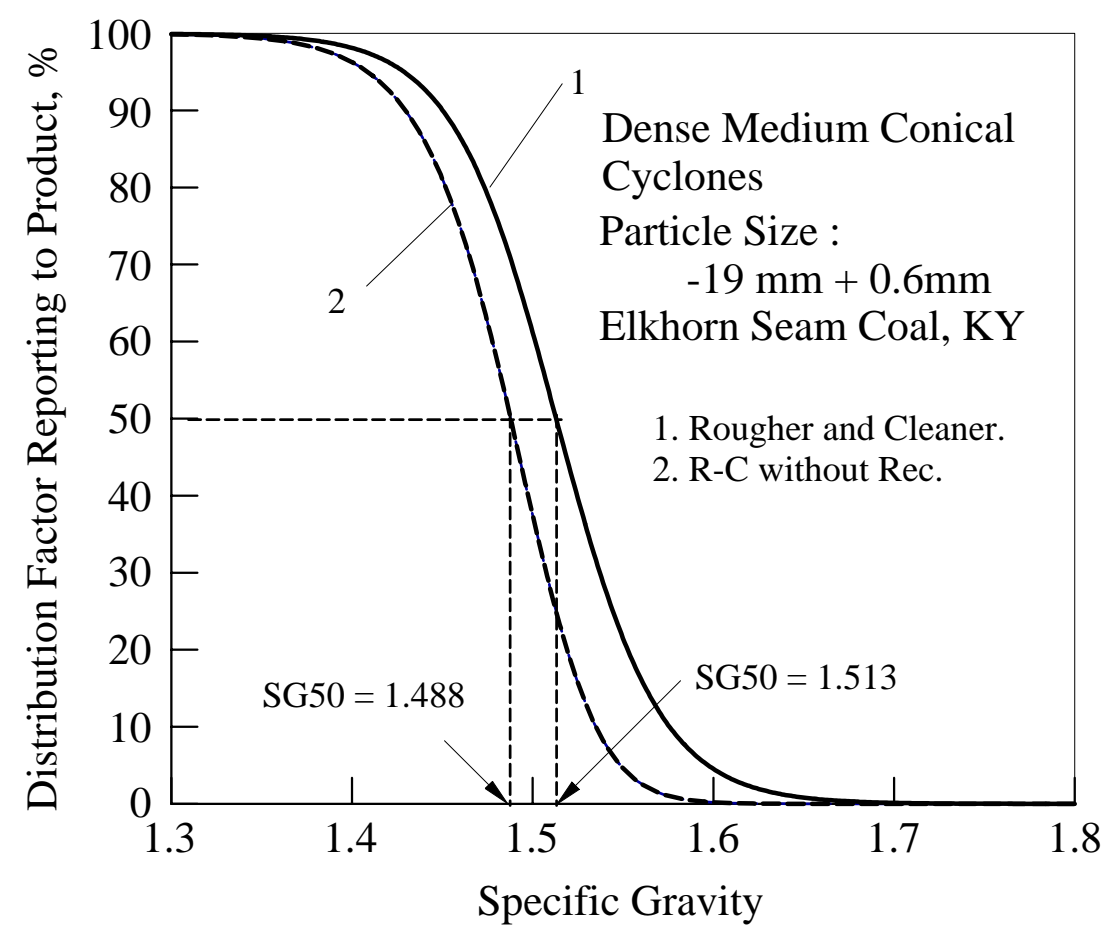

Figure 3-8 Separation Distribution Curves of Dense Medium Conical Cyclones for Rougher, Cleaner, and Rougher-Cleaner without Recirculation 


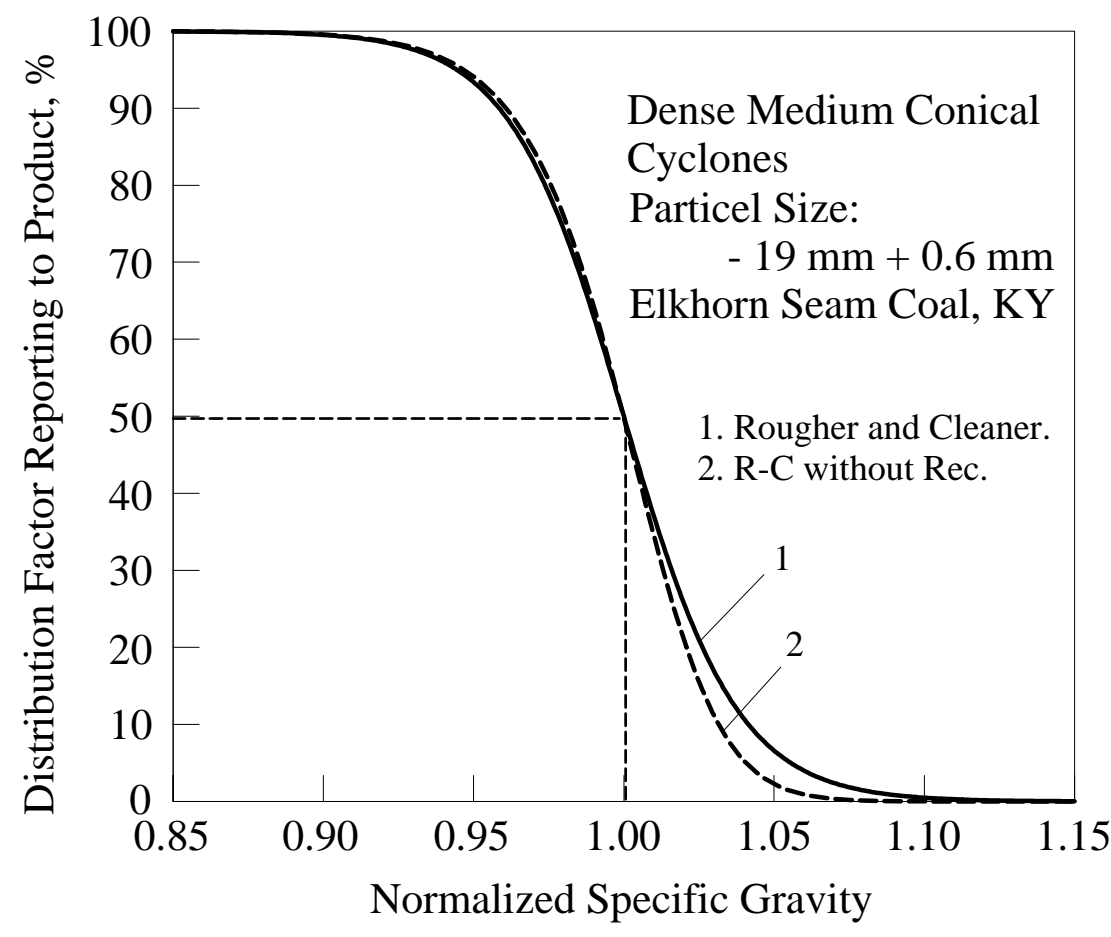

Figure 3-9 Generalized Distribution Curves of Dense Medium Conical Cyclones for Rougher, Cleaner and Rougher-Cleaner without Recirculation 
Table 3-4 Relative Separation Efficiencies of Dense Medium Separators Based Various Concentration Circuit Configurations

\begin{tabular}{|c|c|c|c|}
\hline \multirow{2}{*}{$\begin{array}{c}\text { Circuit } \\
\text { No. }\end{array}$} & \multirow[t]{2}{*}{ Circuit } & \multicolumn{2}{|c|}{$\begin{array}{l}\text { Relative Separation } \\
\text { Efficiency, RSE }\end{array}$} \\
\hline & & This Work & Published Data \\
\hline 1 & Rougher & 1.00 & 1.00 \\
\hline 2 & $\begin{array}{c}\text { Rougher Cleaner } \\
\text { Without } \\
\text { Recirculation }\end{array}$ & 1.17 & 1.19 \\
\hline 3 & $\begin{array}{c}\text { Rougher Cleaner } \\
\text { With } \\
\text { Recirculation }\end{array}$ & 1.38 & 1.40 \\
\hline 4 & $\begin{array}{c}\text { Rougher-Cleaner- } \\
\text { Cleaner } \\
\text { Without } \\
\text { Recirculation }\end{array}$ & 1.24 & 1.27 \\
\hline 5 & $\begin{array}{c}\text { Rougher-Cleaner- } \\
\text { Cleaner } \\
\text { With } \\
\text { Recirculation }\end{array}$ & 1.63 & 1.66 \\
\hline 6 & $\begin{array}{c}\text { Rougher-Scavenger- } \\
\text { Cleaner } \\
\text { With } \\
\text { Recirculation }\end{array}$ & 2.00 & 2.00 \\
\hline 7 & $\begin{array}{c}\text { Rougher-Scavenger } \\
\text { With } \\
\text { Recirculation }\end{array}$ & 1.38 & 1.36 \\
\hline 8 & $\begin{array}{c}\text { Rougher-Scavenger- } \\
\text { Cleaner } \\
\text { Without } \\
\text { Recirculation }\end{array}$ & 1.00 & 1.00 \\
\hline 9 & $\begin{array}{c}\text { Rougher-Scavenger } \\
\text { Without } \\
\text { Recirculation }\end{array}$ & 1.17 & 1.15 \\
\hline
\end{tabular}


recirculation, instead of $\mathrm{RES}=1$ as reported by Luttrell at el., (1998). In other words, the separation efficiency of Rougher-Cleaner without recirculation circuit, significantly increased by the factor of $17 \%$, compared to a single rougher cleaning circuit. The main reason for those authors to conclude no improvement over a single rougher cleaning is due to their fail to recognize the distribution curves of overall circuit, and rougher circuit, can not be formed a generalized distribution curve, as depicted in Fig. 3-7 and Fig. 3-9. Additionally, to describe the performance of overall circuit, to focus only between SG75 and SG25 of the generalized separation distribution curve has defaults (Aplan, 2003; Peng, 1983). For some coal which has more near gravity materials, two tails (two ends) of the separation distribution curve play the very important roles in separation performance of the separator. Particularly, the tail represents the amount of clean coal particles reporting to higher specific gravity stream. This means that the clean coal product lose to or misplaces to the refuse stream. Some circuit configurations have the advantage of cleaning difficult to clean coal, such as Tri-Flo separator or combination of cylindrical and conical cyclones. It is possible that the slopes of the distribution curves for the given multi-stage circuit is the same as the one of single rougher cleaning at SG50, however, to improve the separation efficiency for a given circuit is depend upon the reduction of overall amount of misplaced materials. 


\section{CHAPTER 4 RESULTS AND DISCUSSION}

\subsection{Tri-Flo Cleaning Circuit}

The cylindrical cyclones derived from the DWP have been developed in Italy named as Tri-Flo. Tri-Flo separator differs from the other cyclone separators in that it combines two stages of cylindrical cyclones in a single unit operation as shown in Fig. 4-1. The separator has a cylindrical body, the vessel is divided by a partition wall into two consecutive chambers with an axial orifice. Each chamber is equipped with a medium inlet and sinks discharge. Feed is added to the separator via the feed chute, and special designed feeding system. The medium to the first stage chamber is added via first medium inlet (medium 1). The floats from the first stage of the separator pass through to the second stage of the separator where fresh medium is added via the second medium inlet (medium 2). The reject material from each stage of the separator discharges through the sink1 and sink 2 outlets. As shown in Fig. 4-1, Tri-Flo separator has a natural lower specific gravity of separation in the second stage (cleaner) due to the float materials from the first stage chamber. Actually it is a Rougher-Cleaner two-stage configuration with no recirculation circuit. In addition, three products, sink1 (refuse), sink2 (middlings), and float (clean coal product) in one unit are very useful for smaller coal cleaning plants, which can save investment substantially. No pumping of abrasive material is required, capable of processing high variations of feed are other advantages in using Tri-Flo separators. 


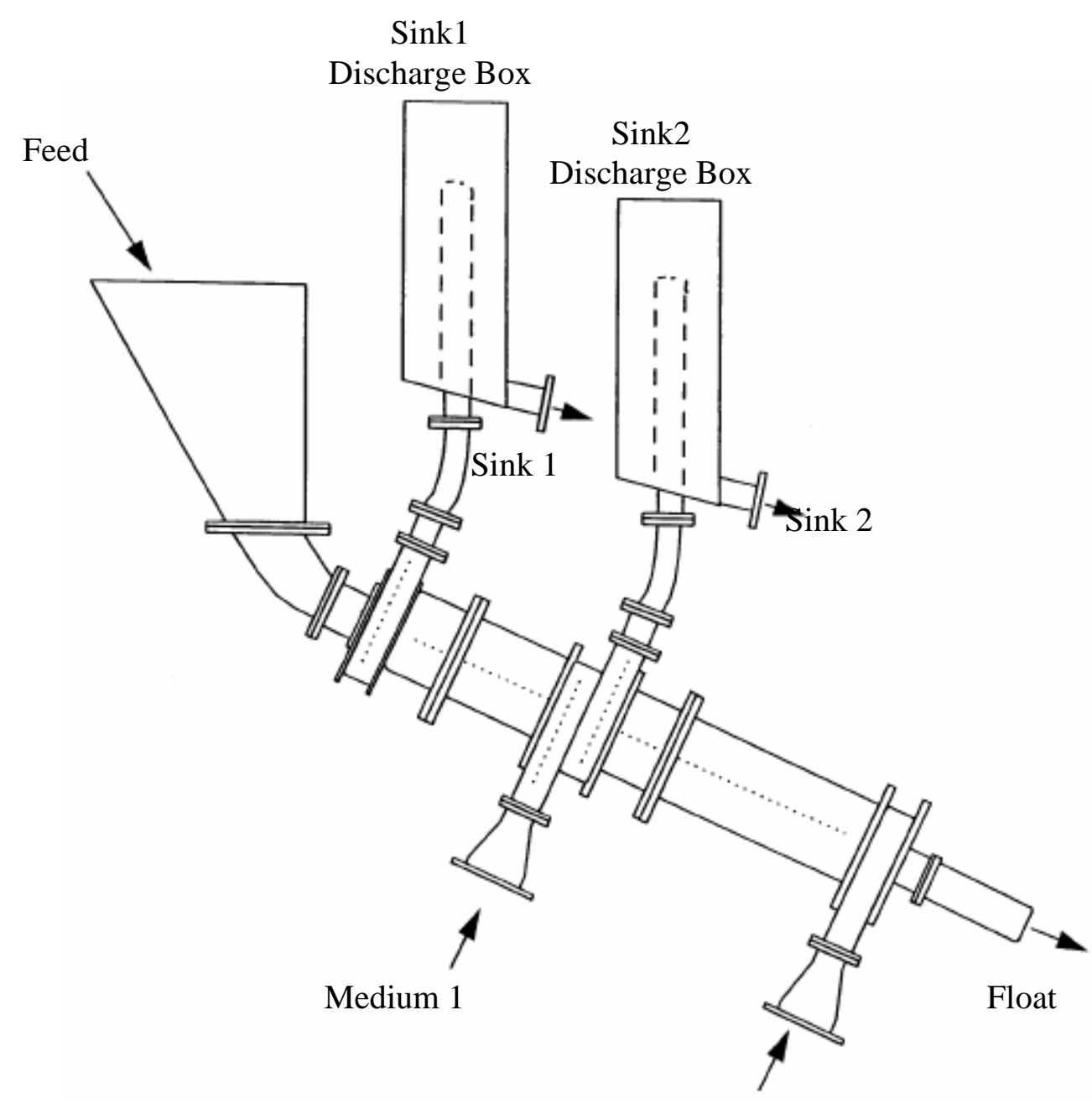

Medium 2

Figure 4-1 Schematic Diagram of Tri-Flo Separator 
Due to coal prices and energy shortages in many coal producing countries, there are interests in using Tri-Flo separators. Some applications of Tri-Flo in coal preparation plants show that it is more efficient in cleaning coal which is fairly difficult to clean, it is used to clean coal reject (very low grade coal). During a recent test in South Africa, Tri-Flo was tested to process coal rejects of $-50 \mathrm{~mm}+0.5 \mathrm{~mm}$ size range. The separation distribution curves for a first stage (rougher) and combined two-stage Tri-Flo (overall) are shown in Fig. 4-2. Table 4-1 summarized the specific gravities of separation, SG50, and the value of probable errors, Ep, for Rougher and overall circuit.

Table 4-1 Separation Results of Coal Rejects by Rougher and Tri-Flo Separator

\begin{tabular}{|l|c|c|c|c|}
\hline & $\begin{array}{c}\text { Specific Gravity of } \\
\text { Separation, SG50 }\end{array}$ & SG25 & SG75 & $\begin{array}{c}\text { Probable Error, } \\
\text { Ep }\end{array}$ \\
\hline Rougher & 1.817 & 1.88 & 1.77 & 0.055 \\
\hline Overall & 1.834 & 1.88 & 1.785 & 0.0475 \\
\hline
\end{tabular}

As illustrated by the curves, the middle portions of the curves often do approximate a straight line closely but the tails usually exhibit curvature. The rougher (first stage) separation distribution curve has quite large tails, its separation is noticeably poor. The difference between a step function (the perfect separation) and the curvature of the curve represents some float particles and sink particles are misplaced to the clean coal stream and refuse stream, respectively. The lower tail has excess about $20 \%$ of refuse (sink) particles to the clean coal product stream. This is Type IV excess misplacement (Aplan, 2003; Peng, 1983). The upper tail has an excess about $15 \%$ of clean coal (float) particles misplaced to the 


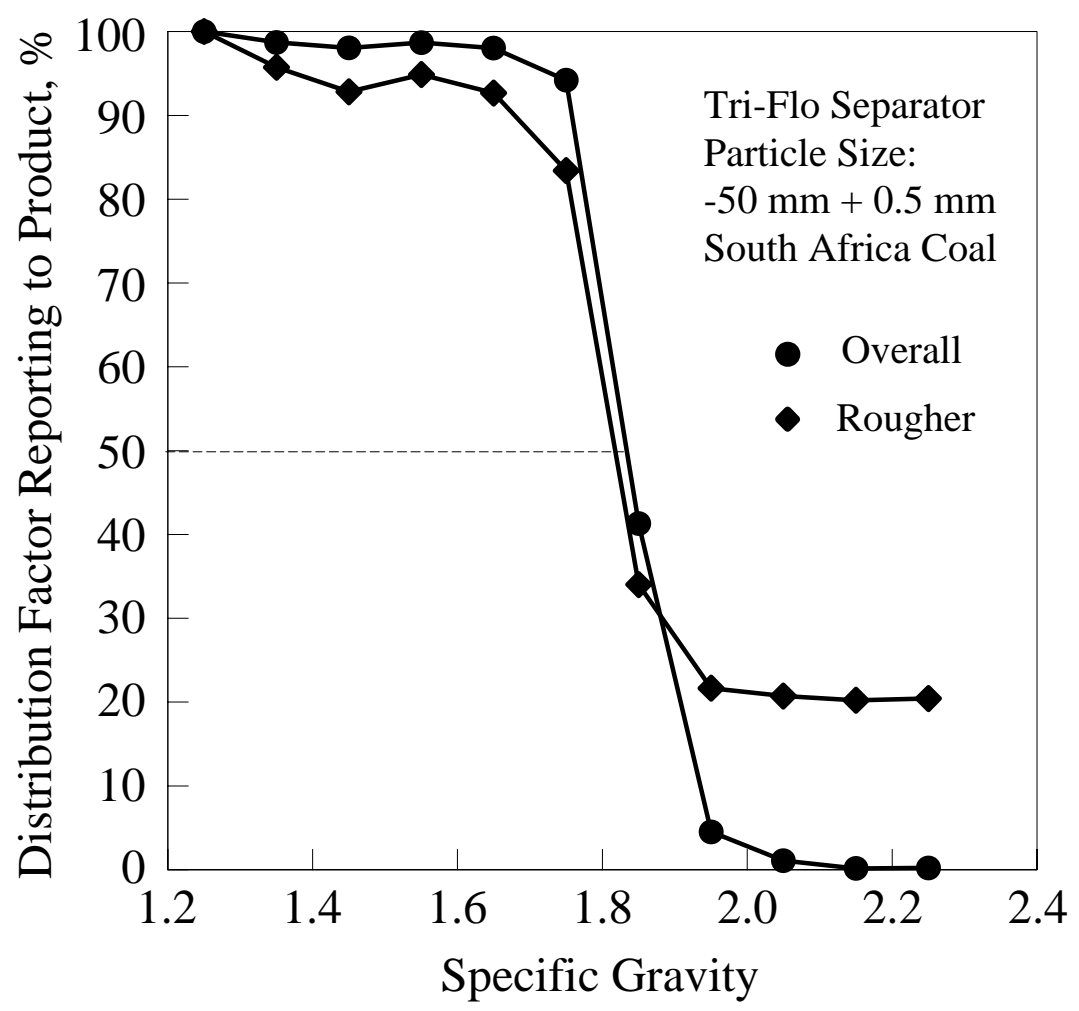

Figure 4-2 Separation Distribution Curves of Tri-Flo for Rougher and Overall Circuit (Combined Two Stage Separators) 
refuse stream. This is Type V excess misplacement. The amount of excess particles heavier than specific gravity of separation can not completely go to refuse stream, and were misplaced to clean coal product. However, the presence of the tails is virtually eliminated by the second-stage re-cleaning, the elimination of excess misplacement of mineral matters in clean coal product. In this case, Ep can not represent the whole separation performance if the significant "tails" are present. The importance of a tail of the distribution curve should not be underestimated.

Both the distribution curves and the tabulated results demonstrated that even if combined two-stages and one stage have similar Ep values, two-stage separation produced a sharper overall separation than just one stage separation. From Eq 3-25, the RSE for Tri-Flo is 1.16 . This result is very close to the estimated value of 1.17 using circuit analysis tools.

Tri-Flo separators not only increase the quantity of clean coal product, but also improve the quality of coal. The coal ash analysis results shows that the ash content of clean coal product decreases from $50.97 \%$ of raw coal reject to $30.08 \%$ using Tri-Flo process. Based on equation of combustion material recovery $=\frac{y_{c} \cdot(100-A c)}{y_{f} \cdot(100-A f)} \cdot 100 \%$, therefore, the combustion material recovery is $59.04 \%$.

\subsection{Two Stage Dense Medium Cyclone Cleaning Circuits}

Dense medium conical cyclones provided efficient, and sharp separations, they are commonly used in coal preparation plants. Most cyclones used in the coal preparation plants in the United States are cylindroconical shape with an angle of approximately $20^{\circ}$. The raw feed and medium are introduced tangentially into the cylindrical section (upper part) of the 
unit, heavy impurities particles move outward and down the wall of conical section and out the apex. The lighter particles (low specific gravity) rise to the central air core and out the top of the vertex finder. Fig. 4-3 shows schematic diagram of dense medium conical cyclone.

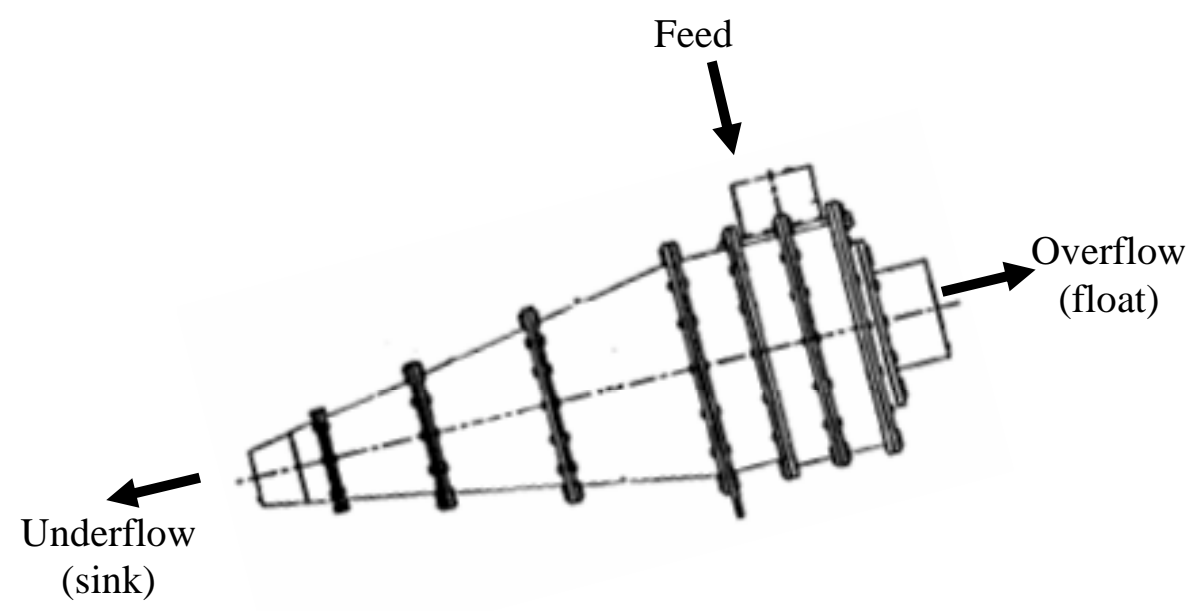

Figure 4-3 Schematic Diagram of Dense Medium Conical Cyclone

To produce high quality clean coal product, or high quantity and quality clean coal product, multi-stage dense medium cyclone circuit is often used to produce two products or three products. The general multi-stage dense medium cyclone circuits are shown in Fig. 4-4. This is corresponding to a two-stage Rougher-Cleaner without recirculation circuit. The raw coal feed and magnetite slurry with predetermine specific gravity are fed into the primary dense medium cyclones where two products are produced, an overflow (clean coal product) and an underflow (refuse). The clean coal product stream from the primary cyclone flows by the gravity flowing into a cleaner feed sump, and then pumped to the secondary cyclone. This primary cyclone overflow is reprocessed in the secondary cyclone where two products are also obtained. The clean coal product from the secondary cyclone are taken as final clean 
coal product, where refuse stream from both primary and secondary cyclone are discard, or sell the refuse from secondary cyclone as middlings. 


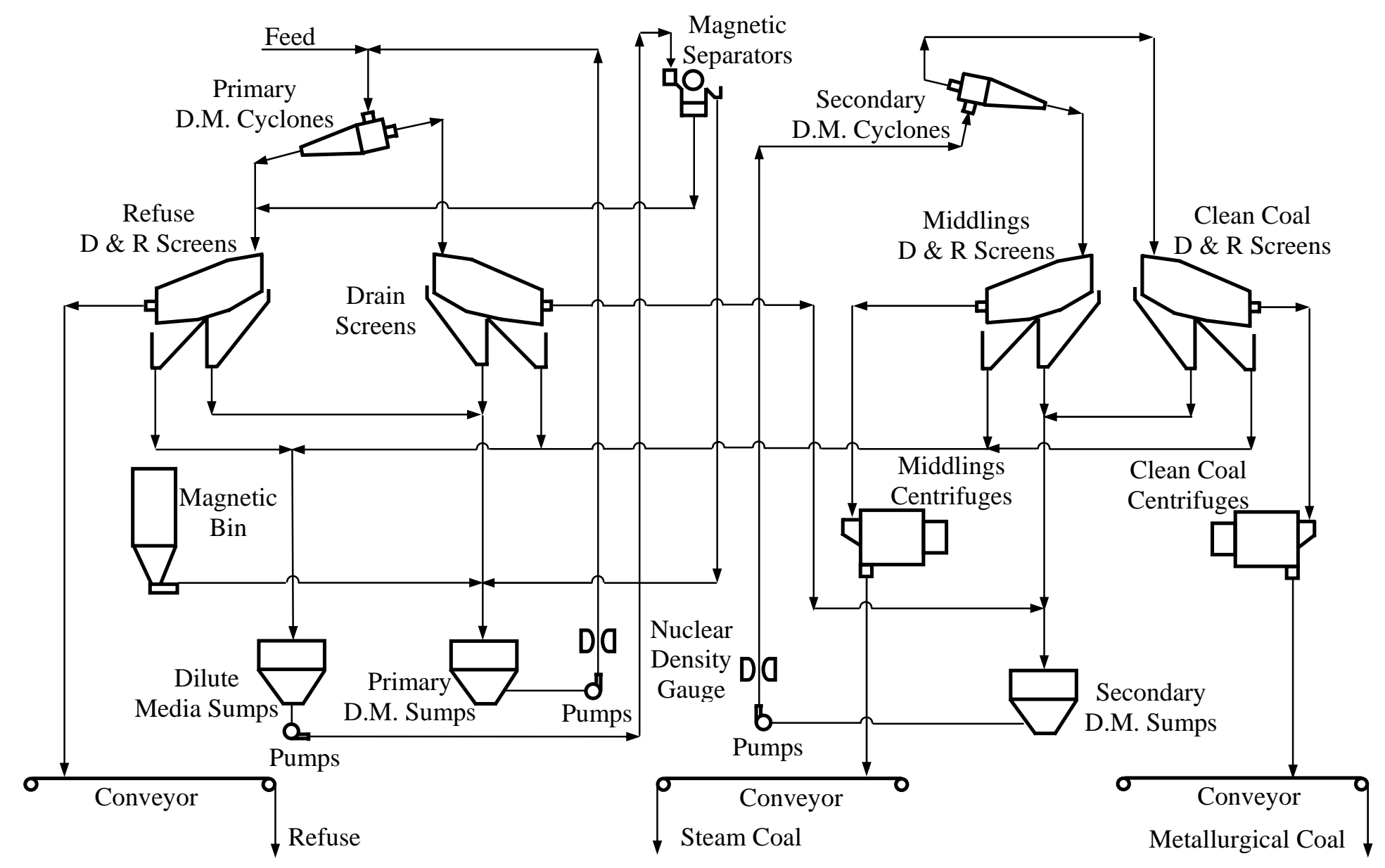

Figure 4-4 A Two-Stage Dense Medium Cyclone Circuit 
Four in-plant data for two stage dense medium cyclone cleaning circuits are obtained from coal preparation plants $\mathrm{H}, \mathrm{I}, \mathrm{J}$, and $\mathrm{K}$ from Alabama, Maryland and Virginia. Performance analysis and circuit analysis tools are used to evaluate the efficiency and performance of various dense medium cyclone cleaning circuit configurations. All plants are operated as two-stage cyclone circuit without recirculation. The operation conditions for these plants are summarized in Table 4-2.

Table 4-2 Cyclone Dimensions and Particle Size Ranges Used for Various Two-stage Dense Medium Conical Cyclone Plants

\begin{tabular}{|c|c|c|c|c|c|}
\hline \multirow{2}{*}{ Plant } & \multicolumn{2}{|c|}{$\begin{array}{c}\text { Particle Size Fraction } \\
\mathrm{mm}\end{array}$} & \multicolumn{2}{c|}{$\begin{array}{c}\text { Cyclone Diameter } \\
\text { in }\end{array}$} & \multirow{2}{*}{$\begin{array}{c}\text { Sampling } \\
\text { Technique }\end{array}$} \\
\cline { 2 - 5 } & $\begin{array}{c}\text { Primary } \\
\text { Cyclone }\end{array}$ & $\begin{array}{c}\text { Secondary } \\
\text { Cyclone }\end{array}$ & $\begin{array}{c}\text { Primary } \\
\text { Cyclone }\end{array}$ & $\begin{array}{c}\text { Secondary } \\
\text { Cyclone }\end{array}$ & \\
\hline Plant H & +1 & +0.5 & 28 & 24 & $\begin{array}{c}\text { Standard } \\
\text { Sampling }\end{array}$ \\
\hline Plant I & $-22.4+0.75$ & $-9.5+0.75$ & 40 & 33 & Tracer \\
\hline Plant J & $-22.4+0.75$ & $-9.5+0.75$ & 40 & 33 & Tracer \\
\hline & $-37.5+12.5$ & $-12.5+6.3$ & 24 & 24 & $\begin{array}{c}\text { Standard } \\
\text { Sampling }\end{array}$ \\
\cline { 2 - 5 } Plant K & $-37.5+12.5$ & $-12.5+6.3$ & 24 & 24 & $\begin{array}{c}\text { Standard } \\
\text { Sampling }\end{array}$ \\
\hline
\end{tabular}

\subsubsection{Two-stage Dense Medium Cyclone Circuit in Plant H}

The separation distribution curves for Plant $\mathrm{H}$ are plotted for rougher, cleaner, and rougher-cleaner circuit to process $+0.5 \mathrm{~mm}$ size fraction in Fig. 4-5. The plant $\mathrm{H}$ is processing much smaller size fractions than other plants studied. SG50 and Ep values for primary cyclone and overall circuit are given in the summary Table 4-3. The RSE for overall circuit is 1 , it is less than the theoretical circuit analyzed value of 1.17 . There is no significant 


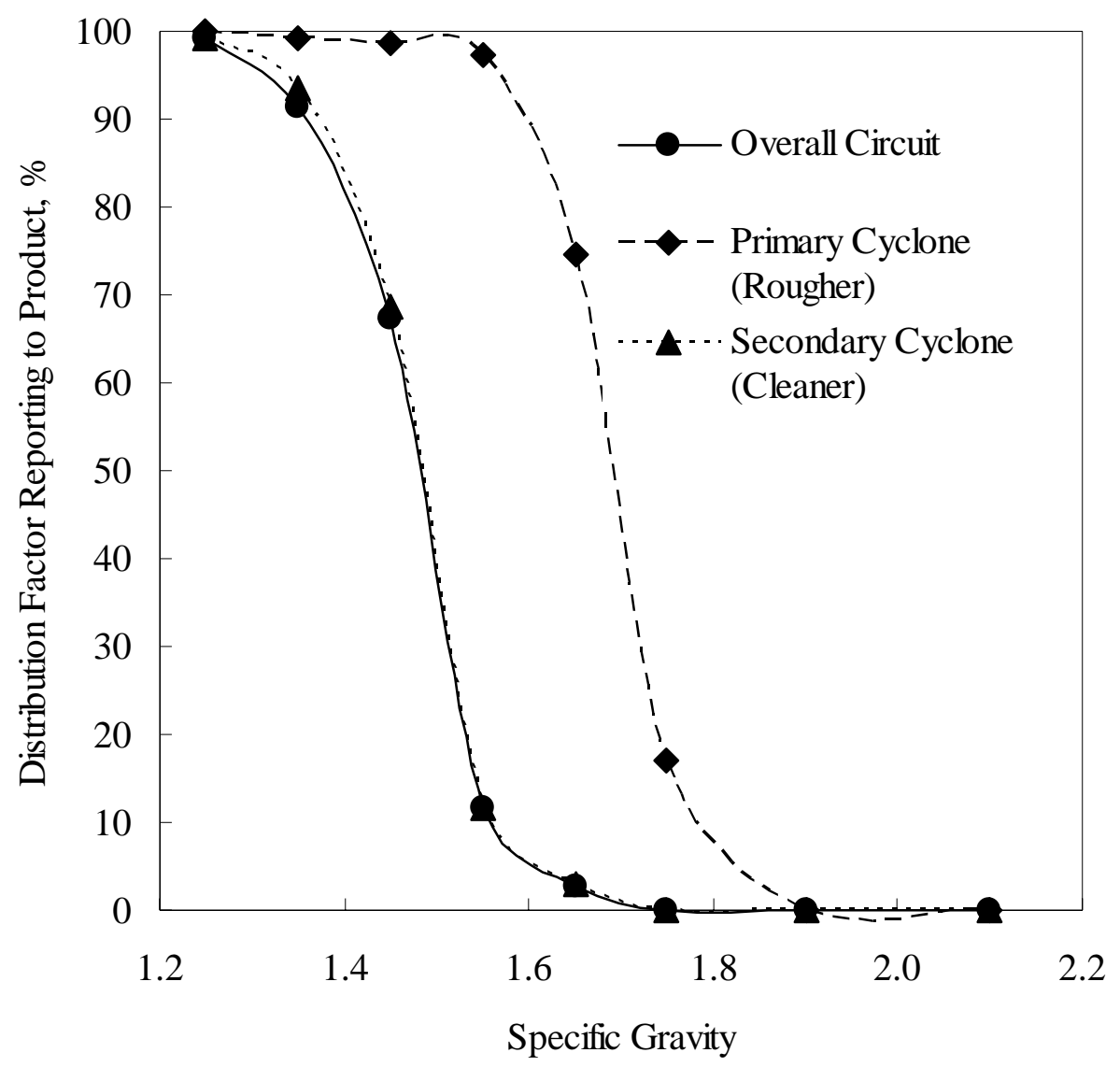

Figure 4-5 Separation Distribution Curves of Dense Medium Conical Cyclones for Rougher, and Rougher-Cleaner without Recirculation in Plant H 
improvement in relative separation efficiency. However, this circuit has advantage comparing with one stage rougher, based on ash analysis data, the ash content of final clean coal product is $9.24 \%$ and the yield of $37.18 \%$ of feed to the cyclone. The ash content of the final clean coal product is lower than that of one stage clean coal product of $14.86 \%$ at the yield of $41.40 \%$ of feed to the cyclone. The higher quality metallurgical coal product is produced using this two-stage circuit.

Table 4-3 Performance Data for Dense Medium Cyclones at Various Plants

\begin{tabular}{|c|c|c|c|c|c|c|}
\hline & \multirow[t]{2}{*}{ Plant } & \multicolumn{2}{|c|}{$\begin{array}{c}\text { Specific Gravity } \\
\text { of Separation } \\
\text { SG50 }\end{array}$} & \multicolumn{2}{|c|}{$\begin{array}{c}\text { Probable Error } \\
\text { Ep } \\
\end{array}$} & \multirow{2}{*}{$\begin{array}{c}\text { Relative } \\
\text { Separation } \\
\text { Efficiency } \\
\text { RSE }\end{array}$} \\
\hline & & $\begin{array}{l}\text { Primary } \\
\text { Cyclone }\end{array}$ & $\begin{array}{l}\text { Overall } \\
\text { Circuit }\end{array}$ & $\begin{array}{l}\text { Primary } \\
\text { Cyclone }\end{array}$ & $\begin{array}{l}\text { Overall } \\
\text { Circuit }\end{array}$ & \\
\hline \multicolumn{2}{|l|}{ Plant H } & 1.7 & 1.45 & 0.045 & 0.045 & 1.00 \\
\hline \multicolumn{2}{|l|}{ Plant I } & 1.72 & 1.46 & 0.012 & 0.011 & 1.09 \\
\hline \multicolumn{2}{|l|}{ Plant J } & 1.72 & 1.77 & 0.012 & 0.01 & 1.20 \\
\hline \multirow{3}{*}{ Plant K } & $(-37.5 \mathrm{~mm}+12.5 \mathrm{~mm})$ & 1.63 & 1.33 & 0.03 & 0.024 & 1.25 \\
\hline & $(-12.5 \mathrm{~mm}+6.3 \mathrm{~mm})$ & 1.59 & 1.33 & 0.03 & 0.025 & 1.20 \\
\hline & $(-37.5 \mathrm{~mm}+6.3 \mathrm{~mm})$ & 1.61 & 1.33 & 0.0301 & 0.0245 & 1.23 \\
\hline
\end{tabular}




\subsubsection{Two-stage Dense Medium Cyclone Circuit in Plants I}

Another Rougher-Cleaner without recirculation circuit configurations was installed in plant I. As shown in Fig. 4-6, the two-stage separation produced a sharper overall separation than just using one stage separation. This can be seen from the straight parts of the distribution curves in the figure, and Ep value in the summarized Table 4-3. From Eq 3-25, the RSE of the overall circuit has the value of 1.20. It shows the significant improvement in the separation of raw coal. There is no ash contents of product is available due to tracer technique is used to determine the distribution curves. SG50 and Ep values of primary and overall circuit are shown in the summarized Table 4-3.

\subsubsection{Two-stage Dense Medium Cyclone Circuit in Plants J}

The distribution curves for rougher, scavenger, and Rougher-Scavenger without recirculation circuit configurations in plant $\mathrm{J}$ are plotted in Fig. 4-7. The RSE of 1.10 can be achieved by using two-stage separation rather than only one stage separation. As shown in the summarized Table 4-3, the primary dense medium cyclone has Ep value of 0.012 at $\mathrm{SG50}=1.72$, while the overall circuit has Ep value of 0.011 at $\mathrm{SG50}=1.77$. Tracer technique were used to obtain the separation distribution curve, as a result, there are no coal quality data are available. SG50 and Ep values for primary cyclone and overall circuit are given in the summarized Table 4-3. 


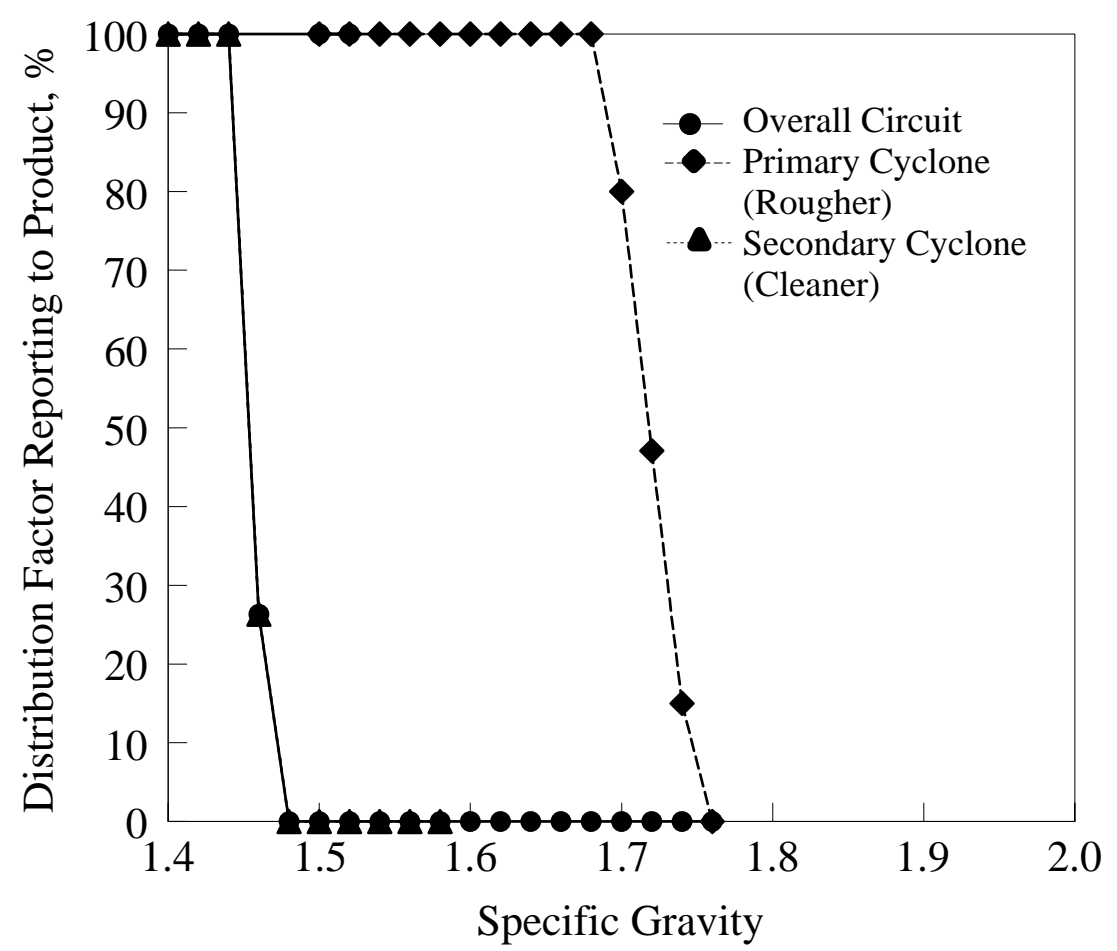

Figure 4-6 Separation Distribution Curves of Dense Medium Conical Cyclones for Rougher, Cleaner, and Rougher-Cleaner without Recirculation in Plant I 


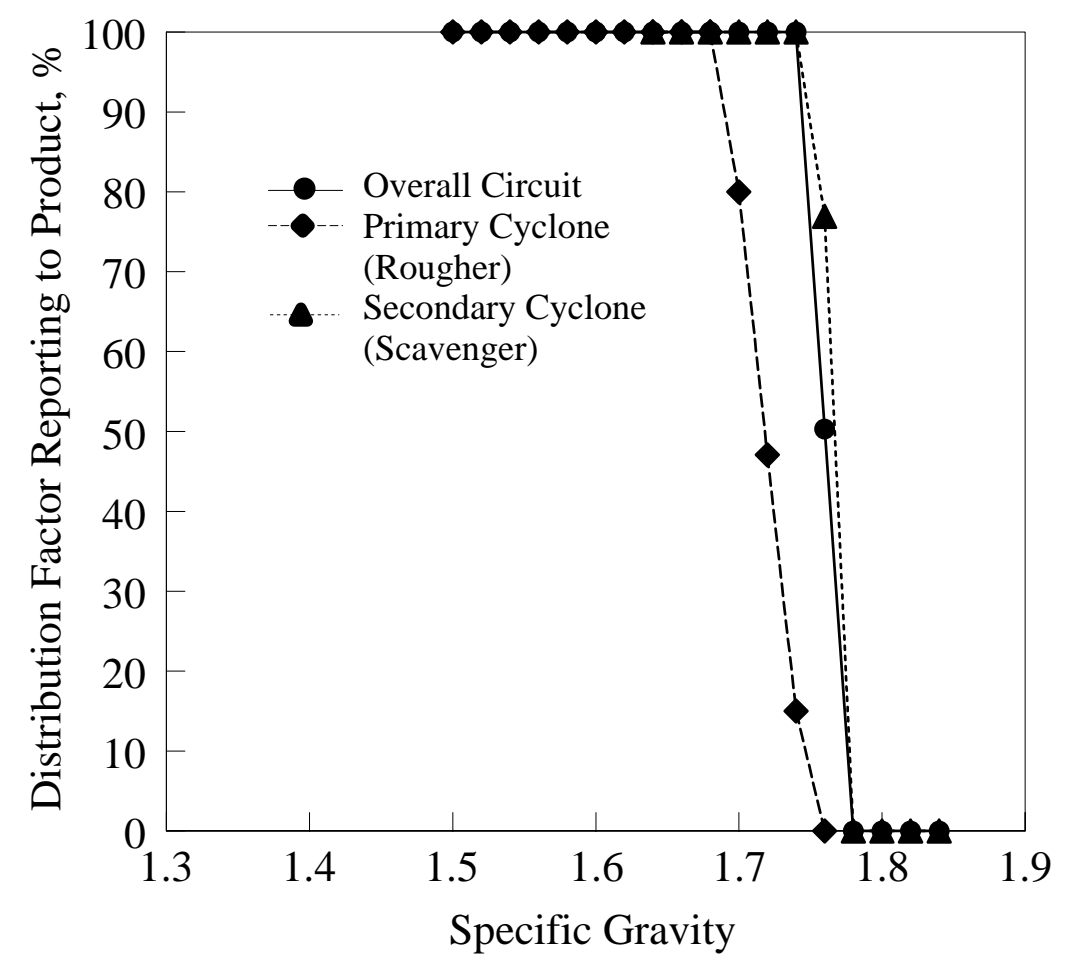

Figure 4-7 Separation Distribution Curves of Dense Medium Conical Cyclones for Rougher, Scavenger, and Rougher-Scavenger without Recirculation in Plant J 


\subsubsection{Two-stage Dense Medium Cyclone Circuit in Plant K}

In plant $\mathrm{K}$, raw coal size fraction of $-37.5 \mathrm{~mm}+6.3 \mathrm{~mm}$ is processed in the RougherCleaner without recirculation circuit. The distribution curves for coal size fractions of -37.5 $\mathrm{mm}+12.5 \mathrm{~mm},-12.5 \mathrm{~mm}+6.3 \mathrm{~mm}$ and $-37.5 \mathrm{~mm}+6.3 \mathrm{~mm}$ are shown in Fig. 4-8, Fig. 4-9 and Fig. 4-10, respectively. Again, Rougher-Cleaner without recirculation circuits are more efficient than one stage circuit as shown in Table 4-3. In addition, the overall two-stage separation efficiency of coarse coal particles has higher $(\mathrm{RSE}=1.24)$ than that of relatively fine coal particles $(\mathrm{RSE}=1.20)$. Although primary cyclones for different size fractions show different SG50s, the overall circuits for different size fractions show the same SG50 of 1.33.

The coal product qualities from primary, secondary cyclones and overall circuit are given in Table 4-4. The clean coal product from the secondary cyclone has $7.65 \%, 7.52 \%$, $7.56 \%$ ash content and $1.06 \%, 1.02 \%, 1.04 \%$ sulfur content for size fractions of $-37.5 \mathrm{~mm}+$ $12.5 \mathrm{~mm},-12.5 \mathrm{~mm}+6.3 \mathrm{~mm}$, and $-37.5 \mathrm{~mm}+6.3 \mathrm{~mm}$, respectively. The refuse (middling) from the secondary cyclone has $18.41 \%, 15.34 \%, 16.85 \%$ ash content and $1.84 \%, 1.78 \%$, $1.81 \%$ sulfur content for size fractions of $-37.5 \mathrm{~mm}+12.5 \mathrm{~mm},-12.5 \mathrm{~mm}+6.3 \mathrm{~mm}$, and $37.5 \mathrm{~mm}+6.3 \mathrm{~mm}$, respectively. For different size fractions, the yields are also given in Table 4-4. The yields of primary, secondary cyclone and overall circuit are $38.25 \%, 27.92 \%$, $10.70 \%, 60.28 \%, 41.69 \%, 25.13 \%$, and $47.60 \%, 35.63 \%, 16.96 \%$ for size fractions of -37.5 $\mathrm{mm}+12.5 \mathrm{~mm},-12.5 \mathrm{~mm}+6.3 \mathrm{~mm}$, and $-37.5 \mathrm{~mm}+6.3 \mathrm{~mm}$, respectively. 


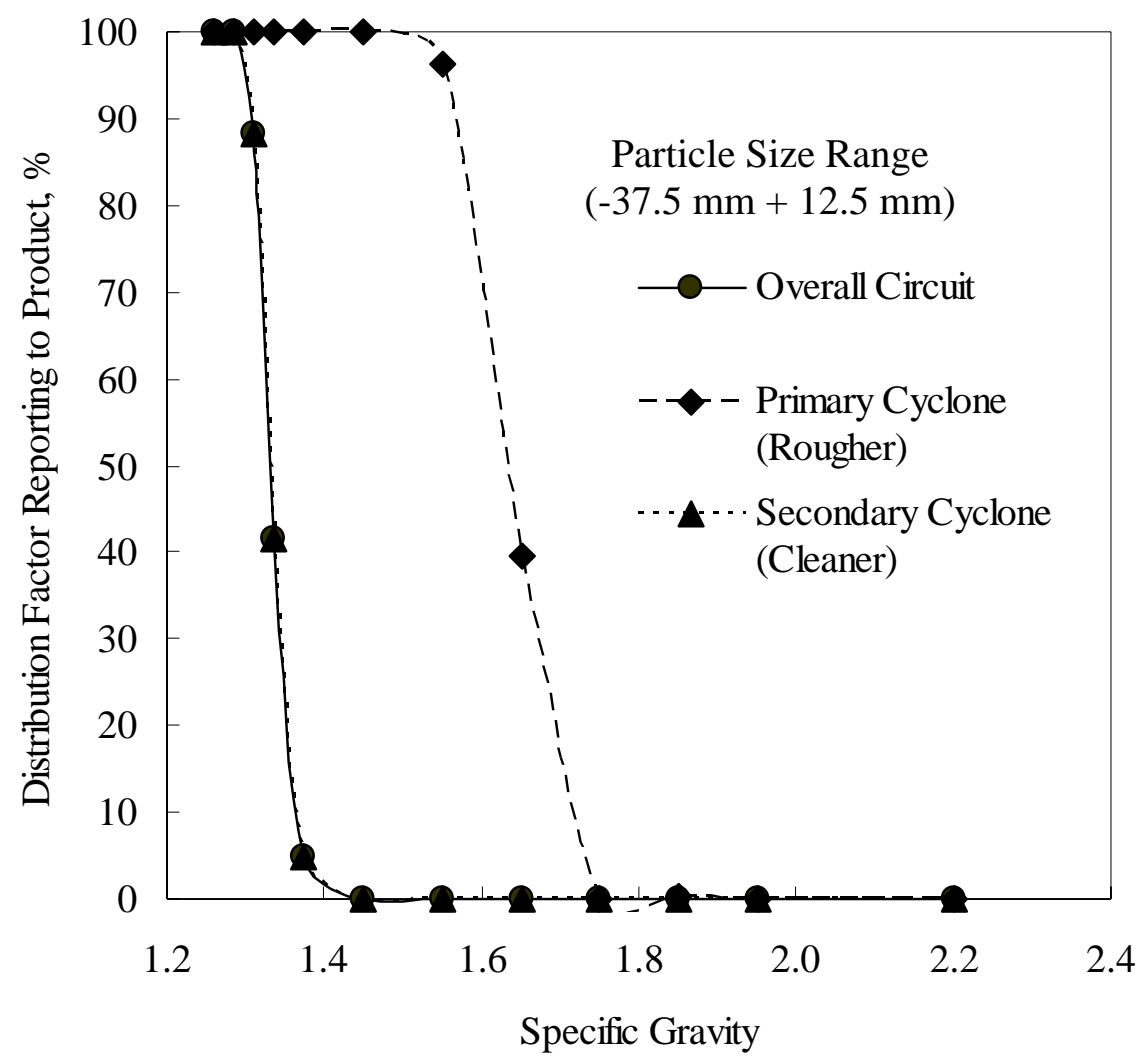

Figure 4-8 Separation Distribution Curves of Dense Medium Conical Cyclones for Rougher, Cleaner, and Rougher-Cleaner without Recirculation in Plant K (size fraction $-37.5 \mathrm{~mm}+12.5 \mathrm{~mm}$ ) 


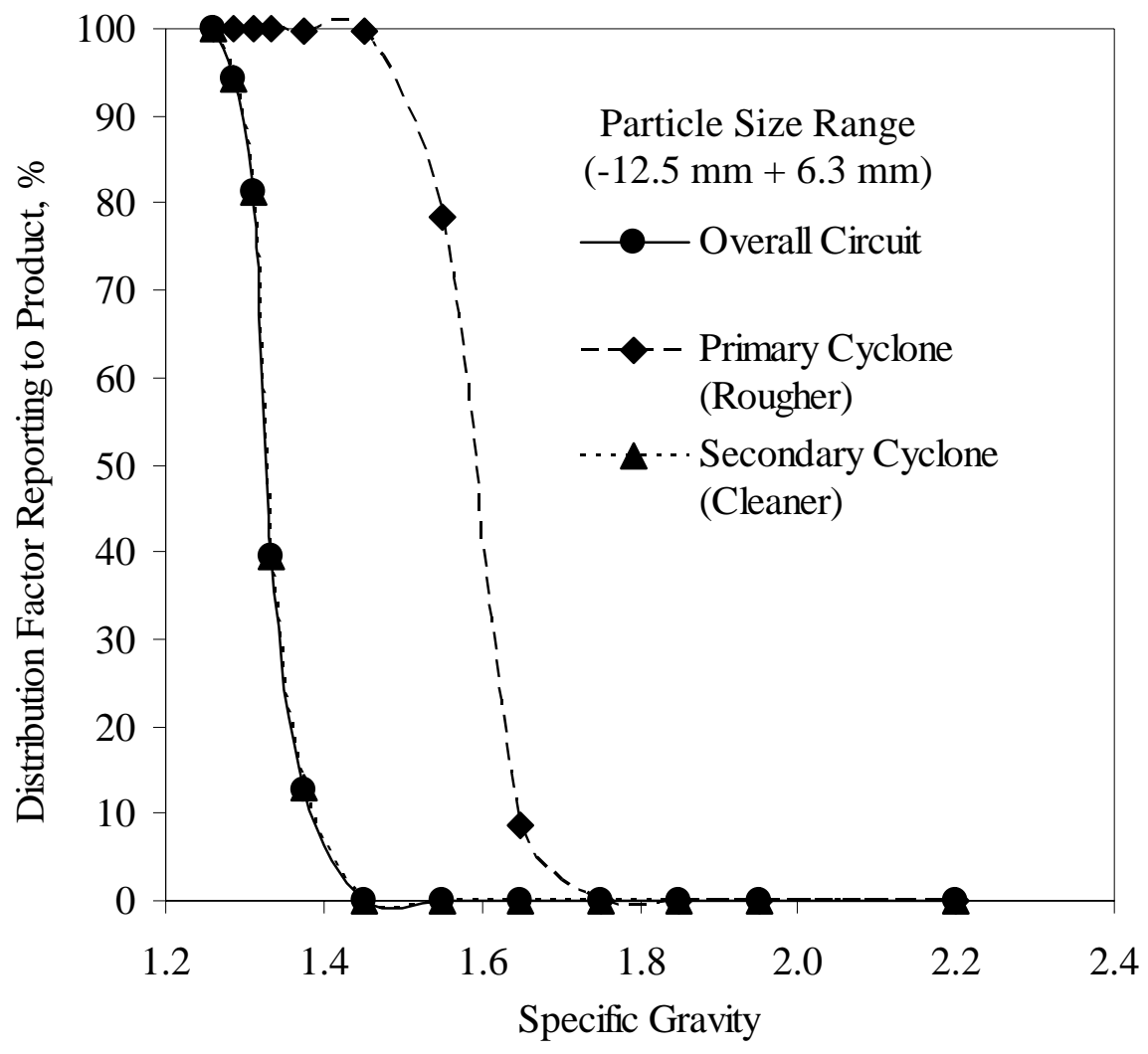

Figure 4-9 Separation Distribution Curves of Dense Medium Conical Cyclones for Rougher, Cleaner, and Rougher-Cleaner without Recirculation in Plant K (size fraction $-12.5 \mathrm{~mm}+6.3 \mathrm{~mm}$ ) 


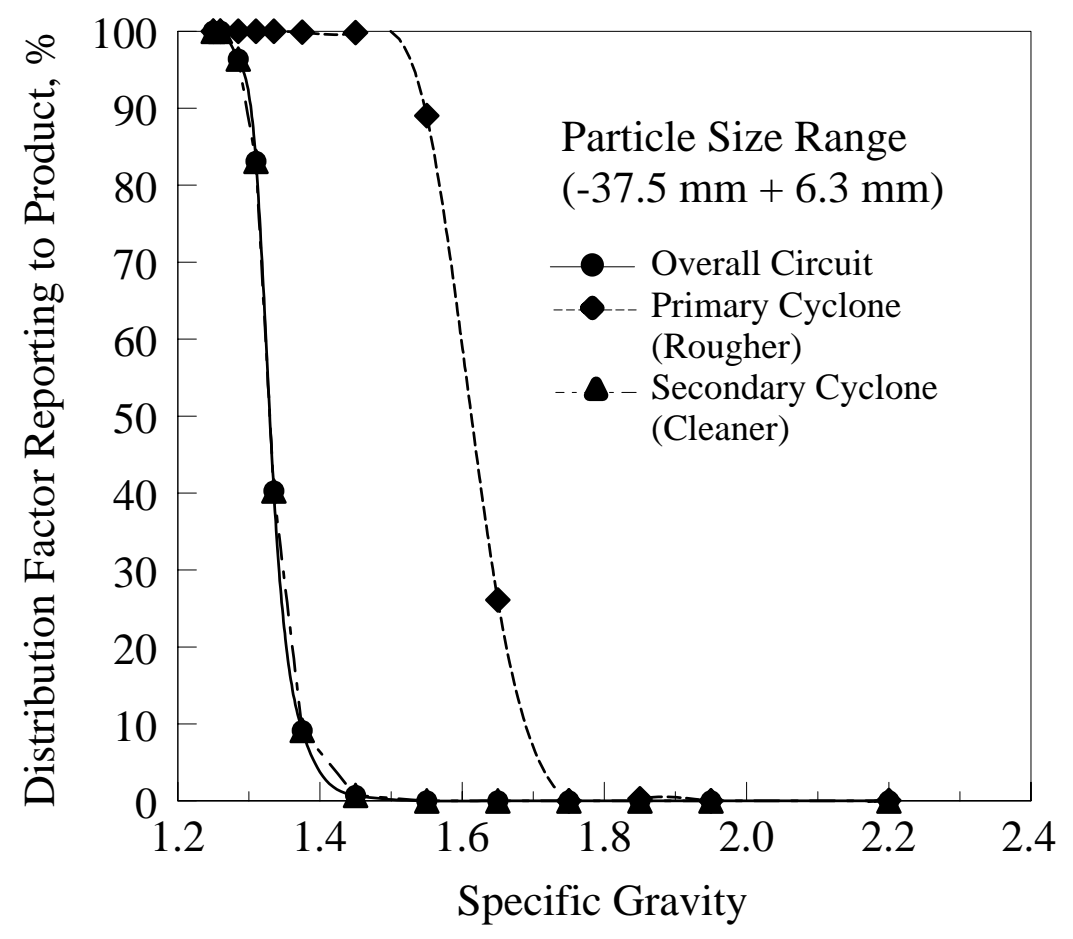

Figure 4-10 Separation Distribution Curves of Dense Medium Conical Cyclones for Rougher, Cleaner, and Rougher-Cleaner without Recirculation in Plant K (size fraction $-37.5 \mathrm{~mm}+6.3 \mathrm{~mm}$ ) 
Table 4-4 Ash, and Sulfur Contents and Yields of Clean Coal Product for Rougher, Cleaner and Overall Circuit at Various Size Fractions

\begin{tabular}{|c|c|c|c|c|c|}
\hline & $\begin{array}{c}\text { Particle } \\
\text { Size } \\
\mathrm{mm}\end{array}$ & $\begin{array}{c}\text { Raw } \\
\text { Coal } \\
\text { Feed }\end{array}$ & $\begin{array}{c}\text { Primary } \\
\text { Cyclone } \\
\text { Clean Coal }\end{array}$ & $\begin{array}{c}\text { Secondary } \\
\text { Cyclone } \\
\text { Middling }\end{array}$ & $\begin{array}{c}\text { Overall Circuit } \\
\text { Clean Coal }\end{array}$ \\
\hline \multirow{2}{*}{$\begin{array}{c}\text { Ash } \\
\%\end{array}$} & $-37.5+12.5$ & 51.48 & 15.4 & 18.41 & 7.65 \\
\cline { 2 - 6 } & $-12.5+6.3$ & 35.17 & 12.08 & 15.34 & 7.52 \\
\cline { 2 - 6 } & $-37.5+6.3$ & 44.56 & 13.62 & 16.85 & 7.56 \\
\hline \multirow{2}{*}{$\begin{array}{c}\text { Sulfur } \\
\%\end{array}$} & $-37.5+12.5$ & 2.08 & 1.73 & 1.84 & 1.06 \\
\cline { 2 - 6 } & $-12.5+6.3$ & 2.31 & 1.47 & 1.78 & 1.02 \\
\hline \multirow{2}{*}{$\begin{array}{c}\text { Yield } \\
\%\end{array}$} & $-37.5+6.3$ & 2.17 & 1.59 & 1.81 & 1.04 \\
\cline { 2 - 6 } & $-37.5+12.5$ & 57.55 & 38.25 & 27.97 & 10.7 \\
\cline { 2 - 6 } & $-12.5+6.3$ & 42.45 & 60.28 & 41.69 & 25.13 \\
\hline \multirow{2}{*}{} & $-37.5+6.3$ & 100.00 & 47.60 & 35.63 & 16.96 \\
\hline
\end{tabular}

Note: yields are based on feed to the primary cyclones.

The particle size effects on separation performance of overall circuit are shown in Fig.

4-11. The specific gravity of separations are 1.33 for all three size fractions, and the Ep value is 0.024 for $-37.5 \mathrm{~mm}+12.5 \mathrm{~mm}$ size fraction, and 0.0245 for $-12.5 \mathrm{~mm}+6.3 \mathrm{~mm}$ and -37.5 $\mathrm{mm}+6.3 \mathrm{~mm}$ size fractions. The separation distribution curves show that highest sharpness of separation for $-37.5 \mathrm{~mm}+12.5 \mathrm{~mm}$ size fraction, and less sharpness of separation for $12.5 \mathrm{~mm}+6.3 \mathrm{~mm}$ and $-37.5 \mathrm{~mm}+6.3 \mathrm{~mm}$ size fraction.

Also, three products can be obtained from the two-stage circuit, including, final clean coal product, middlings, and refuse. Coal company can sell the products for various markets, such as blending the clean coal with raw coal for steam coal market, middlings for steam coal market, and clean coal product for metallurgical coal market, to gain high profit. 


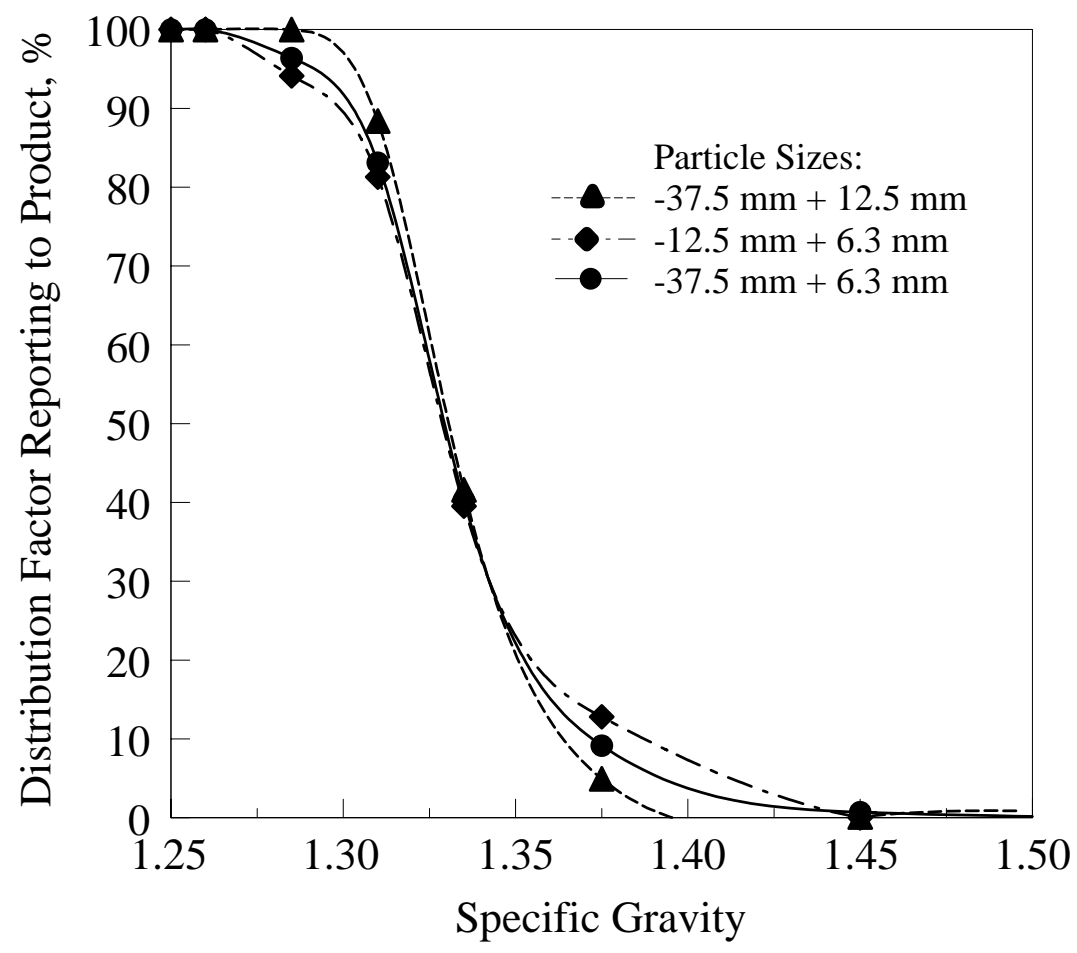

Figure 4-11 Separation Distribution Curves of Various Size Fractions for the Overall Circuit of Two-Stage Dense Medium Conical Cyclones, Plant K 


\subsection{Economic Analysis}

Due to high coal price, there is interest in using multi-stage separation circuits to produce high quality coal for metallurgical coal market, and to blend with raw coal to produce high quality coal for steam coal market. Assume a coal preparation plant was operated at a feed rate capacity of 2,000 tph. The 1,000 tph feed was processed by a dense medium cyclone circuit, and 1,000 tph fine feed was processed by other fine coal processes and produced $50 \%$ yield of fine clean coal product. Based on the coal analysis data, the steam coal was produced at $50.22 \%$ yield with $14.8 \%$ ash content of clean coal product. If twostage dense medium cyclone circuit is used to produce metallurgical coal, the clean coal product has $37.18 \%$ yield with $9.24 \%$ ash content. Considering the plant operating time is 14 hours per day, and the plant utilization is $70 \%$. The annual steam coal production rate is:

$1000 \mathrm{tph} \times 365$ day $/ \mathrm{yr} \times 70 \% \times 14 \mathrm{hr} /$ day $\times 50.22 \%=1,796,369($ ton $)=1,629,638(\mathrm{mton})$

and annual Metallurgical coal production rate is:

1000 tph $\times 365$ day $/ \mathrm{yr} \times 70 \% \times 14 \mathrm{hr} /$ day $\times 37.18 \%=1,329,929($ ton $)=1,206,491$ (mton)

The sales value for steam coal and metallurgical coal are $\$ 60 /$ ton, and $\$ 120 /$ ton, thus, the annual sales from dense medium cyclone circuits are $\$ 107,782,140$ and $\$ 159,591,432$, respectively. The difference of annual sales is $\$ 51,809,292$. The summary of economic analysis and quality of clean coal product for one stage and two-stage dense medium cyclone circuit in plant $\mathrm{H}$ is given in Table 4-5. 
Table 4-5 Summary of Annual Economic Analysis for Dense Medium Circuit Product in Plant $\mathrm{H}$

\begin{tabular}{|c|c|c|c|c|c|c|}
\hline $\begin{array}{c}\text { Dense Medium } \\
\text { Circuit }\end{array}$ & $\begin{array}{c}\text { Clean } \\
\text { Coal Product }\end{array}$ & $\begin{array}{c}\text { Ash } \\
(\%)\end{array}$ & $\begin{array}{c}\text { Yield } \\
(\%)\end{array}$ & $\begin{array}{c}\text { Yearly Output } \\
\text { mton }\end{array}$ & $\begin{array}{c}\text { Price } \\
\$ / \text { mton }\end{array}$ & $\begin{array}{c}\text { Annual Sales } \\
\$\end{array}$ \\
\hline One stage & Steam & 14.8 & 50.22 & $1,629,638$ & 66 & $107,782,140$ \\
\hline Two stage & Metallurgical & 9.24 & 37.18 & $1,206,491$ & 132 & $159,591,432$ \\
\hline
\end{tabular}

The analysis results show that the multi-stage dense medium cyclone without recirculation circuit has both technical and economic advantage over the one stage separation circuit, for the raw coals have the potential to be processed for metallurgical coal. 


\section{CHARPTER 5 CONCLUSIONS}

Circuit analysis tools to evaluate various separation circuit configurations have been developed. The conclusions are derived from this works and listed bellows:

1) Circuit analysis tools are developed based on the concept of generalized distribution curve (unified family curve) for different specific gravity of separation. The circuit analysis tools are used to define the correct circuit analysis procedures, and relative separation efficiency (RSE) for the various multi-stage separation circuits configurations.

2) Based on the definition of RSE, probable error, Ep, for a specific circuit configuration can be readily derived without using washability data of raw coal.

3) Application of the multi-stage separation circuit configurations in coal cleaning, not only increase the separation efficiency, but also significantly improve the quality of clean coal product by minimizing misplaced materials in the product and refuse stream.

4) For Tri-Flo, two-stage dense medium cylindrical cyclone without recirculation, the in-plant actual RSE for combined two stage circuit was 1.16 times higher than that of only one stage circuit (rougher). The actual RSE value is closed to the value of 1.17 calculated by circuit analysis tools.

5) Four cases of in-plant two-stage dense medium conical cyclone circuits without recirculation were studied to perform the separation efficiency analysis. The actual values of RSE for all plants studied except in plant $\mathrm{H}$, range from 1.16 to 1.24 . The 
actual values of RSE are also closed to the value of 1.17 calculated by circuit analysis tools.

6) Although two-stage dense medium cyclone circuit without recirculation in plant $\mathrm{H}$ has the same value of $\operatorname{RSE}(=1)$ as the rougher circuit. The economic analysis for the annual sales clearly shows that two-stage circuit without recirculation is capable of producing high quality metallurgical coal, and generating the high annual sales over a single stage circuit. 


\section{REFERENCE}

Aplan, F. F., 2003, Principle of mineral processing, Chapter 6, Gravity concentration, pp185219.

ASTM D 4371-91, Vol 05.05 Gaseous Fuels; coal and coke, 2002.

Bozzato, P., Peng, F. F., and Gu, Z., 2005, "Dense medium Tri-Flow separator-A review and new development," Preprint 05-132, 2005 SME Annual Meeting, Slat Lake City, UT, Feb. 28-March 2.

Cammack, P., 1987, "LARCODEMS - a new dense medium separation $100 \mathrm{~mm} \sim 0.5 \mathrm{~mm}$ raw coal,” Aufbereitungs-Technik, Vol. 8, Aug., pp. 427-434.

Childs, N., 1996, "Field testing of a zero offset dense medium separator," Australia Coal Association Research Program (ACARP), December, 19, Melbourne, Australia.

Coal Preparation, 2001, Technology Status Report, Department of Trade \& Investment, UK, January.

Davis, J. J., Wood, C. J., and Lyman, G. J., 1986, "Density tracers give option to float-sink tests," Coal Age, Vol. 91, No. 5, May, pp. 60-62.

Deurbrouck, A. W., and J. Hudy, Jr., 1972, "Performance characteristics of coal-washing equipment: Dense-Medium Cyclones," BuMines RI 7673, 34 pp.

Ferrara, G., Bozzato, P., and Chine, B., 1999, "Performance of conical and cylindrical separatory vessels in dynamic dense-medium separation processes," Minerals \& Metallurgical Processing, Vol. 16, No.2, pp. 8-15.

Ferrara, G., Ruff, H. J., 1982, "Dynamic dense medium separation processes-further developments with particular reference to the Tri-Flo separator," Erzmetall, Vol. 35, No. 6, pp.294-298 and No. 7, pp. 395-398.

Gottfried, B. S., and Jacobsen, P. S., 1977, "Generalized distribution curve for characterizing the performance of coal-cleaning equipment," U. S. Dept. of the Interior, BuMines RI 8238, pp. 2-5. 
Gottfrid, Byran S., 1978 "Generalization of distribution data for characterizing the performance of float-sink coal cleaning," International Journal of Mineral Processing, Vol. 5, No. 1, Mar, pp. 1-20.

Harrison, S. T., Woodman J. R., and Peatfield, D. M., 1998, "LARCODEM-more than a proven de-stoning vessel on South African Coals?" Presented at South Africa Coal Processing Society Meeting, September.

Jain, S. M, 2002, “Heavy media washer,” CPSA Journal, Vol. 1, No. 2, pp. 8-10.

Klimam, M.S., and Luckie, P.T., 1986, "Using model discrimination to select a mathematical function for generating separation curves," Coal Preparation, Vol. 3, pp. 33-47.

Luttrell, G.H., Kohmuench, J.N., Stanley, F.L., and Trump, G.D., 1998, "Improving spiral performance using circuit analysis," Minerals \& Metallurgical Processing, Vol. 15,

No. 4, pp. 16-21.

Luttrell, G. H., Barbee, C. J., Wood, C. J., and Bethell, P. J., 2003, "Operating guidelines for heavy-media cyclone circuits," Coal Age, Vol. 108, No. 4, April, pp. 30-34.

Meloy, T.P., 1983, "Analysis and optimization of mineral processing and coal cleaning circuits-circuit analysis,” Intl Journal of Mineral Processing, Vol. 10, pp. 61-80.

Maronde, C. P., Killmeyer, R. P., and Deurbrouck, A. W., 1983, "Performance characteristics of coal-washing equipment: the dynawhirlpool separator," DOE/PETC/ TR$83 / 8$.

Nicol, S. K., 2001, Fine Coal Beneficiation, Australian Coal Preparation Monograph Series, Vol. IV, Part 9, pp. 37-41.

Peng, F. F., 1983, "Graphic routine and digital simulation - the aids in prediction of coal preparation plant performance and yield optimization," In proceedings, The First Conference on Use of Computers in the Coal Industry, edited by Y. J. Wang and R. Sanford, West Virginia University, Morgantown, WV, SME, Littleton, Co, pp. 187-199.

Peng, F. F., and Xia, Y., 2005, "Analysis of dense medium vessel for coarse coal separation using computation fluid dynamic tool," Preprint 05-126, SME Annual Meeting, Salt Lake City, UT, February 28 - March 2. 
Peng, F. F., and Bozzato, P., 2002, "Medium stability and performance of dynamic cylindrical dense medium separators," SME Annual Meeting, Preprint 02-183, Feb. 25-27, Phoenix, Arizona.

Peng, F. F., and Chang, D., 1996, "Mass balance and process evaluation for coarse coal cleaning circuit using a dense-medium separator," SME Annual Meeting, Preprint 96-184, March 11-14, Phoenix, Arizona.

Rakowsky, V., "Centrifugal method and apparatus for separating solids," 1959, U.S. Patent No. 2,917,173.

Weale, W. G., and Swanson, A. R., 2002, "An improved design and operational data for large diameter dense medium cyclones," In-Proceedings, the Ninth Australian Coal Preparation Conference, Yeppoon, Australia, October, pp. 90-106. 


\section{APPENDIX I}

Separation Distribution Data for Dense Medium Conical Cyclones at Seven Coal Preparation Plants 
Table I-1 Separation Distribution Data for Dense Medium Conical Cyclones at Seven Coal Preparation Plants

\begin{tabular}{|c|c|c|c|c|}
\hline \multirow{2}{*}{$\begin{array}{c}\text { Specific } \\
\text { Gravity } \\
\text { Interval }\end{array}$} & \multicolumn{4}{|c|}{ Distribution Factors Reporting to Product, \% } \\
\cline { 2 - 5 } & Plant A & Plant C & Plant F & Plant G \\
\hline$<1.30$ & 99.9 & 99.9 & 99.8 & 97.9 \\
\hline $1.30-1.35$ & 99.8 & 99.8 & 99.9 & 98.0 \\
\hline $1.35-1.40$ & 99.7 & 99.4 & 99.9 & 93.4 \\
\hline $1.40-1.45$ & 99.2 & 98.8 & 99.8 & 69.2 \\
\hline $1.45-1.50$ & 95.5 & 93.2 & 99.4 & 28.0 \\
\hline $1.50-1.60$ & 50.5 & 33.0 & 95.7 & 8.1 \\
\hline $1.60-1.70$ & 5.4 & 2.6 & 43.0 & 2.4 \\
\hline $1.70-1.80$ & 0.2 & 0.0 & 5.3 & 2.0 \\
\hline$>1.80$ & 0.0 & 0.0 & 0.0 & 0.3 \\
\hline
\end{tabular}

Table I-1 Separation Distribution Data for Dense Medium Conical Cyclones Separators at Seven Coal Preparation Plants (Continued)

\begin{tabular}{|c|c|c|c|}
\hline \multirow{2}{*}{\begin{tabular}{c} 
Specific \\
\multirow{2}{*}{$\begin{array}{l}\text { Gravity } \\
\text { Interval }\end{array}$}
\end{tabular}} & \multicolumn{3}{|c|}{ Distribution Factors Reporting to Product, \% } \\
\cline { 2 - 4 } & Plant B & Plant D & Plant E \\
\hline$<1.28$ & 100.0 & 99.5 & 99.7 \\
\hline $1.28-1.30$ & 99.9 & 99.4 & 99.5 \\
\hline $1.30-1.35$ & 99.9 & 98.4 & 99.3 \\
\hline $1.35-1.40$ & 99.8 & 88.6 & 98.8 \\
\hline $1.40-1.45$ & 98.6 & 46.4 & 94.8 \\
\hline $1.45-1.50$ & 78.1 & 15.4 & 53.4 \\
\hline $1.50-1.60$ & 22.1 & 3.9 & 9.3 \\
\hline $1.60-1.70$ & 2.1 & 1.2 & 2.1 \\
\hline $1.70-1.80$ & 2.0 & 0.5 & 0.5 \\
\hline$>1.80$ & 0.1 & 0.0 & 0.3 \\
\hline
\end{tabular}


Table I-2 Performance Characteristics of Dense Medium Conical Cyclones at Seven Coal Preparation Plants

\begin{tabular}{|l|c|c|c|c|}
\hline & $\begin{array}{c}\text { Specific Gravity of } \\
\text { Separation, SG50 }\end{array}$ & $\begin{array}{c}\text { Probable Error, } \\
\text { Ep }\end{array}$ & $\begin{array}{c}\text { Imperfection, } \\
\text { I }\end{array}$ & $\begin{array}{c}\text { Error Area, } \\
\text { Ae }\end{array}$ \\
\hline Plant A & 1.55 & 0.028 & 0.018 & 22 \\
\hline Plant B & 1.51 & 0.034 & 0.022 & 23 \\
\hline Plant C & 1.53 & 0.030 & 0.020 & 18 \\
\hline Plant D & 1.42 & 0.029 & 0.020 & 21 \\
\hline Plant E & 1.48 & 0.031 & 0.021 & 20 \\
\hline Plant F & 1.63 & 0.026 & 0.016 & 21 \\
\hline Plant G & 1.45 & 0.029 & 0.020 & 25 \\
\hline
\end{tabular}




\section{APPENDIX II}

Separation Distribution Data for Dynawhirlpool Separators at Four Coal Preparation Plants 
Table II-1 Separation Distribution Data for Dynawhirlpool Separators at Four Coal Preparation Plants

\begin{tabular}{|c|c|c|c|c|}
\hline \multirow{2}{*}{$\begin{array}{c}\text { Specific } \\
\text { Gravity } \\
\text { Interval }\end{array}$} & \multicolumn{4}{|c|}{ Distribution Factors Reporting to Product, \% } \\
\cline { 2 - 5 } & Plant DA & Plant DB & Plant DD1 & Plant DD2 \\
\hline-1.30 & 86.1 & 96.2 & 98.7 & 99.6 \\
\hline $1.30-1.35$ & 72.1 & 92.7 & 95.7 & 99.0 \\
\hline $1.35-1.40$ & 51.2 & 76.0 & 77.5 & 94.9 \\
\hline $1.40-1.45$ & 32.5 & 46.2 & 48.0 & 76.8 \\
\hline $1.45-1.50$ & 17.9 & 26.1 & 30.4 & 47.9 \\
\hline $1.50-1.60$ & 8.4 & 14.7 & 15.9 & 25.2 \\
\hline $1.60-1.70$ & 3.5 & 8.7 & 14.3 & 15.0 \\
\hline $1.70-1.80$ & 1.5 & 5.7 & 4.3 & 9.8 \\
\hline+1.80 & 0.4 & 1.9 & 1.8 & 2.8 \\
\hline
\end{tabular}

Table II-1 Separation Distribution Data for Dynawhirlpool Separators at Four Coal Preparation Plants (Continued)

\begin{tabular}{|c|c|}
\hline $\begin{array}{c}\text { Specific } \\
\text { Gravity } \\
\text { Interval }\end{array}$ & $\begin{array}{c}\text { Distribution Factors } \\
\text { Reporting to Product, \% } \\
\text { Plant DC }\end{array}$ \\
\hline-1.30 & 100.0 \\
\hline $1.30-1.35$ & 100.0 \\
\hline $1.35-1.40$ & 99.9 \\
\hline $1.40-1.45$ & 99.7 \\
\hline $1.45-1.50$ & 98.7 \\
\hline $1.50-1.55$ & 93.1 \\
\hline $1.55-1.60$ & 77.9 \\
\hline $1.60-1.70$ & 44.1 \\
\hline $1.70-1.80$ & 15.2 \\
\hline $1.80-2.00$ & 5.9 \\
\hline+2.00 & 0.9 \\
\hline
\end{tabular}


Table II-2 Performance Characteristics of Dynawhirlpool Separators at Four Coal Preparation Plants

\begin{tabular}{|l|c|c|c|c|}
\hline & $\begin{array}{c}\text { Specific Gravity of } \\
\text { Separation, SG50 }\end{array}$ & $\begin{array}{c}\text { Probable Error, } \\
\text { Ep }\end{array}$ & $\begin{array}{c}\text { Imperfection, } \\
\text { I }\end{array}$ & $\begin{array}{c}\text { Error Area, } \\
\text { Ea }\end{array}$ \\
\hline Plant DA & 1.375 & 0.066 & 0.048 & 43 \\
\hline Plant DB & 1.422 & 0.050 & 0.035 & 48 \\
\hline Plant DC & 1.641 & 0.057 & 0.035 & 43 \\
\hline Plant DD1 & 1.423 & 0.054 & 0.038 & 45 \\
\hline Plant DD2 & 1.471 & 0.060 & 0.041 & 54 \\
\hline
\end{tabular}




\section{VITA}

Hongyan Sun was born in Chaoyang, Liaoning Province, the People's Republic of China (P.R. China) in 1968. She received her B.S. degree in Civil Engineering, Shenyang Jianzhu University, Shenyang, China, in 1996. From 1993 to 2001, she was a Civil Engineer at Anshan Engineering \& Research Incorporation of Metallurgical Industry (AERIMI) under the Ministry of Metallurgical Industry of P.R. China.

Ms. Sun went to the United States in 2002 for graduate study at Statistic Department, West Virginia University. In August, 2003, she enrolled in the Master of Science in Mining Engineering Program, West Virginia University (WVU). Currently she is a candidate for MS in Mining Engineering program, emphasized in mineral processing engineering.

Hongyan married to Qinghua Jin in 1993. Mr. Jin is currently in Ph.D. Mining Engineering Program, WVU, emphasized in mine ventilation system modeling. They have one son, Dun Jin, 7 years old. 